UNIVERSITY OF HAWAII LIBRARY,

\title{
The Spatial Distribution and Size Evolution of Particles in Asian Outflow: The Significance of Primary and Secondary Aerosols during ACE-Asia and TRACE-P
}

A THESIS SUBMITTED TO THE GRADUATE DIVISION OF THE UNIVERSITY OF HAWAI'I IN PARTIAL FULFILLMENT OF THE REQUIREMENTS FOR THE DEGREE OF

MASTER OF SCIENCE

IN

OCEANOGRAPHY

MAY 2003

By

Cameron Stuart $\mathrm{M}^{\mathrm{c}}$ Naughton

Thesis Committee:

Antony D. Clarke, Chairperson

Barry J. Huebert

John N. Porter 


\section{Acknowledgments}

This research was completed under NASA Grant NCC-1-416 and NSF Grant ATM00-02070. I would like to take the time to thank all the members of the TRACE-P and ACE-Asia field campaigns. These experiments were a massive undertaking, impossible without intense cooperation, open data policies and the leadership efforts of Dr. B. Huebert, Dr. D. Jacob and Dr. J. Crawford. I would also like to personally thank:

Dr. Antony D. Clarke. Tony, thank you for supporting me during my masters thesis, allowing me to travel and to participate in these unique and exciting field campaigns at the leading edge of research in geophysics. Peering down from the window of the C-130 somewhere over the Yellow Sea I remember saying to myself, "I love my job." This opportunity could never have happened without your continued belief in my abilities.

Dr. Barry Huebert. Barry, before the ACE-Asia field campaign I had the feeling that you doubted my capabilities. After working together in the field I think we have developed a great relationship. Personally I am both awed and inspired by your ability to navigate the cultural, scientific and philosophical differences between all of the people involved in field campaigns of this size. The success of the ACE-Asia campaign is in large part due to your efforts.

Dr. John Porter. John, your recommendation on the pictographs for my conclusions was some of the best input I received. Personally I feel that they are a great compliment to the work and, as you suggested, sum up my understanding of this process in a concise way that should be clear, even to laymen, who are unconcerned about the details of this phenomenon.

Ian and Barbara $\mathbf{M}^{\mathrm{c}}$ Naughton. My parents, for years, have supported my quest for advanced education not only financially but also emotionally. Without a doubt you have been the single biggest influence in my life, shaping my morals, ideas and beliefs. I hope that as I pursue this career path that at the very least I can explain these scientific theories to you both in language free from jargon and formulated around old-fashioned Canadian common sense.

Lianne Mailloux. Lianne, is there any way to thank you for the support you provide me each day? Flying around the World "for NASA" makes for long weeks spent apart. Your patience, understanding and love make the time apart bearable. There is no limit to my hopes and dreams as we begin our life together.

Yohei Shinozuka. Crown Prince Akahito scholar, it has been a joy and a pleasure to work beside someone so bright and whose skills so effectively compliment my own. I will forever value our friendship as I treasure the memory of my time spent living and working in your native Japan. 
Byron Blomquist and Steve Howell. Steve and Byron, thank you for the many long hours that you have spent patiently encouraging me and continually enlightening me as to just how little we all know about the natural world. You have both been an inspiration in teaching me about the balance between work and play. You are both true mentors and your personal lives are an inspiration for me to pursue my own dreams outside of work.

Mitchell Pinkerton. Mitch, you are a truly gifted technician with abilities I can only hope to develop. More importantly you never fail to remind me to look on the lighter side of each situation or to remind me how insignificant this work might seem to the average individual.

\section{Kenneth Moore, Volodia Kapustin, Oliver Vetter, Steve Owens and Vera}

Brekhovskikh. I am indebted many hours to each member of the HiGEAR team. The shear volume of work completed by this team is staggering. I want you all to know that your efforts made much of this work possible, thank you.

I would also like to thank the citizens of Japan, the Republic of Korea, Taiwan and the Peoples Republic of China for hosting us during the intensive observation periods of both campaigns. Hopefully our improved understanding of aerosols over Asia will benefit you personally through improvements to your quality of life.

Sincerely,

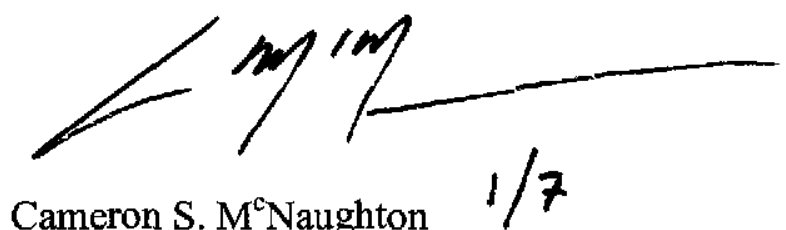

Earthstronaut - April 11 $1^{\text {th }}, 2003$ 


\begin{abstract}
During the ACE-Asia and TRACE-P field campaigns aircraft measurements over the Yellow Sea, East China Sea and Sea of Japan revealed widespread secondary aerosol formation in the marine boundary layer. Similar observations were made throughout the day at the Gosan surface site on Jeju Island South Korea and aboard the American research vessel the R/V Ron Brown. Intercomparisons between the surface aerosol platforms and the airborne platforms show excellent agreement. Two post-frontal airmasses were characterized by concentrations of $3-12 \mathrm{~nm}$ particles as high as $40,000 \mathrm{~cm}^{-3}$, and $\mathrm{SO}_{2}$ concentrations of 2 -12 ppbv. Aerosol surface area in the marine boundary layer associated with regional air pollution and in one case, mineral dust, was in excess of $300 \mu \mathrm{m}^{2} \mathrm{~cm}^{-3}$ and as high as 1200 $\mu \mathrm{m}^{2} \mathrm{~cm}^{-3}$. Thermodynamic profiles of the regional airmass suggest that steep gradients of aerosol surface area, relative humidity and temperature associated with elevated levels of $\mathrm{SO}_{2}$ created microphysical environments where new particle production is favoured.

Although nucleation events were not observed directly, evidence for recently formed secondary aerosols were detected up to 48 hours after leaving the Asian landmass and were associated with $\mathrm{SO}_{2}$ concentrations in excess of 1 ppbv. Molar ratios of $\left[\mathrm{NH}_{4}{ }^{+}\right]:\left(2\left[\mathrm{SO}_{4}{ }^{2-}\right]+\right.$ $\left[\mathrm{NO}_{3}{ }^{-}\right]$) in excess of 0.68 and volatility analysis showing partial neutralization of the nucleation and accumulation mode aerosols suggest a ternary nucleation mechanism involving $\mathrm{H}_{2} \mathrm{SO}_{4}, \mathrm{H}_{2} \mathrm{O}$, and $\mathrm{NH}_{3}$. Growth rates of nucleation mode aerosols of 2.4 and 1.7 $\mathrm{nm} \mathrm{hr} \mathrm{r}^{-1}$ were observed over a broad spatial extent during two consecutive flights. Based on the nucleation mode growth rates, the flux rate of vapour to the full size distribution suggests condensation rates of $2.4+/-1.2 \times 10^{6}$ molecules $\mathrm{cm}^{-3} \mathrm{~s}^{-1}$. Calculations of the coagulation rate for the nucleation mode particles suggest that most may be scavenged by the primary aerosol in less than 72 hours over the coastal waters of Asia before being transport out toward the Pacific Ocean.
\end{abstract}




\section{Table of Contents}

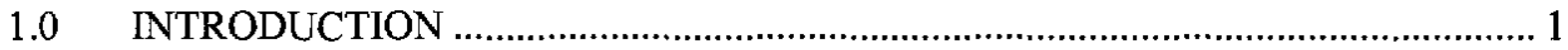

1.1 THE INFLUENCE OF PRIMARY AEROSOLS ON SECONDARY AEROSOLS ........................2

1.2 RECENT WORK RELATED TO SECONDARY AEROSOL FORMATION ..............................5

1.3 Regional Climatology and Long Range Transport of ASian

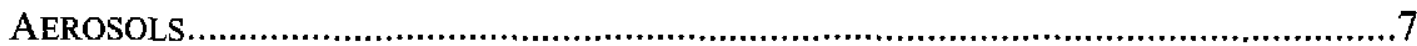

1.4 Transport AND CHEMICAL EVOLUTION OVER THE PACIFIC EXPERIMENT

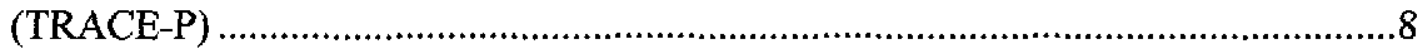

1.5 ASIAN AEROSOl CHARACTERIZATION EXPERIMENT (ACE-ASIA) ..........................

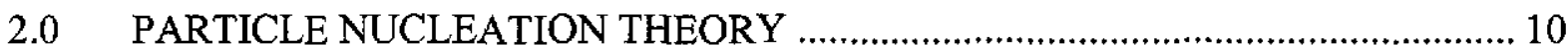

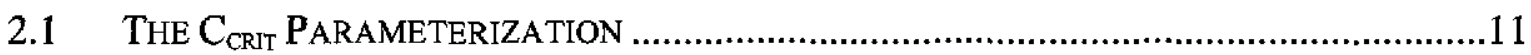

2.2 FlUX RATE OF SUlfURIC ACID TO THE SIZE DISTRIBUTION ...................................12

2.3 COAGULATION RATE OF NUCLEATION MOdE PARTICLES ......................................14

3.0 RESEARCH AIRCRAFT AND INSTRUMENTATION ..................................... 15

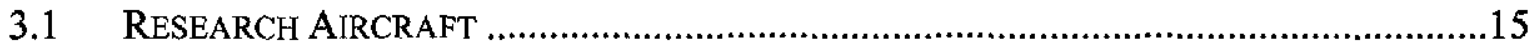

3.2 CONDENSATION NUCLEI COUNTERS .............................................................. 16

3.3 THERMO-OPTICAL AEROSOL DISCRIMINATOR (TOAD) ...................................17

3.4 DIFFERENTIAL MOBILITY ANALYZER (DMA) .............................................18

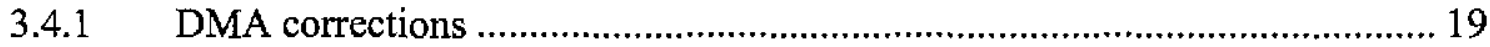

3.4.2 Accuracy of the total number integral ....................................................... 22

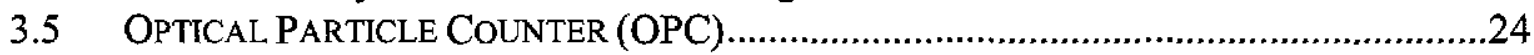

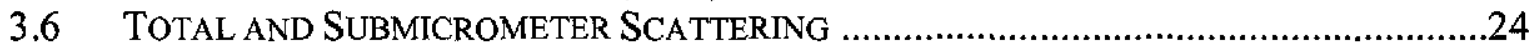

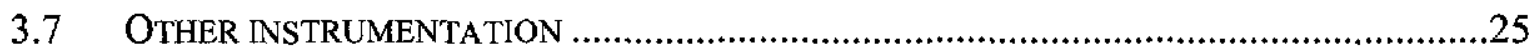

4.0 SECONDARY AEROSOL FORMATION ON A SYNOPTIC SCALE ..................25

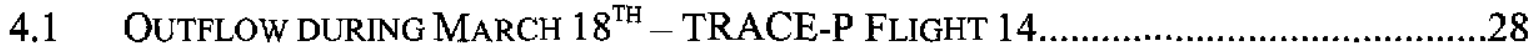

4.2 OUTFLOW DURING APRIL 12 ${ }^{\mathrm{TH}}$ AND $13^{\mathrm{TH}}$ - ACE-ASIA FLIGHTS 7 AND 8 $\ldots \ldots \ldots \ldots \ldots . . . . . .29$

4.3 AIRCRAFT PROFILES FOR MARCH $18^{\mathrm{TH}}$ AND APRIL 12 ${ }^{\mathrm{TH}}, 13^{\mathrm{TH}}$ CASES........................31

4.3.1 TRACE-P - Flight 14 - North Profile ...................................................... 31

4.3.2 TRACE-P - Flight 14 - Central Profile ..................................................... 32

4.3.3 TRACE-P - Flight 14 - South Profile ........................................................ 32

4.3.4 ACE-Asia - Flight 07 - North Profile ........................................................ 35

4.3.5 ACE-Asia - Flight 07 - Central Profile.................................................... 35

4.3.6 ACE-Asia - Flight 07 - South Profile ............................................... 36

4.3.7 ACE-Asia - Flight 08 - North Profile ................................................. 38

4.3.8 ACE-Asia - Flight 08 - Central Profile ................................................... 38

4.3.9 ACE-Asia - Flight 08 - Southern Profile..................................................... 39

5.0 SIZE DISTRIBUTIONS MEASURED ABOARD THE AIRCRAFT ..................42

5.1 SIZE DISTRIBUTIONS FROM TRACE-P RF14 .....................................................42

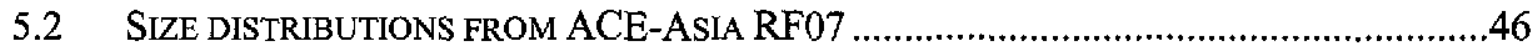

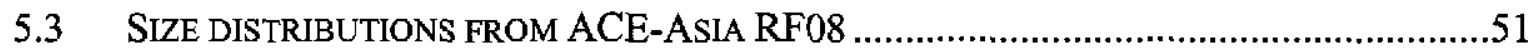


6.0 PARTICLE GROWTH RATES FOR APRIL $12^{\mathrm{TH}}$ AND APRIL $13^{\mathrm{TH}} \ldots \ldots \ldots \ldots . . . . . . .53$

6.1 GROWTH RATES AS OBSERVED BY THE C-130 ......................................................53

6.2 EVIDENCE For PaRtial NeUtralization of the NuCleation Mode

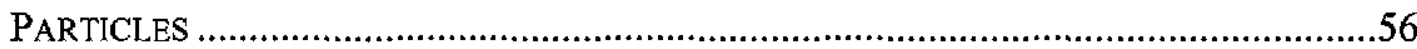

6.3 EVOLUTION OF THE SIZE DISTRIBUTION AT THE SURFACE.................................60

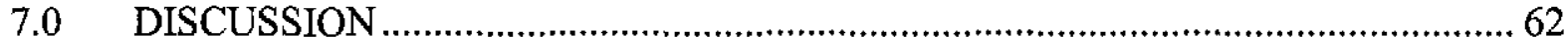

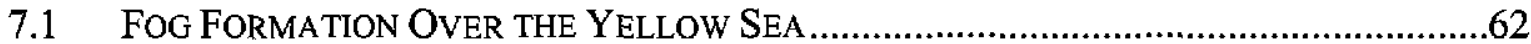

7.2 FluX RATE OF SULFURIC ACID TO THE SIZE DisTRIBUTION .................................68

7.3 Coagulation Rate of Nucleation Mode Particles........................................72

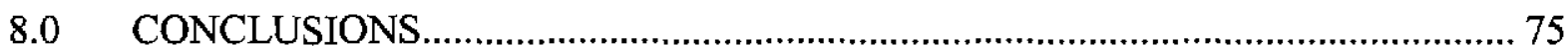

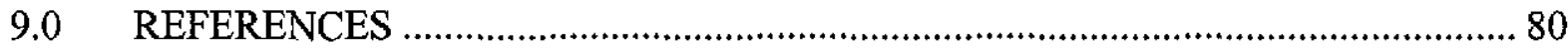

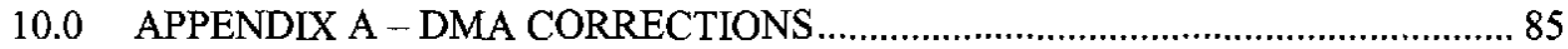

10.1 MULTIPLICATION FACTORS FOR TRANSMISSION EFFICIENCY ...............................85

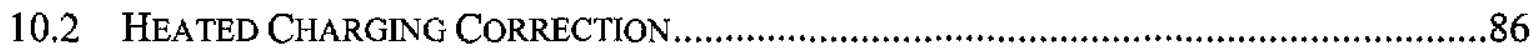

10.3 APPLYING CORRECTION FACTORS TO THE DMA SIZE DISTRIBUTIONS.....................88

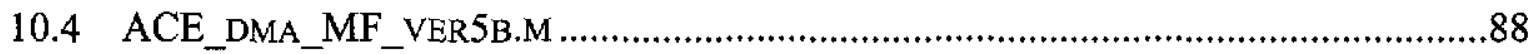

11.0 APPENDIX B - MATLAB SIZE DISTRIBUTION FUNCTION ........................ 92

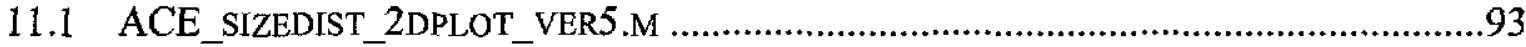

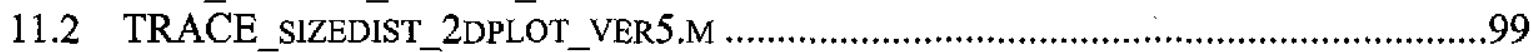

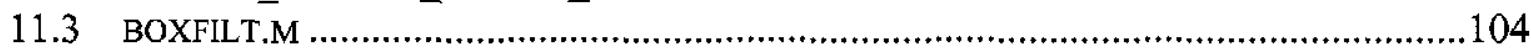

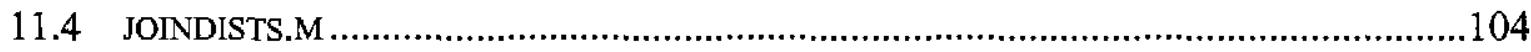

12.0 APPENDIX C - MATLAB CONDENSATION AND COAGULATION

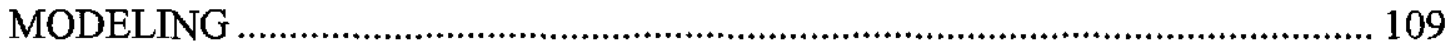

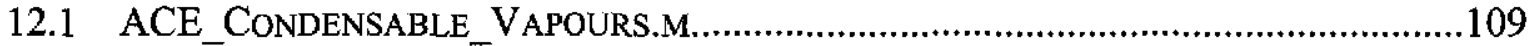

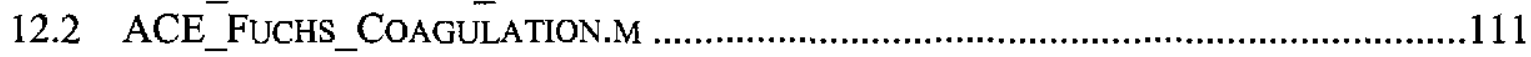




\section{List of Tables and Figures}

Table 1.1 - Nomenclature and size classes of the aerosol size distribution............................ 3

Figure 1.1 - Flight paths for the NASA P3-B and NSF/NCAR C-130 during

TRACE-P and ACE-Asia.

Figure 3.1 - Comparison of the transmission efficiency curves applied to the rDMA data sets for ACE-Asia and TRACE-P.

Figure 3.2 - Example of over-counting aerosol number due to false Boltzman charging of the heated DMA scans (left). Example of the ratio of number concentrations for neutralizer after heater vs. the standard neutralizer position before heater (right).

Figure 3.3 - Gaussian fit to the logarithm of total particle number recorded by the rDMA + OPC instruments compared to; (a) the UCN, (b) the RAF $\mathrm{CN}$, (c) the $\mathrm{UH}$ Cold $\mathrm{CN}$, as well as the $300^{\circ} \mathrm{C}$ size distributions as compared to the UH Hot CN (d).

Figure 3.4 - Gaussian fit to the logarithm of total particle number recorded for the dry ambient rDMA + OPC size distributions as compared to the UH Cold $\mathrm{CN}$ (a), as well as the $300^{\circ} \mathrm{C}$ size distributions as compared to the $\mathrm{UH}$ Hot CN (b).

Figure 4.1 - Plan and meridional views of nucleation events for ACE-Asia from rDMA analysis (first row), for TRACE-P from PHA-UCN analysis (second row), and for TRACE-P from rDMA analysis (last row)

Figure 4.2 - Meteorology for the Northwest Pacific during TRACE-P RF14 on March $18^{\text {th }}, 2001$.

Figure 4.3 - Back trajectories for profiles from TRACE-P RF14 on March $18^{\text {th }}, 2001$ (left) and ACE-Asia RF07 and RF08 on April 12-13 ${ }^{\text {th }}, 2001$ (right).

Figure 4.4 - Meteorology for the Northwest Pacific during ACE-Asia RF07 on April $12^{\text {th }}, 2001$.

Figure 4.5 - Thermodynamic, gas phase and aerosol properties during the North (top), Central (middle) and Southern (bottom) profiles of TRACE-P RF 14 on March $18^{\text {th }}, 2001$.

Figure 4.6 - Thermodynamic, gas phase and aerosol properties during the North

(top), Central (middle) and Southern (bottom) profiles of ACE-Asia

RF07 on April $12^{\text {th }}, 2001$.

Figure 4.7 - Thermodynamic, gas phase and aerosol properties during the North

(top), Central (middle) and Southern (bottom) profiles of ACE-Asia

RF08 on April $13^{\text {th }}, 2001$,

Figure 4.8 - Sea Surface Temperatures for April $12^{\text {th }}$ (top) as well as SST's measured by infrared (IR) sensors aboard the P3-B (left) and C-130 (right) during TRACE-P RF14 on March $18^{\text {th }}$ and ACE-Asia RF07 and RF08 on April $12^{\text {th }}$ and $13^{\text {th }}, 2001$.

Figure 5.1 - Aerosol number (top), area (middle) and volume (bottom) distributions recorded at $663 \mathrm{~m}$ above the Yellow Sea along $124.4^{\circ} \mathrm{E}$ during TRACE-P RF14, March $18^{\text {th }}, 2001$. Distribution highlights the presence of nucleation mode particles just above a shallow layer of 
evaporative cooling. Accumulation mode aerosol shows near complete neutralization.

Figure 5.2 - Aerosol number (top), area (middle) and volume (bottom) distributions recorded at $118 \mathrm{~m}$ above the Yellow Sea along $124.4^{\circ} \mathrm{E}$ during TRACE-P RF14, March $18^{\text {th }}, 2001$. Distributions show doubling of surface area and reduced number (note scale change compared to Figure 5.1) and diameter of nucleation mode particles within the layer of evaporative cooling.

Figure 5.3 - Aerosol number (top), area (middle), and volume (bottom) distributions measured during the morning fly-by of the Gosan surface site during ACE-Asia RF07, April 12 $2^{\text {th }}, 2001$. Nucleation mode particles are identical to those observed at the ground station.

Figure 5.4 - Vertical structure of aerosol surface area over the Yellow Sea along $124.4^{\circ} \mathrm{E}$ during ACE-Asia RF07 on April $12^{\text {th }}, 2001$. Aerosol surface area is highest within the shallow layer of evaporative cooling. Larger accumulation mode sizes and mineral dust account for approximately $60 \%$ and $40 \%$ of the surface area within the OBL. Nucleation mode particles are present in highest concentrations above the OBL where total surface area is lower and the accumulation mode area is centered at smaller particle diameters.

Figure 5.5 - Aerosol number (top), area (middle) and volume (bottom) distributions measured during the afternoon fly-by of the Gosan surface site during ACE-Asia RF07, April $12^{\text {th }}, 2001$. Nucleation mode particles are identical to those observed at the ground station and have shifted to larger size classes than those recorded during the morning fly-by (Figure 5.3).

Figure 5.6 - Vertical structure of the aerosol number distribution near AmamiOhshima during ACE-Asia RF08 on April $13^{\text {th }}, 2001$. Highest concentrations of nucleation mode particles exist near the MBL inversion where the $\mathrm{C}_{\text {crit }}$ parameterization indicates gas-to-particle conversion of sulfuric acid is favoured. Presence of nucleation mode particles throughout the marine boundary layer suggests that they are forming throughout the column or that they are being mixed after forming near the inversion.

Figure 6.1 - Evolution of the nucleation mode aerosols observed over a synoptic scale during ACE-Asia flights RF07 and RF08 flown on April $12^{\text {th }}$ and $13^{\text {th }}$ of 2001. The top row indicates the size of the peak diameter of nucleation mode particles as measured at dry conditions. Bottom row indicates the peak diameter of neutralized nucleation mode after heating to $150^{\circ} \mathrm{C}$.

Table 6.1 - Particle growth rates published for other regions and environmental conditions.....

Table 6.2 - Percent neutralization of nucleation mode volume at $150^{\circ} \mathrm{C}$ as inferred from volatility and size distributions near Jeju Island (Yellow Sea) during ACE-Asia RF07 on April 12 $2^{\text {th }}, 2001$ 
Table 6.3 - Percent neutralization of nucleation mode volume at $150^{\circ} \mathrm{C}$ as inferred from volatility and size distributions near Amami-Ohshima (East China Sea) during ACE-Asia RF08 on April $18^{\text {th }}, 2001$.

Figure 6.2 - Aerosol number (top), area (middle) and volume (bottom) distributions near Gosan during ACE-Asia flight RF07 shows $48.0 \%$ neutralization (inset) of the nucleation mode volume after heating to $150^{\circ} \mathrm{C}$ and suggests the participation of ternary species $\left(\mathrm{NH}_{3}\right.$ or organics) during gas-to-particle conversion.

Figure 6.3 - Aerosol number (top), area (middle) and volume (bottom) distributions near Amami during ACE-Asia flight RF08 shows $18.3 \%$ neutralization (inset) of the nucleation mode volume after heating to $150^{\circ} \mathrm{C}$ and suggests the participation of ternary species $\left(\mathrm{NH}_{3}\right.$ or organics) during gas-to-particle conversion.

Figure 6.4 - Evolution of the nucleation mode aerosols as observed by the Gosan surface site on April 12 $2^{\text {th }}, 2001$ and observed by the R/V Ron Brown on April $13^{\text {th }}, 2001$. Growth rates are broadly consistent with the linear regression of nucleation mode growth rates calculated from the $\mathrm{C}-130$ while surveying the regional airmass

Figure 7.1 - Altitude and non-reactive tracers along $124.4^{\circ} \mathrm{E}$ during TRACE-P flight 14 (top). Volatile $\mathrm{CN}$ (VCN), $\mathrm{SO}_{2}$ and $\mathrm{H}_{2} \mathrm{SO}_{4}$ are negatively correlated to relative humidity during the boundary layer run (middle and bottom). Calculations of $\mathrm{C}_{\text {crit }}$ at ambient $\mathrm{RH}$ indicated binary nucleation is not possible. However, calculations at $97 \% \mathrm{RH}\left(\mathrm{C}_{\text {crit97 }}\right)$ suggest binary nucleation was possible during the initial descent over a shallow layer of fog that may have existed earlier in the day

Figure 7.2 - Linear regressions of the relationship between $\mathrm{SO}_{2}$ (top left), $\mathrm{H}_{2} \mathrm{SO}_{4}$ (top right), volatile $\mathrm{CN}$ (bottom left) and relative humidity. Positive correlations outside the OBL (black lines) indicate production of sulfuric acid and secondary aerosols is favoured in the high $\mathrm{RH}$ environment. Within the OBL (red lines) the formation of surface fog has depleted gas phase precursors and new particle number through aqueous phase chemistry and coagulation.

Table 7.1 - Extrapolation of thermodynamic parameters from TRACE-P RF14 on March $18^{\text {th }}, 2001$ from $\sim 115 \mathrm{~m}$ to $25 \mathrm{~m}$. Coastal fog appears likely in the OBL for the Central and Southern profiles but is absent from the Northern profile (see also Figures 4.5, 7.1 and 7.2).

Table 7.2 - Sulfuric acid flux rate to size distributions observed during TRACE-P RF14 on March $18^{\text {th }}, 2001$ and ACE-Asia RF07 and RF08 on April $12^{\text {th }}$ and $13^{\text {th }}, 2001$

Table 7.3 - Volumetric increases to three types of aerosol size distributions based on the calculated sulfuric acid flux rates. The three distributions represent airmasses dominated by pollution (TRACE-P RF14), pollution with dust (ACE-Asia RF07) and dust (ACE-Asia RF06) as illustrated by the proportions of accumulation and coarse mode surface areas. 
Table 7.4 - Coagulation rates and e-folding times for the nucleation mode particles observed in size distributions from TRACE-P RF14 on March $18^{\text {th }}$, 2001 and for ACE-Asia RF07 and RF08 on April 12 $2^{\text {th }}$ and $13^{\text {th }}, 2001$.

Figure 8.1 - Physical and meteorological conditions leading to synoptic scale secondary aerosol formation during spring in East Asia.

Figure 8.2 - Interactions between primary and secondary aerosols in continental outflow from East Asia.

Figure 10.1 - Comparison of the transmission efficiency curves applied to the rDMA data sets for ACE-Asia and TRACE-P.

Figure 10.2 - Neutralizer charging correction factor based upon laboratory experiments and applied to the ACE-Asia and TRACE-P rDMA size distributions 


\subsection{Introduction}

The International Panel on Climate Change has recently indicated that our understanding of the origin and evolution of aerosols as well as their impact on global climate is incomplete [IPCC, 2001]. Natural and anthropogenic aerosols from primary emissions and those formed in situ (secondary aerosols) have the ability to directly affect the Earth's radiative balance by scattering and/or absorbing incoming solar radiation.

Additionally, aerosols have the potential to affect the number and size of cloud condensation nuclei (CCN) altering cloud albedo in what is referred to as the aerosol indirect effect [Albrecht, 1989; Twomey, 1974].

Aerosols can be divided into two categories based on their sources. Primary aerosols are particles formed by physical or mechanical means that then become suspended in the atmosphere. Examples of primary aerosols are mineral dusts from the Sahara or Gobi deserts, sea salt, pollen and spores, volcanic ash, materials from break parts wear, road dust, and fly ash. Secondary aerosols are formed by gas-to-particle conversion. This process requires gas phase precursors that typically undergo a series of chemical transformations in the Earth's atmosphere. Examples of gas phase precursors for the formation of secondary aerosols are $\mathrm{SO}_{2}$ (from volcanoes, industrial processes and coal), $\mathrm{NH}_{3}$ (from agricultural and biological activities), monoterpenes (from forests), halogenated hydrocarbons (from the ocean), $\mathrm{H}_{2} \mathrm{SO}_{4}$ (volcanoes), $\mathrm{NO}_{\mathrm{x}}$, and volatile organic compounds (VOC's) from vehicle exhaust. Black carbon $(\mathrm{BC})$ particles defy strict classification as primary or secondary aerosols because they are formed from gas phase precursors in high temperature combustion. These aerosols typically condense as particles near their sources (industrial smoke-stacks or engine tail-pipes). Examples of sources for this aerosol type are incomplete combustion in diesel and 2-stroke engines as well as in many industrial processes. In this work BC will be classed as a primary aerosol because they have formed particulate matter well before they were observed.

When the concentration of gas phase precursors become saturated with respect to the ambient atmosphere the gases have the potential to form new secondary aerosols. When a single gas species is involved in the formation of new particles the process is referred to as homogeneous-homomolecular nucleation. Nucleation of this type is rare in the atmosphere 
[Seinfeld and Pandis, 1998]. When two or more vapour species exist in the atmosphere nucleation can occur when the gases are saturated with respect to a liquid solution of the components. This can occur even if the gases are not individually saturated with respect to the atmosphere [Ibid.]. Nucleation of this type is termed homogeneous-heteromolecular nucleation. Secondary aerosols formed by this mechanism are particularly important for the species being considered in this work.

Sulfuric acid $\left(\mathrm{H}_{2} \mathrm{SO}_{4}\right)$, formed from the photo-oxidation of sulfur dioxide $\left(\mathrm{SO}_{2}\right)$ precursor exists as a hydrated monomer throughout the earth's atmosphere $\left(\mathrm{H}_{2} \mathrm{SO}_{4} \cdot \mathrm{nH}_{2} \mathrm{O}\right)$. The degree of hydration of the monomer is a function of relative humidity and temperature. It has been theorized that equilibrium concentrations of stable sulfuric acid clusters (1-3 nm in diameter) exist throughout the Earth's atmosphere [Kulmala et al., 2000]. When suitable conditions occur, i.e. those that favour cluster stability and growth, a nucleation event is triggered that results in the rapid formation and growth of these clusters. When this process involves only sulfuric acid and its associated waters of hydration this process is termed binary-homogeneous nucleation.

The atmospheric environment considered in this work is classified as "polluted marine" due to the large urban-industrial regions located in Mainland China, North and South Korea, Taiwan and Japan. As a result, tertiary gas phase precursors exist that are available to participate in the homogeneous-heteromolecular nucleation process. Examples of ternary species that might participate in the gas-to particle conversion process for this environment are ammonia and low vapour pressure organics. In this study we focus on the $\mathrm{H}_{2} \mathrm{SO}_{4}-\mathrm{H}_{2} \mathrm{O}-$ $\mathrm{NH}_{3}$ system. Ternary nucleation involving $\mathrm{H}_{2} \mathrm{SO}_{4}-\mathrm{H}_{2} \mathrm{O}$ and low vapour pressure organics is a poorly understood process. Given the magnitude of the anthropogenic impacts on regional airmasses there is the possibility that ternary nucleation involving organic compounds is also an important pathway for the formation of secondary aerosols.

\subsection{The Influence of Primary Aerosols on Secondary Aerosols}

The relative significance of secondary aerosols compared to primary aerosols is related to whether their growth and removal rates result in conditions where they contribute new particle number to the background atmosphere. Under conditions that favour their formation and growth secondary aerosols may dominate the number distribution and could 
influence the Earth's radiative balance by growing to optically significant sizes or indirectly by affecting the number and size distribution of the cloud condensation nuclei [Albrecht, 1989; Twomey, 1974].

Table 1.1 - Nomenclature and size classes of the aerosol size distribution.

\begin{tabular}{|l|r|}
\hline \multicolumn{1}{|c|}{ Size Class } & \multicolumn{1}{c|}{ Particle Diameters $(\mu \mathrm{m})$} \\
\hline Nucleation mode & $0.001-0.010$ \\
\hline Aitken mode & $0.010-0.100$ \\
\hline Accumulation mode & $0.100-1.0$ \\
\hline Coarse mode & $1.0-20.0$ \\
\hline
\end{tabular}

The aerosol size distribution can be divided into four size classes based on particle diameter (Table 1.1). Nucleation mode particles are those that have recently formed from gas-to-particle conversion. These particles are typically on the order of minutes to hours old. The Aitken mode particles represent those aerosols that have recently formed but have experienced condensational growth shifting them to larger size classes. The nucleation and Aitken mode particles typically dominate the aerosol number distribution. For the purpose of this work we will refer to nucleation mode particles as those that exist in both the nucleation mode and the lower half of the Aitken mode. We adopt this convention because of the rapid condensational growth of nucleation mode particles to Aitken mode sizes in this polluted marine environment. Accumulation mode particles are so named because of the tendency of physical and chemical transformations within the atmosphere (particularly cloud processing) to aggregate particles into these size classes [Hoppel et al., 1987; Hoppel et al., 1986]. They are removed through precipitation processes because coagulation and growth of particles out of the accumulation mode size range is relatively slow. Accumulation mode aerosols typically dominate the aerosol surface area distribution. Since accumulation mode aerosols have diameters the same order of magnitude as the wavelengths of visible light this makes them efficient at scattering and absorbing incoming solar radiation.

Coarse mode aerosols within the MBL typically dominate the aerosol volume distribution despite their low number concentration. The diameters of these particles are orders of magnitude larger than the nucleation mode particles making them efficient at collecting smaller particles by coagulation. Condensational processes have little effect on 
coarse mode aerosol size. In this environment coarse mode aerosols are typically either sea salt derived from the coastal Pacific or mineral dusts derived from arid regions in Northern and Western China. Mineral dusts represent an alkaline surface while condensing species are typically acidic (sulfuric and nitric acids). Therefore, there is the potential for heterogeneous chemical reactions to occur on the surface of the mineral dusts due to condensation of sulfuric acid.

Once a nucleation event has been triggered, and while gas phase concentrations remain supersaturated (with respect to the liquid solution), material will continue to condense on both the primary and secondary aerosols. The condensation process adds mass to the aerosol size distribution but does not affect total particle number. Because condensation adds similar surface layers to all sizes the nucleation mode particles experience larger relative rate of growth compared to accumulation or coarse mode particles. As a result, condensation can rapidly move nucleation mode particles into the Aitken mode size classes (within hours). The slow relative growth of accumulation and coarse mode aerosols prevents appreciable numbers of accumulation mode aerosols from growing into the coarse mode aerosol population.

Coagulation, in contrast to condensation, does not add mass to the aerosol size distribution. Instead the coagulation process transfers aerosol mass from smaller size classes to larger classes reducing particle number. Smaller, mostly secondary aerosols, are collected by the larger, mostly primary aerosols. Self coagulation ${ }^{1}$ is relatively inefficient and peaks at particle diameters near $0.020-0.030 \mu \mathrm{m}$ [Seinfeld and Pandis, 1998]. Coagulation rates for a given particle size are a function of the total aerosol size distribution but are most efficient between nucleation mode particles and coarse mode particles. Rapid Brownian motion of the smallest particles increases the probability of encountering the much larger (1-3 orders of magnitude in diameter) accumulation and coarse mode aerosols.

Coagulation rates under the polluted marine conditions discussed here are on the order of minutes to hours for the nucleation mode particles. Aitken mode particles have coagulation rates from hours to several days (see Section 7.0). Since condensation can move nucleation mode particles into the Aitken mode over several hours, high rates of condensational growth increase the probability that nucleation mode particles will survive as

\footnotetext{
${ }^{1}$ Coagulation between particles of the same diameter.
} 
new particle number in the background atmosphere. At the same time, coagulation reduces nucleation mode particle number transferring mass to larger size classes. Where coagulation rates are high and growth rates low then nucleation mode particles are likely to contribute few new particles to the background atmosphere.

\subsection{Recent Work Related to Secondary Aerosol Formation}

Interest in issues related to secondary aerosol formation has stimulated a variety of experiments designed to investigate these processes. In the near-shore environment the PARticle FORmation and fate in the Coastal Environment (PARFORCE) experiment illustrated that binary homogenous nucleation was insufficient to explain observations related to the formation of secondary aerosols. However, concentrations of sulfuric acid and ammonia were higher than required to cause homogeneous ternary nucleation of $\mathrm{H}_{2} \mathrm{SO}_{4}, \mathrm{H}_{2} \mathrm{O}$ and $\mathrm{NH}_{3}$ [Kulmala et al., 2002]. Also during PARFORCE, Kunz et al. [2002] predicted that $\mathrm{H}_{2} \mathrm{SO}_{4}$ concentrations were insufficient to produce the observed particle growth. However, co-incident chemical data showed that photo-oxidation of organic $\mathrm{CH}_{2} \mathrm{I}_{2}$ compounds (from exposed tidal flats) contributed the mass necessary to explain the growth rate of the nucleation mode aerosol. At a clean continental site on the eastern slope of the Rocky Mountains in Colorado Weber et al. [1997] found concentrations of $\mathrm{H}_{2} \mathrm{SO}_{4}$ and $\mathrm{H}_{2} \mathrm{O}$ that were well below predicted values for binary nucleation during a nucleation event. In addition, the observed growth rates were approximately 5 - 10 times higher than the rate predicted from sulfuric acid and water alone. This observation implies that $\mathrm{NH}_{3}$, organics or some other condensing species is involved in the growth of these particles.

Regardless of the microphysical nature of the newly formed secondary aerosols, Raes et al. [2000] suggest that too often we have not examined these secondary aerosols with regard to large-scale atmospheric circulation. Atmospheric processes involving temperature and humidity changes within a single air parcel (atmospheric waves, turbulence, large convective eddies) or mixing of two air parcels with different relative humidity and temperature (gradients and/or entrainment) can enhance binary nucleation for the $\mathrm{H}_{2} \mathrm{SO}_{4}$ and $\mathrm{H}_{2} \mathrm{O}$ system [Easter and Peters, 1994; Kerminen and Wexler, 1994a; Nilsson and Kulmala, 1998]. These same phenomena should enhance any ternary nucleation mechanism involving $\mathrm{H}_{2} \mathrm{SO}_{4}, \mathrm{H}_{2} \mathrm{O}$ and $\mathrm{NH}_{3}$. This appears to be the case during the European BIOgenic aerosol 
FORmation in the boreal forest (BIOFOR) experiment where synoptic scale new particle formation was observed in the continental boundary layer [Nilsson et al., 2001].

With regard to gas phase organics as nucleation precursors Buzorius et al. [2001] show no support for biogenic gases from the boreal forest as precursors for nucleation during BIOFOR. Leaitch et al. [1999] could not distinguish whether $\mathrm{H}_{2} \mathrm{SO}_{4}$ or forest derived organics initiated a nucleation event at a clean continental site in Eastern Canada. However, they did show that subsequent growth of the aerosol could be attributed to organic oxidation products. More recently Janson et al. [2001] observed nucleation over a forest ecosystem at a clean continental site in Finland. They found monoterpene oxidation products were not nucleation precursors but that low vapour pressure organics were needed to explain the observed growth rates because of insufficient concentrations of $\mathrm{H}_{2} \mathrm{SO}_{4}$ and $\mathrm{NH}_{3}$. In the TRACE-P and ACE-Asia environments organic vapours could certainly contribute to condensation growth, however due to the magnitude of the regional $\mathrm{SO}_{2}$ emissions it seems unlikely that gas to particle conversion of organic vapours is the dominant mechanism for forming secondary aerosols. Organic compounds may be important for the subsequent growth of particles to Aitken mode sizes.

Airborne measurements of the transport of natural and anthropogenic aerosols throughout the Pacific have been documented [Clarke et al., 2001; Clarke and Kapustin, 2002; Husar et al., 2001]. Secondary aerosols are of particular interest because of their potential to contribute new particle number to the background atmosphere. However, depending upon environmental conditions condensable material and newly formed particles may be collected by the existing aerosol surface area and therefore contribute new mass but not new number to the atmosphere. In polluted regions with high aerosol surface area we expect that many of these particles will coagulate on the order of 1-2 days with the primary aerosol [Raes et al., 2000]. This work is concerned with answering the following questions with regard to the importance of primary and secondary aerosols.

- Where and when during the TRACE-P and ACE-Asia campaigns were recently formed secondary aerosols found?

- Is the binary homogeneous nucleation mechanism able to explain their formation or is it more likely a ternary mechanism involving species other than $\mathrm{H}_{2} \mathrm{SO}_{4}$ and $\mathrm{H}_{2} \mathrm{O}$ ?

- How do the observed growth rates for these nuclei compare with published values? 
- Can we use a coagulation/condensation model to evaluate the fate of these newly formed secondary aerosols?

\subsection{Regional Climatology and Long Range Transport of Asian Aerosols}

Springtime in Asia is a transitional period between the winter and summer monsoon. In winter an intense atmospheric high exists over Asia while the Aleutian low persists over the North Pacific. In summer the situation is reversed with a stable low positioned over Northwestern India and Pakistan with a corresponding high existing over the North Pacific [Tomczak and Godfrey, 1994]. The frequency of wave cyclones is highest during Spring resulting in transient cyclones moving through Mainland China across the Korean peninsula and Japan toward the North Pacific [Hannan et al., submitted 2002]. In the upper free troposphere the Japan jet is strongest at $\sim 30^{\circ} \mathrm{N}$ along $140^{\circ} \mathrm{E}$ between the $300-200 \mathrm{hPa}$ level $(10-14 \mathrm{~km})$. Wind speeds are typically $50-60 \mathrm{~m} \mathrm{~s}^{-1}$ at this altitude but may reach speeds of up to $100 \mathrm{~m} \mathrm{~s}^{-1}$. In the lower free troposphere zonal winds of $10-30 \mathrm{~m} \mathrm{~s}^{-1}$ exist between the $800-550 \mathrm{hPa}$ levels $(3-6 \mathrm{~km})$ [Fuelberg et al., submitted 2002; Merrill et al., 1997].

Three dominant weather phenomena are responsible for transporting mineral dusts and anthropogenic pollution from the planetary boundary layer (PBL) and the marine boundary layer (MBL) into the free troposphere (FT). Wind speeds at the surface over the desert plateaus of Asia (1000-2000 m above mean sea level, AMSL) can exceed $20 \mathrm{~m} \mathrm{~s}^{-1}$ transporting dust into the PBL [Husar et al., 2001]. Convection in the warm front associated with the moving cyclone can lift mineral dusts from the PBL into the FT between 3 and 6 kilometers over the Gobi and Taklamakan deserts. Also, upslope flow along mountain ranges such as the Tian Shan (4500 - 5500 m AMSL) to the North of the Taklamakan and along the Tibetan plateau South of the Taklamakan ( $4000 \mathrm{~m}$ AMSL) can loft mineral dust into the lower FT through orographic lifting.

Behind the advancing cold front mineral dusts are also transported within the planetary boundary layer toward the coastal regions of China [Uno et al., 2001]. As the weather system moves over the coastal lowlands ( $0-1000 \mathrm{~m}$ AMSL) the boundary layer air picks up anthropogenic pollution from the regional urban and industrial complexes.

Orographic lifting over the Korean peninsula and along the Japanese archipelago is responsible for some transport of dust and pollution from the boundary layer into the free 
troposphere [Liu et al., submitted 2002]. However, most pollution is transported within the MBL fanning out over the coastal bodies of water. Pollution from Mainland China often lingers offshore when the first low dissipates or weakens. As the next low approaches the anthropogenically impacted warm sector is undercut by the advancing cold front and lofted into the FT. This mechanism is the so-called warm conveyor belt (WCB) theory [Hannan et al., submitted 2002; Liu et al., submitted 2002; Mari et al., submitted 2002].

Instead of lingering over the coastal waters, pollution in the MBL fanning out from China can also parallel the coast to be entrained into the Philippine high. Moving around the anti-cyclone the polluted airmass can then be transported toward Southeast Asia. This region experiences deep convection that directly pumps boundary layer air into the FT where it is entrained into the fast upper level Japan jet. This phenomenon is also important for transporting combustion derived pollution because Southeast Asia is an area which experiences poor air quality due to widespread biomass burning [Liu et al., submitted 2002]. Regardless of whether transport from the boundary layer to the FT is due to orographic lifting, warm conveyor belt transport or convection, once the aerosols associated with these airmasses are brought into the FT they are available for long range transport out over the North Pacific toward North America by the zonal upper level winds. Due to the enhanced frequency of cold fronts and their associated wave cyclones during spring it is this time of year that dust and pollution from Asia has the highest potential for reaching North America.

\subsection{Transport and Chemical Evolution over the Pacific Experiment (TRACE-P)}

The National Aeronautics and Space Administration (NASA) conducted the Transport and Chemical Evolution over the Pacific experiment (TRACE-P) from February $26^{\text {th }}$ to April $9^{\text {th }}$ of 2001 . This mission was part of a larger, ongoing research program called the Global Tropospheric Experiment (GTE) [McNeal et al., 1998]. The goals of TRACE-P, as outlined in the white paper (http://www-gte.larc.nasa.gov/trace/tracep.html) are:

- to determine the pathways for outflow of chemically and radiatively important gases and aerosols, and their precursors, from eastern Asia to the western Pacific;

- to determine the chemical evolution of the Asian outflow over the western Pacific, and understand the ensemble of processes that control this evolution. 
TRACE-P was designed as a multi-national, multi-agency experiment involving shipbased, ground-based, aircraft, and satellite data collection together with real-time forecasting by a number of meteorology and atmospheric chemistry transport models (CTM's). An overview of the TRACE-P experiment can be found in Jacob et al. [submitted 2002]. The Hawai i Group for Environmental Aerosol Research (HiGEAR) participated in TRACE-P by supplying a suite of aerosol instrumentation designed to assess the physical and optical properties of aerosols. This instrumentation was installed aboard the NASA P3-B aircraft which completed 20 research flights during the field campaign. Figure 1.1 shows the flight tracks of the NASA P3-B during TRACE-P.

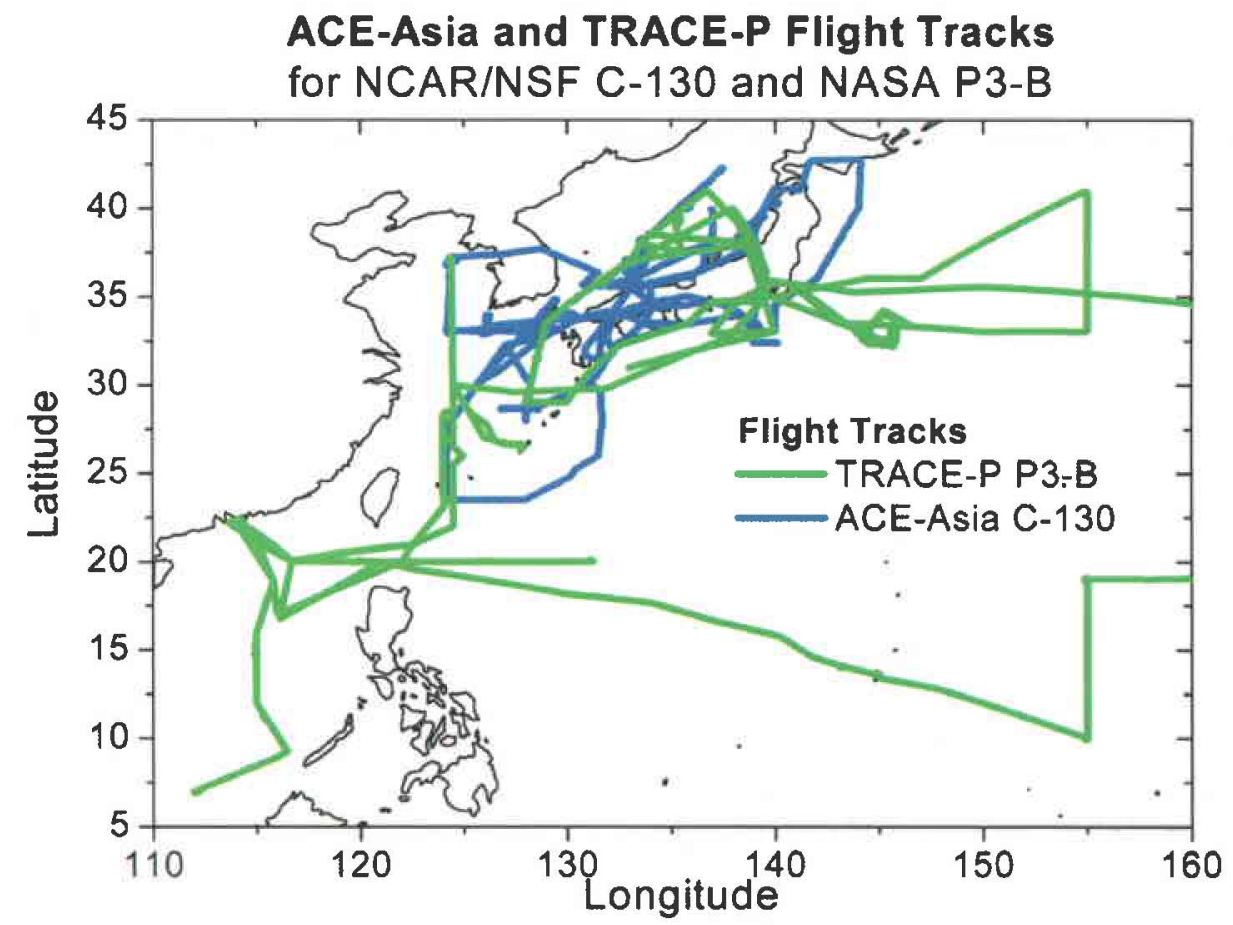

Figure 1.1 - Flight paths for the NASA P3-B and NSF/NCAR C-130 during TRACE-P and ACE-Asia.

Flights 4 through 14 were based out of Hong Kong and were designed to intercept biomass burning and urban emissions from South-East Asia. Flights $15-24$ were based at Yokota Air Force base near Tokyo Japan and flights were designed to intercept anthropogenic pollution plumes as well as natural volcanic and dust emissions from China, the Korean peninsula and Japan. 


\subsection{Asian Aerosol Characterization Experiment (ACE-Asia)}

The United States' National Science Foundation (NSF) as part of the International Global Atmospheric Chemistry Project (IGAC) supported the Asian Aerosol

Characterization Experiment (ACE-Asia) from March $31^{\text {st }}$ to May $4^{\text {th }} 2001$. ACE-Asia had three objectives (http://saga.pmel.noaa.gov/aceasia/ACEAsiaDescription.html).

- Objective 1. Determine the physical, chemical, and radiative properties of the major aerosol types in the Eastern Asia and Northwest Pacific region and investigate the relationships among these properties.

- Objective 2. Quantify the interactions between aerosols and radiation in the Eastern Asia and Northwest Pacific region

- Objective 3. Quantify the physical and chemical processes controlling the evolution of the major aerosol types and in particular their physical, chemical, and radiative properties.

ACE-Asia was also a multi-national, multi-agency experiment involving multiple platforms and observations sites in conjunction with forecasting meteorology and atmospheric chemistry transport models. An overview of the ACE-Asia experiment can be found in Huebert et al. [submitted 2003]. Again, HiGEAR participated with instrumentation designed to assess the physical and optical properties of aerosols. This instrumentation operated aboard the NSF/NCAR C-130 during 19 research flights. The C-130 aircraft was stationed at the Marine Corps Air Station Iwakuni located in Iwakuni Japan, $\sim 50$ kilometers south of Hiroshima. Flight tracks for the NCAR C-130 are also shown in figure 1.1.

\subsection{Particle Nucleation Theory}

Part of the significance of secondary aerosols relative to the primary aerosols hinges on whether newly produced particles will survive coagulation processes long enough to grow by condensation to optically significant sizes and/or sizes which could affect the number and distribution of cloud condensation nuclei. In order to address this issue the following section briefly outlines a number of theoretical approaches that we have used to investigate these processes. The results of the application of this theory to our analysis are covered in the discussion (Section 7.0). 


\subsection{The $\mathrm{C}_{\text {crit }}$ Parameterization}

In the atmosphere, collisions between sulfuric acid and water molecules occur at random due to Brownian motion. Stable clusters of hydrated sulfuric acid exist in equilibrium until the system is perturbed in such a way that allows a significant fraction of these clusters to remain stable and grow [Kulmala et al., 2000]. In order for clusters to stabilize and grow the cluster must exceed its critical radius. The critical radius is a function of the Gibbs free energy. For the binary nucleation scenario the free energy change associated with the cluster formation is a function of temperature as well as the concentration of sulfuric acid and water molecules [Seinfeld and Pandis, 1998]. When atmospheric conditions associated with the free energy change are such that clusters can breach the saddle point for the collision iso-surface, stable clusters grow by condensation initiating a nucleation event. Free energies of formation appear to be lower by perhaps an order of magnitude for the ternary system involving $\mathrm{H}_{2} \mathrm{SO}_{4}, \mathrm{H}_{2} \mathrm{O}$ and $\mathrm{NH}_{3}$ [Ball et al., 1999; Kulmala et al., 2000].

The theoretical framework for nucleating cluster formation is complicated and covered in detail in other publications [Seinfeld and Pandis, 1998]. In our discussion of secondary aerosol formation we will refer to a simpler formulation for the concentration of sulfuric acid required to produce a nucleation event. The $\mathrm{C}_{\text {crit }}$ parameterization of JaeckerVoirol and Mirabel [1989] and Wexler et al. [1994] expresses the critical concentration of sulfuric acid necessary to achieve a binary homogeneous nucleation rate of $1 \mathrm{~cm}^{-3} \mathrm{~s}^{-1}$ in terms of relative humidity and temperature. The empirical formula is parameterized as:

$$
C_{c r i t}=0.16 \cdot \exp (0.1 T-3.5 R H-27.7)
$$

where $\mathrm{T}$ is temperature $\left({ }^{\circ} \mathrm{K}\right), \mathrm{RH}$ is relative humidity $(0-1)$ and the units of $\mathrm{C}_{\text {crit }}$ are $\mu \mathrm{g} \mathrm{m}^{-3}$. This simple formulation has been used as an indicator for potential binary homogeneous nucleation of $\mathrm{H}_{2} \mathrm{SO}_{4}$ and $\mathrm{H}_{2} \mathrm{O}$ in the clean marine environment near cloud outflow [Clarke et al., 1999; Clarke et al., 1998; Weber et al., 1999]. This parameterization is based on Jaecker-Voirol and Mirabel [1989] which tends to predict nucleation at lower $\mathrm{H}_{2} \mathrm{SO}_{4}$ relative 
acidities $^{2}$ than the Wilemski [1984] model due to a thermodynamic inconsistency inherent to the model (see Weber et al. [1999]). We employ the Wexler et al. formulation because of its simplicity and because it represents a conservative estimate for binary nucleation. Modeling by Pirjola et al. [2000] suggests that binary nucleation only occurs under extreme conditions when free tropospheric air containing very low aerosol condensation sinks and high sulfuric acid concentrations $\left(>10^{8}\right.$ molecules $\left.\mathrm{cm}^{-3}\right)$ is entrained into the marine boundary layer. They suggest that instead a ternary nucleation mechanism involving $\mathrm{H}_{2} \mathrm{SO}_{4}, \mathrm{H}_{2} \mathrm{O}$ and $\mathrm{NH}_{3}$ predicts new particle formation under more realistic sulfuric acid $\left(1.2 \times 10^{7}\right.$ molecules $\left.\mathrm{cm}^{-3}\right)$ and ammonia ( $>5$ pptv) concentrations for the unperturbed marine boundary layer (MBL).

\subsection{Flux Rate of Sulfuric Acid to the Size Distribution}

Because the relative rate of diameter change for nucleation mode particles is higher than that for accumulation and coarse mode aerosols it is possible to calculate the change of particle diameter with respect to time, $\mathrm{dDp} / \mathrm{dt}$. By adopting the method of Kulmala et al. [2001] we calculate the condensation sink (CS) a parameter relating the rate at which condensable vapours are lost to the existing aerosol size distribution. Calculations of this type allow us to estimate the flux rate of vapour (believed to be dominated by sulfuric acid) to the size distribution.

The differential equation:

$$
\frac{d C}{d t}=Q-C S \cdot C
$$

is evaluated assuming steady state $\frac{d C}{d t}=0$, where $\mathrm{Q}$ is the flux rate of vapour, $\mathrm{C}$ is the vapour concentration and CS is the condensational sink. The growth rate is given by:

$$
\frac{d D p}{d t}=\frac{2 m_{v} \beta_{m} D_{v} C}{\rho D p}
$$

\footnotetext{
${ }^{2}$ Like relative humidity, relative acidity is the ratio of the mixing ratio of sulfuric acid gas to it value at saturation for the same temperature and pressure.
} 
where $m_{v}$ is the molecular mass of the condensable vapour $A\left(98.0794 \mathrm{~g} \mathrm{~mol}^{-1}\right), D_{v}$ is the diffusion coefficient of gas A toward a particle when both are suspended in background gas B (in this case air), $\rho$ is the particle density $\left(1.4 \mathrm{~g} \mathrm{~cm}^{-3}\right)$, and $\beta_{\mathrm{m}}$ is the transitional correction factor (Eqn. 2.6) for mass flux integrated over the size distribution. We calculate the vapour concentration, $\mathrm{C}$, using:

$$
C=\frac{\rho}{m_{v} D_{v} \Delta t} \cdot\left[2\left(D p^{2}-D p_{o}^{2}\right)+\lambda_{A B}(12 \alpha-0.623)\left(\frac{D p}{2}-\frac{D p_{o}}{2}\right)+0.623 \lambda_{A B}^{2} \ln \left(\frac{\lambda_{A B}+\frac{D p}{2}}{\lambda_{A B}+\frac{D p_{o}}{2}}\right)\right]
$$

where $\mathrm{Dp}$ is the particle diameter after some time interval $\Delta \mathrm{t}, \alpha$ is the mass accommodation coefficient $(\alpha=1)$ and $\lambda_{\mathrm{AB}}$ is the mean free path of gas particle $\mathrm{A}$ with respect to gas $\mathrm{B}$.

The condensational sink CS is expressed as $2 \pi \mathrm{D}_{\mathrm{AB}} \mathrm{CS}$ ' where:

$$
C S^{\prime}=\sum_{i} \beta_{m i} D p_{i} N_{i}
$$

and,

$$
\beta_{m i}=\frac{K n_{i}+1}{0.377 K n_{i}+1+\frac{4}{3 \alpha}\left(K n_{i}+K n_{i}^{2}\right)}
$$

$\mathrm{Kn}$ is the Knudsen number (Eqn. 2.10) a dimensionless parameter relating the length scales of fluid processes (transfer of heat, momentum and mass) to the length scales associated with the particle radius [Seinfeld and Pandis, 1998].

This estimate of the condensation rate of sulfuric acid is based on the size distributions measured by the rDMA and OPC instrument systems (Section 3.0). Other methods are available and we compare some published values to those calculated by this method in the discussion (Section 7.0). 


\subsection{Coagulation Rate of Nucleation Mode Particles}

We can also calculate the coagulation sink (CoagS) using the time rate of change of particle diameter, $\mathrm{dDp} / \mathrm{dt}$. The method of Kulmala et al. [2001] allow us to calculate the expected coagulation rate of the nucleation mode particles and will provide a rough estimate of their atmospheric lifetime.

The loss rate for a given size particle is expressed as,

$N(t)=N_{o} e^{-\operatorname{coag} S \cdot t}$

where the coagulation sink, CoagS, is integrated over the whole size distribution according to,

$\operatorname{Coag} S=\sum_{j} K_{i j} N_{j}$

Using the Fuchs form of the Brownian coagulation coefficient, $\mathrm{K}_{12}$ can be expressed as:

$K_{12}=2 \pi\left(D_{1}+D_{2}\right)\left(D p_{1}+D p_{2}\right)\left(\frac{D p_{1}+D p_{2}}{D p_{1}+D p_{2}+2\left(g_{1}^{2}+g_{2}^{2}\right)^{1 / 2}}+\frac{8\left(D p_{1}+D p_{2}\right)}{\left(\bar{c}_{1}^{2}+\bar{c}_{2}^{2}\right)^{1 / 2}\left(D p_{1}+D p_{2}\right)}\right)^{-1}$

where,

$K n_{i}=\frac{2 \lambda_{\text {air }}}{D p_{i}}$

$\bar{c}=\left(\frac{8 k T}{\pi m_{i}}\right)^{1 / 2}$

$D_{i}=\frac{k T}{3 \pi \mu D p_{i}} \cdot\left(\frac{5+4 K n_{i}+6 K n_{i}^{2}+18 K n_{i}^{3}}{5-K n_{i}+(8+\pi) K n_{i}^{2}}\right)$

$l_{i}=\frac{8 D_{i}}{\pi \bar{c}_{i}}$

$g_{i}=\frac{1}{3 D p_{i} l_{i}} \cdot\left[\left(D p_{i}+l_{i}\right)^{3}-\left(D p_{i}^{2}+l_{i}^{2}\right)^{3 / 2}\right]-D p_{i}$ 
and where $\mathrm{k}$ is the boltzman constant, $\lambda_{\text {air }}$ is $0.0686 \mu \mathrm{m}, \mathrm{m}_{\mathrm{i}}$ is the mass of the particle based on a density of $1.4 \mathrm{~g} \mathrm{~cm}^{-3}$, and $\mu$ is the viscosity of air, $1.83 \times 10^{-5} \mathrm{~kg} \mathrm{~m}^{-1} \mathrm{~s}^{-1}$. All calculations are based on an unhydrated molecular mass of $\mathrm{H}_{2} \mathrm{SO}_{4}$ of $98.0794 \mathrm{~g} \mathrm{~mol}^{-1}$, temperature (T) of $298.15^{\circ} \mathrm{K}$ and a pressure (p) of $101.325 \mathrm{kPa}$ [Kulmala et al., 2001; Seinfeld and Pandis, 1998].

From theory we expect that the nucleation mode particles will coagulate with the primary aerosol on the order of 1-2 days [Raes et al., 2000]. In the discussion section of the thesis we tabulate the e-folding times for the nucleation mode particles from the observed size distributions.

\subsection{Research Aircraft and Instrumentation}

Our research team (HiGEAR) installed a variety of aerosol instrumentation aboard the NASA P3-B and NSF/NCAR C-130 during the TRACE-P and ACE-Asia field campaigns. Two intercomparison flights between the two aircraft showed excellent agreement [Moore et al., submitted 2003]. The following sections outline the research platforms and the instrumentation used during the field campaigns.

\subsection{Research Aircraft}

During TRACE-P HiGEAR instrumentation was installed aboard the NASA P3-B aircraft. NASA's Wallops Flight Facility located in Wallops Island Virginia manages this aircraft. The aircraft can operate between 50 and 7000 meters with a typical airspeed of 100 $150 \mathrm{~m} \mathrm{~s}^{-1}$. Aerosol instrumentation aboard the P3-B was linked to a solid diffuser type inlet and was mounted in a standard research rack. The solid diffuser inlet is designed to sample isokinetically. If the inlet is sampling isokinetically the velocity of the sample air through the cross section of the inlet tip is the same as the air speed for the aircraft. In order to achieve this the sample stream is connected to a venturi type exhaust port that increases sample flow rate as the aircraft increases speed (the venturi effect). Losses of supermicrometer particles in this type of system become significant near about $4 \mu \mathrm{m}$ but have a negligible effect on total particle number. No significant losses of nucleation mode particles are expected. 
During ACE-Asia HiGEAR instrumentation was installed aboard the National Science Foundation (NSF) C-130 research aircraft. An experimental Low Turbulence Inlet (LTI) was designed and installed aboard the $\mathrm{C}-130$ by the University of Denver. This active flow system maintains laminar flow within the sample stream while sampling isokinetically. This system is expected to substantially reduce losses and even enhance the concentrations of supermicrometer particles entering the sampling systems. The OPC system (see Section 3.5) was mounted on the starboard side of the aircraft and was directly linked to LTI. Nephelometers (see Section 3.6) were mounted vertically in the second starboard rack and were operated by the University of Washington. The nephelometers were also linked directly to the LTI system by flow splitters. The condensation nuclei counters (see Section 3.2) and the DMA (see Section 3.4) aboard the C-130 sampled from a solid diffuser inlet and were located on the starboard side of the aircraft.

\subsection{Condensation Nuclei Counters}

Three separate models of $\mathrm{CN}$ counters were employed during ACE-Asia and TRACE-P. Aboard the NASA P3-B two TSI model $3010 \mathrm{CN}$ counters were used. The first operates at ambient temperature the second operates at $300^{\circ} \mathrm{C}$. The model $3010 \mathrm{CN}$ has a $50 \%$ counting efficiency at $0.01 \mu \mathrm{m}$ (its smallest useful size) and can detect particles up to 3 $\mu \mathrm{m}$ in size (its largest useful size). The concentration range for this instrument is $0.0001-$ $10,000 \mathrm{~cm}^{-3}$, with $<10 \%$ coincidence counting at $10,000 \mathrm{~cm}^{-3}$ [TSI, 1992]. The model 3010 $\mathrm{CN}$ counters operate at a $1.0 \mathrm{~L} \mathrm{~min}^{-1}$ flow rate. Aboard the $\mathrm{C}-130$ aircraft two model 3760 $\mathrm{CN}$ counters operated at ambient temperature and $300^{\circ} \mathrm{C}$. A third $3760 \mathrm{CN}$ counter, operated by the NCAR Research Aviation Facility, is referred to as the "RAF CN". The model 3760 $\mathrm{CN}$ counter measures particles $>0.01 \mu \mathrm{m}$ with concentrations up to $9886.8 \mathrm{~cm}^{-3}\left(2.8 \times 10^{8} \mathrm{ft}^{-}\right.$ $\left.{ }^{3}\right)$ [TSI, 1986]. However, 50\% counting efficiency for this instrument is more likely $\sim 0.012$ $\mu \mathrm{m}$ [A.D. Clarke, personal communication]. The model $3760 \mathrm{CN}$ counters operate with a 1.5 $\mathrm{L} \mathrm{min}^{-1}$ flow rate. A model $3025 \mathrm{~A} \mathrm{CN}$ counter, also aboard the $\mathrm{C}-130$, operated at ambient temperature. This instrument has 50\% detection efficiency at $0.003 \mu \mathrm{m}$ and $90 \%$ detection efficiency at $0.005 \mu \mathrm{m}$. The model $3025 \mathrm{~A}$ counter records concentrations with an accuracy of $+1-10 \%$ at $9.99 \times 10^{4} \mathrm{~cm}^{-3}$ and operates with a sample flow rate of $1.5 \mathrm{~L} \mathrm{~min}^{-1}[T S I, 1996]$. 
When referring to the data from the $\mathrm{CN}$ counters we will use a number of acronyms. For both the $\mathrm{P} 3-\mathrm{B}$ and the $\mathrm{C}-130$ the $\mathrm{CN}$ counters operating at ambient conditions are referred to as the "Cold CN" or "UH Cold CN". For the CN counters operating at $300^{\circ} \mathrm{C}$ the designations are "Hot CN" or "UH Hot CN". Volatile CN (VCN) is the difference between the Cold $\mathrm{CN}$ and the Hot $\mathrm{CN}$ and is an indication of the number of particles which contain primarily sulfates and neutralized sulfate species (ammonium sulfate and ammonium bisulfate) [Clarke et al., 1998]. However, due to the polluted nature of this marine environment we note that any organic compounds with boiling points $<300^{\circ} \mathrm{C}$ will also be volatilized during the heating process and is a possible source of error. Refractory CN $(\mathrm{RCN})$ is the same as the Hot $\mathrm{CN}$ and refers to the fact that those particles counted after heating to $300^{\circ} \mathrm{C}$ contain primary aerosols either as internally mixed soot, fly ash or externally mixed dust and/or sea salt. Refractory ratio is the ratio of Hot CN:Cold CN. RCN ratios tending toward unity indicate the aerosol is dominated by internal mixtures containing primary aerosols (soot, fly ash) or external mixtures of exclusively refractory material (sea salt and/or dust). Ratios tending toward zero indicate the aerosol is nearly completely volatile at $300^{\circ} \mathrm{C}$ and contains no refractory component. It is convention to define nucleation mode particles as particles with $\mathrm{Dp}<0.01 \mu \mathrm{m}$ [Raes et al., 2000]. However, we can estimate concentrations for nucleation mode particles by subtracting total concentration as measured by the model 3025A (referred to as the UCN) and the model $3760 \mathrm{CN}$ counters. Based on the $50 \%$ counting efficiencies for these two instruments our nucleation mode particle concentrations are measured between 3 and $\sim 12 \mathrm{~nm}$. This is sometimes referred to as DCN.

\subsection{Thermo-Optical Aerosol Discriminator (TOAD)}

A Thermo-Optical Aerosol Discriminator (TOAD) operated by the HiGEAR team is coupled to both the DMA and OPC sampling systems (see Sections $3.4 \& 3.5$ ). This simple system of heaters and valves allows size distributions to be obtained at dry ambient ${ }^{3}$ temperature, $150^{\circ} \mathrm{C}$ and $300^{\circ} \mathrm{C}$. We use the differences between the heated and unheated size distributions in order to measure aerosol volatility which is related to composition [Clarke, 1991]. In the clean marine atmosphere we have shown that the difference between the dry

\footnotetext{
${ }^{3}$ Sheath flows for both the rDMA and OPC system are dried $(\mathrm{RH}<20 \%)$ using desiccant chambers. We therefore refer to the sample streams' size distribution as being recorded at "dry ambient conditions".
} 
ambient and the $150^{\circ} \mathrm{C}$ scan represents primarily unneutralized sulfuric acid [Clarke et al., 1998]. The TOAD volatilizes neutralized sulfate species such as ammonium sulfate and ammonium bisulfate $\left(\left(\mathrm{NH}_{4}\right)_{2} \mathrm{SO}_{4}\right.$ and $\left.\mathrm{NH}_{4} \mathrm{HSO}_{4}\right)$ between $150^{\circ} \mathrm{C}$ and $300^{\circ} \mathrm{C}$. We refer to the aerosol volume remaining after $300^{\circ} \mathrm{C}$ as the "refractory component" which typically consists of black carbon species, fly ash, sea salt and/or mineral dust. The more polluted environment of the ACE-Asia and TRACE-P study region makes the interpretation of volatile species more uncertain due to our inability to distinguish between sulfate aerosols and nitrates, organic aerosols and other components volatile at temperatures $<300^{\circ} \mathrm{C}$. However, links between size-resolved volatility and rapid measurement of aerosol chemistry (PILS) aid in the interpretation of the data.

\subsection{Differential Mobility Analyzer (DMA)}

Radial Differential Mobility Analyzers (rDMA's) were installed aboard both the NASA P3-B and the NCAR C-130. The rDMA operates using a 90 second data scan followed by a 30 second down time (no data recorded). The rDMA effectively sizes particles between 0.007 and $0.213 \mu \mathrm{m}$ with a resolution of 32 channels per logarithmically spaced decade. The rDMA system sizes particles using an electrical field. Particles are singly charged by a radioactive polonium source before entering the electric field. As the voltage is logarithmically ramped between 0 and 10,000 volts particles of successively larger sizes are deflected into the counting instrument (a modified TSI model $3010 \mathrm{CN}$ counter). More information on the theory behind the use of the rDMA system can be found in Zhang et al. [1995].

In order to sample the same air over up to a 6-minute sampling period the IDMA is coupled to a Lagged Aerosol Grab (LAG) chamber. The LAG chamber samples the airmass over a 20 second period and holds the sample in a thermally stratified column [Clarke et al., 1998]. During level legs the rDMA system completes three consecutive scans at dry ambient conditions, $150^{\circ} \mathrm{C}$ and $300^{\circ} \mathrm{C}$ using the TOAD ( 6 minute sampling time). During vertical profiles the rDMA completes single scans at dry ambient conditions ( 2 minute sampling time) improving vertical resolution of the size distribution. 


\subsubsection{DMA corrections}

Of particular relevance to this thesis is the accuracy with which the number distribution of aerosols is measured. The number distribution is dominated by the smallest particles, i.e. those measured by the rDMA system. In this regard a number of important corrections were made to the rDMA data in order that the total number of particles measured by the rDMA and OPC were within a confident range of values as compared to the UCN and Cold $\mathrm{CN}$ counters. The UCN and Cold $\mathrm{CN}$ counters have slightly different cut-off sizes compared to the rDMA system but give a more accurate estimate of total aerosol number because they do not suffer the same losses as the rDMA system. The corrections applied to the rDMA system are:

- the transmission efficiency correction,

- the neutralizer charging correction for heated scans $\left(150^{\circ} \mathrm{C}\right.$ and $\left.300^{\circ} \mathrm{C}\right)$,

- and the correction to standard atmospheric temperature and pressure (SATP, $298.15^{\circ} \mathrm{K}, 101.325 \mathrm{kPa}$ ).

When particles enter the rDMA system or when samples are sequestered inside the LAG chamber, nucleation mode particles can be rapidly lost to tubing walls and other surfaces due to their high rate of diffusion. In order to correct for this effect field and laboratory experiments were conducted in order to evaluate losses based on the particle sizes. The transmission efficiency curves for ACE-Asia and TRACE-P were generated based on these calculations. The transmission efficiency curves for ACE-Asia and TRACE-P are shown in figure 3.1, more information can be found in Appendix A. 


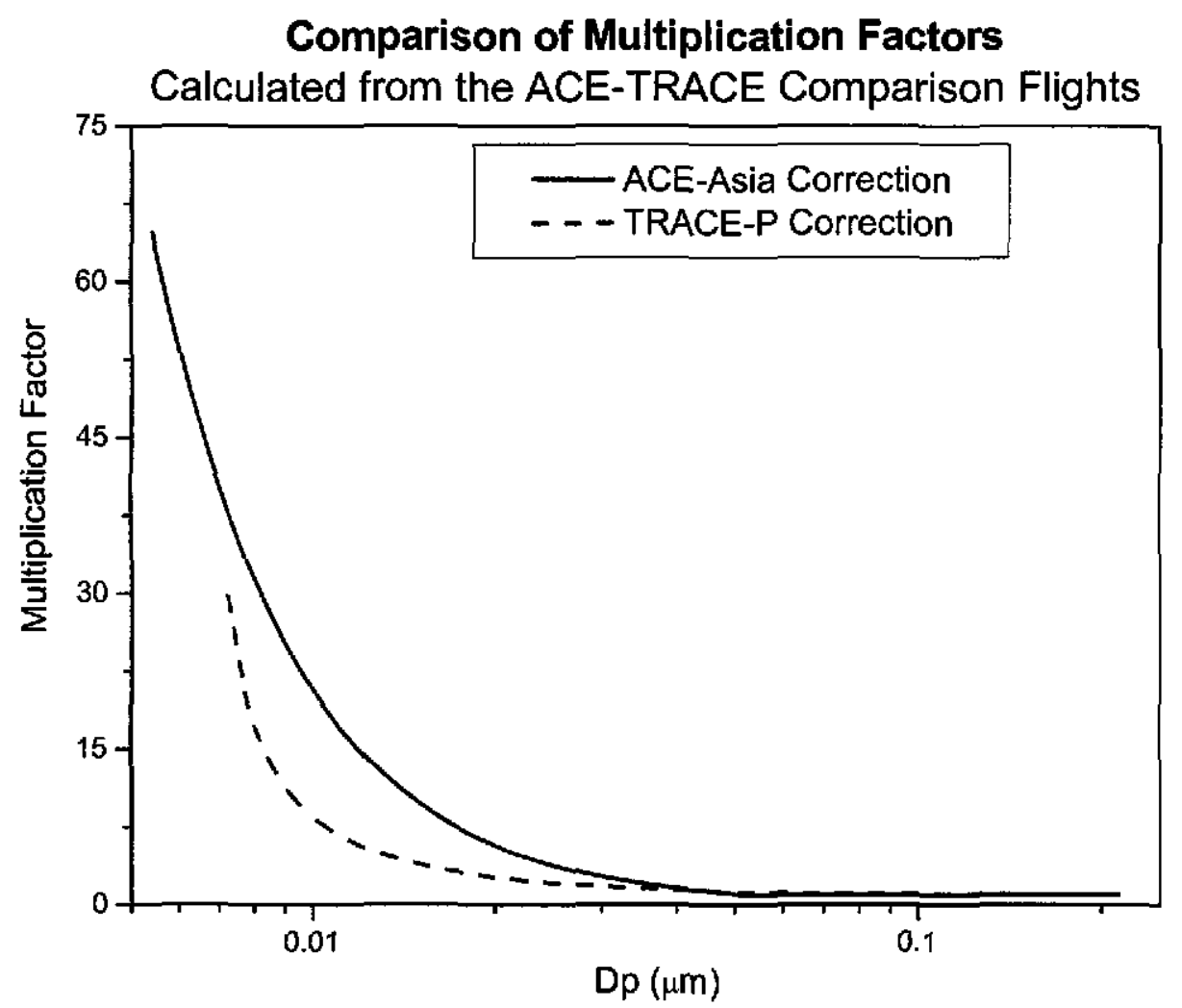

Figure 3.1 - Comparison of the transmission efficiency curves applied to the rDMA data sets for ACE-Asia and TRACE-P.

The second type of correction to the size distribution applies only to the heated scans. The correction stems from the inability of the DMA data acquisition program to properly invert data to get the original size of the charged particle (before heating) based upon its size after heating. The result is a false Boltzman charge distribution being assigned to particle sizes when the inversion is applied to the heated aerosol size distribution.

In laboratory experiments we were able to evaluate the magnitude of this correction by swapping the position of the polonium source from its standard position, upstream of the TOAD heaters, to a position downstream of the heaters (i.e. the polonium source was swapped to neutralize the size distribution after heating). The left panel of figure 3.2 shows an example of over counting due to the position of the neutralizer. Dry ambient size distributions are identical regardless of the neutralizer position. For $10 \mathrm{~nm}$ particles the actual particle concentrations at $150^{\circ} \mathrm{C}$ are only $\sim 70 \%$ of the concentration measured using the standard configuration (right panel of Figure 3.2). At $300^{\circ} \mathrm{C} 10 \mathrm{~nm}$ particle 
concentrations are only $\sim 60 \%$ of the concentrations measured in the standard configuration. Ratios of the difference between size distributions obtained from the standard procedure and that for the modified neutralizer position were generated for various aerosols under a range of total number concentrations. From the analysis we generated an empirical correction for the DMA charging which was then applied to all of the $150^{\circ} \mathrm{C}$ and $300^{\circ} \mathrm{C}$ DMA scans measured during ACE-Asia and TRACE-P. More detailed information regarding this correction can be found in Appendix A.

The final correction made to the rDMA size distribution is a conversion to standard atmospheric temperature and pressure $\left(101.325 \mathrm{kPa}\right.$ and $\left.298.15^{\circ} \mathrm{K}\right)$ from the "ambient" conditions recorded by temperature and $\mathrm{RH}$ sensors in the rDMA sample flow.
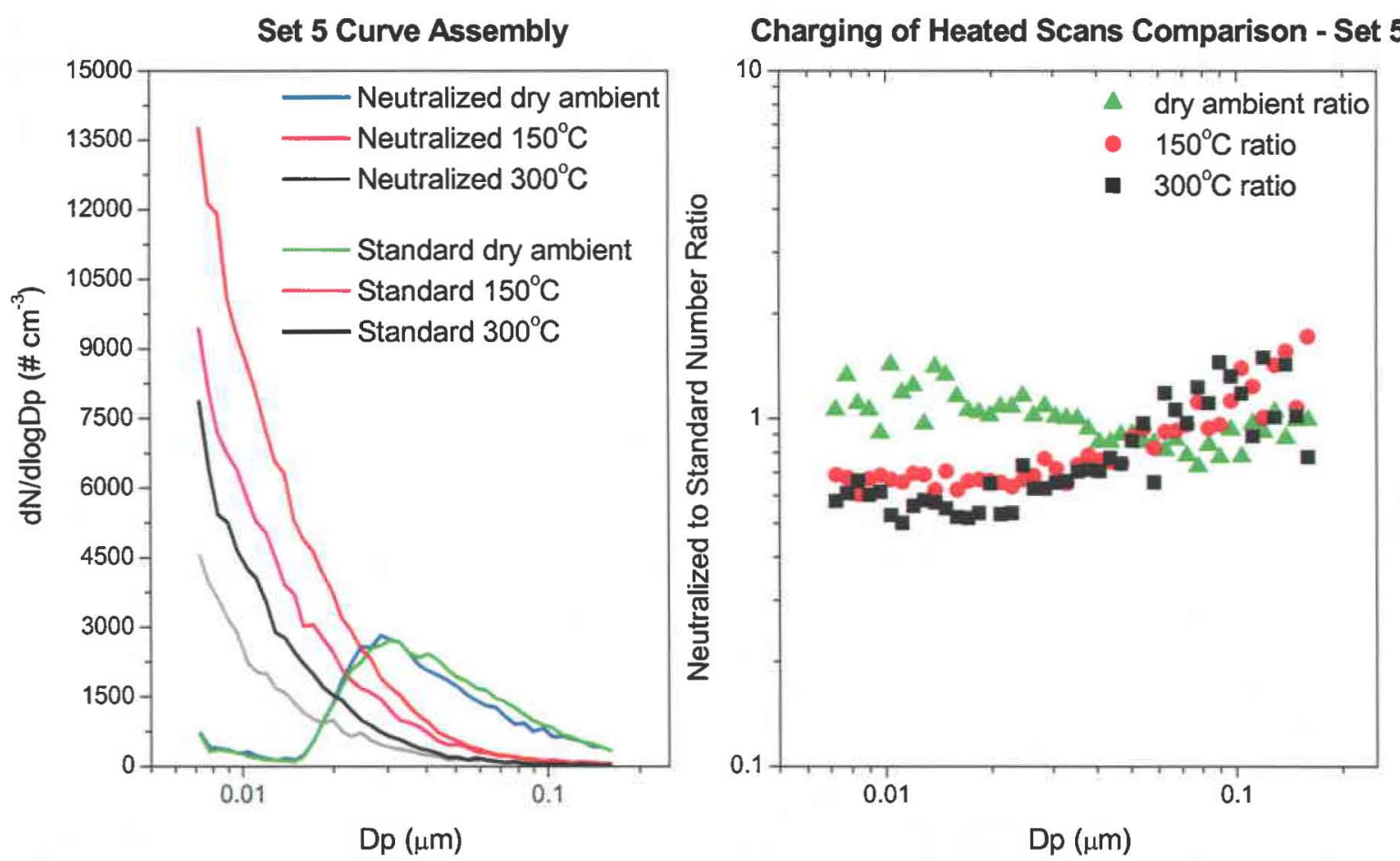

Figure 3.2 - Example of over-counting aerosol number due to false Boltzman charging of the heated DMA scans (left). Example of the ratio of number concentrations for neutralizer after heater vs. the standard neutralizer position before heater (right). 


\subsubsection{Accuracy of the total number integral}

The total integral number of particles between 0.007 and $20.0 \mu \mathrm{m}$ can be calculated by combining the DMA and OPC number distributions. We then compare the size distribution integrals to the $\mathrm{CN}$ counters aboard both aircraft in order to determine whether or not the total number integrals from the DMA and OPC are accurate. Figures 3.3 and 3.4 describe the statistics of the difference between calculated DMA and measured CN concentrations. Gaussian fits to the logarithm of the ratio between the total particle concentrations measured using the rDMA and OPC are compared to the $\mathrm{CN}$ counters.
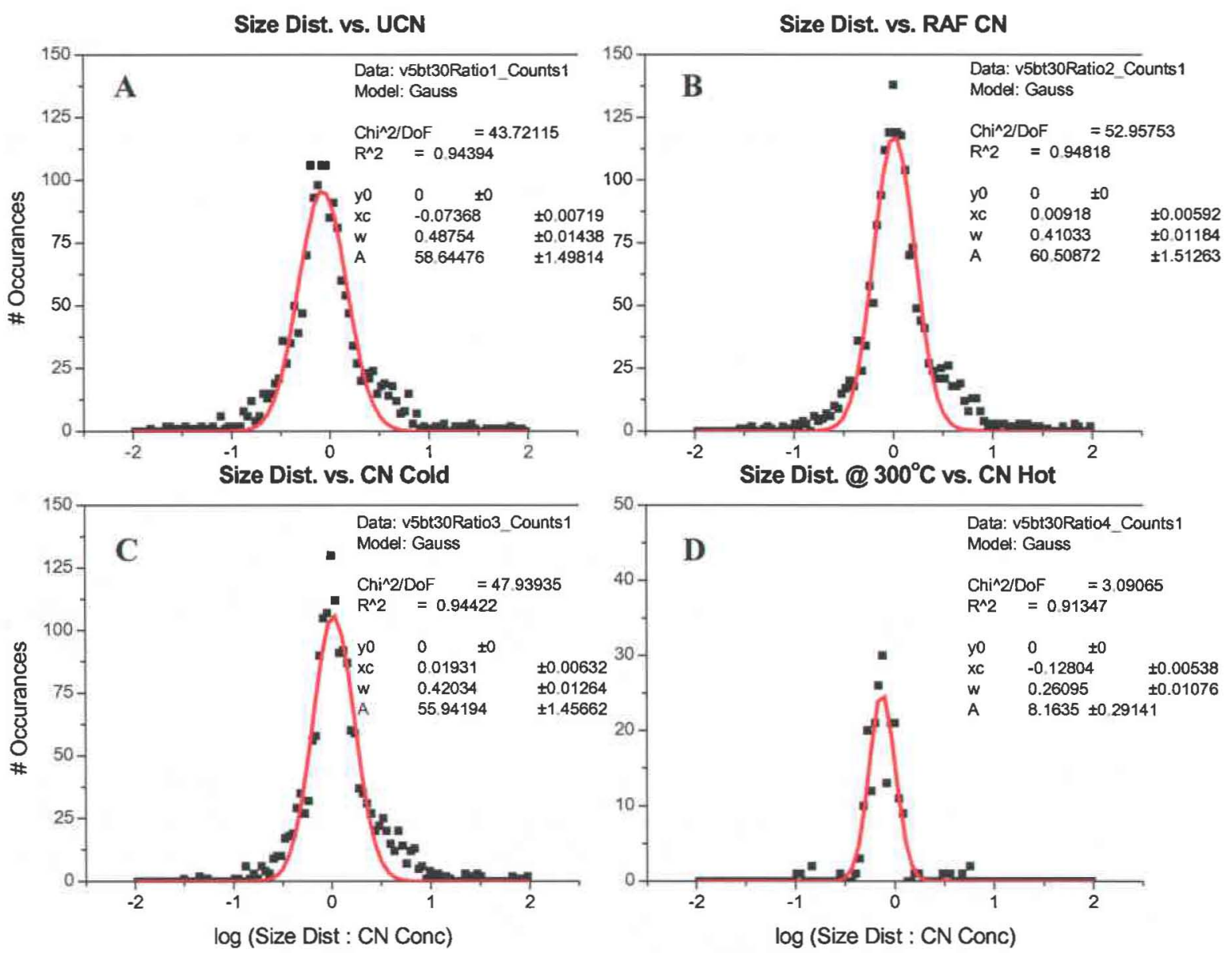

Figure 3.3 - Gaussian fit to the logarithm of total particle number recorded by the rDMA + OPC instruments compared to; (a) the UCN, (b) the RAF CN, (c) the UH Cold CN, as well as the $300^{\circ} \mathrm{C}$ size distributions as compared to the UH Hot CN (d).

Since the UCN cutoff size is $3 \mathrm{~nm}$ and the rDMA cutoff size is $7 \mathrm{~nm}$ we expect that the rDMA size distribution will slightly underestimate total particle number in a comparison. 
We see this in the first panel of figure 3.3 where the mean ratio of size distribution counts to UCN counts of total particle concentration is 0.8440 . The half-width parameter (w) for the Gaussian fit is $10^{0.4875}$ and corresponds to a range of $0.275-2.59$ for the ratio of the size distribution number integral to the total measured by the UCN. The RAF CN and UH CN Cold have slightly larger cutoff sizes than the rDMA so we expect a ratio $>1.0$. The ratios for the RAF CN and the UH Cold CN show values of $1.021(0.397-2.57)$ and $1.045(0.397$ $-2.75)$. The ratio of the heated scans $\left(300^{\circ} \mathrm{C}\right)$ to the $\mathrm{UH}$ Hot $\mathrm{CN}$ showed a ratio of 0.7447 $(0.408-2.75)$. There is no explanation at this time for the instrument disparity. One source of error is the fact that the $\mathrm{UH}$ Hot $\mathrm{CN}$ performed well for a smaller fraction of time than either the RAF CN, or the $\mathrm{UH}$ CN Cold. Additionally the neutralizer correction applied to the heated scans may not be entirely appropriate. Also, due to the intermittent nature of the heated scans by the rDMA and OPC the number of samples is substantially lower than for the unheated scans.

The same comparison of total counts to integral number from size distributions was completed for the TRACE-P data. This information is summarized in figure 3.4. The ratio of size distribution integral number to the Cold $\mathrm{CN}$ during TRACE-P was calculated at $0.8385(0.480-1.46)$. The corresponding Hot $\mathrm{CN}$ ratio is $0.7820(0.528-1.16)$ for TRACE-P.
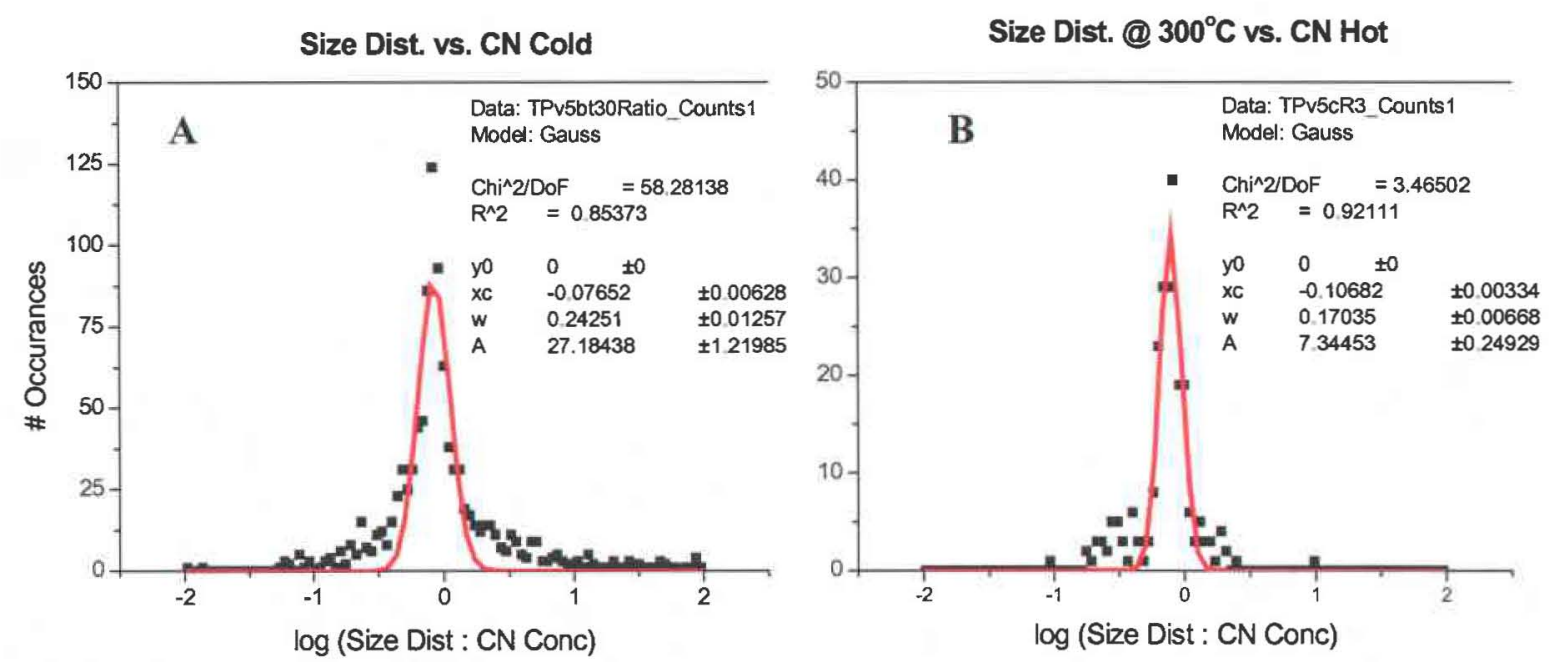

Figure 3.4 - Gaussian fit to the logarithm of total particle number recorded for the dry ambient rDMA + OPC size distributions as compared to the UH Cold CN (a), as well as the $300^{\circ} \mathrm{C}$ size distributions as compared to the UH Hot CN (b). 


\subsection{Optical Particle Counter (OPC)}

Laser optical particle counters (PMS LAS-X with customized electronics) were used aboard both the P3-B and the C-130 to measure the aerosol size distributions. The OPC effectively sizes particles between 0.100 and $20.0 \mu \mathrm{m}$ with a resolution of 112 logarithmically spaced channels per decade. The OPC completes scans every 30 seconds at dry ambient temperature, $150^{\circ} \mathrm{C}$ and $300^{\circ} \mathrm{C}$ during level legs. This process is computer controlled by sequential cycling of the TOAD unit. During vertical profiles we only measure the dry ambient size distribution with the OPC allowing us to obtain better vertical resolution.

The sample stream is dilution dried $\left(\mathrm{RH}<20 \%\right.$ ) by mixing $0.3 \mathrm{~L} \mathrm{~min}{ }^{-1}$ sample and $0.3 \mathrm{~L} \mathrm{~min}^{-1}$ desiccated air upstream of the optical cavity. The OPC uses a Helium-Neon (He$\mathrm{Ne}$ ) laser operating at a wavelength of $632.8 \mathrm{~nm}$ inside of the optical cavity. Particles in the sample stream scatter the laser light and the intensity of the scattered light is measured by the photo-detector. The electrical response recorded by the photo-detector is calibrated in the laboratory by using polystyrene spheres and glass beads (borosilicate glass) of known uniform sizes $(0.100-4.51 \mu \mathrm{m} ; 2.5-15.4 \mu \mathrm{m})$ and refractive indices (1.588 - $0 \mathrm{i} ; 1.54-0 \mathrm{i})$. OPC response to the monodisperse aerosols is recorded for the 256 channels of the OPC and a resulting calibration curve for the $\mathrm{OPC}$ is generated empirically. Since the intensity of the scattered light measured by the photo-detector is a function of the aerosol size, shape and chemical composition the optical effective size of the environmental aerosol based upon the OPC calibration may differ from its physical size. The reader should keep in mind that the size distribution from the $\mathrm{OPC}$ represents the apparent optical diameter which may differ slightly from the DMA's mobility diameter in the region of overlap $(0.100-0.213 \mu \mathrm{m})$.

\subsection{Total and Submicrometer Scattering}

Total scattering is measured aboard the NASA P3-B using a 3-wavelength $(450,550$, $700 \mathrm{~nm}$ ) TSI model 3563 nephelometer. Two model 3563 nephelometers aboard the NCAR $\mathrm{C}-130$ were used to measure total and submicrometer scattering by installing a $1 \mu \mathrm{m}$ impactor upstream of the second nephelometer. More information about the operation and 
corrections made to the nephelometer data can be found in Anderson et al. [1996] and Anderson and Ogren [1998].

\subsection{Other instrumentation}

During TRACE-P a modified TSI ultrafine condensation particle counter (model $3025 \mathrm{~A}$ ) equipped with pulse height analysis (PHA-UCN) was operated by the Georgia Institute of Technology aboard the NASA P3-B aircraft. This instrument measures then calculates a one minute average of 3-8 nm particle concentrations [Marti et al., 1996; Saros et al., 1996; Weber et al., 1998b]. Soluble ions $\left(\mathrm{Na}^{+}, \mathrm{K}^{+}, \mathrm{NH}_{4}{ }^{+}, \mathrm{Ca}^{2+}, \mathrm{Mg}^{2+}, \mathrm{Cl}^{-}, \mathrm{NO}_{3}{ }^{-}, \mathrm{SO}_{4}{ }^{2-}\right)$ were measured using ion chromatography in the Georgia Institute of Technology ParticleInto-Liquid Sampling (PILS) system aboard both the NASA P3-B and the NCAR-C-130 [Orsini and Weber, 2002; Weber et al., 2001b]. Gas phase $\mathrm{SO}_{2}$ was measured using an atmospheric pressure ionization mass spectrometer (APIMS) using isotopically labeled internal standards. The APIMS instrument was operated by Drexel University aboard both aircraft [Thornton et al., 2002]. Gas phase concentrations of $\mathrm{H}_{2} \mathrm{SO}_{4}, \mathrm{OH}$ and MSA were measured exclusively aboard the NASA P3-B by the team from the National Center for Atmospheric Research (NCAR) in Boulder Colorado using a selected ion chemical ionization mass spectrometer (SCIMS) [Eisele and Tanner, 1993].

\subsection{Secondary Aerosol Formation on a Synoptic Scale}

Nucleation mode particles ( $D p<63 \mathrm{~nm}$ ) were typically observed downwind of the urban/industrial regions of Asia with strong sources of $\mathrm{SO}_{2}$ emissions. The top $501^{\circ} \times 1^{\circ}$ $\mathrm{SO}_{2}$ emission areas for the study region are plotted as red circles in figure 4.1. The highest $\mathrm{SO}_{2}$ source grid has an emission rate of $\sim 310 \mathrm{kt} \mathrm{year}^{-1}$ while the $50^{\text {th }}$ ranked grid has an emission rate of $\sim 83 \mathrm{kt} \mathrm{year}^{-1}$ [Carmichael et al., submitted 2002; Streets et al., submitted 2002]. The top $50 \mathrm{SO}_{2}$ point sources for the study region are plotted as numeric values in the second row of figure 4.1. Each numbered point source exceeds $9 \mathrm{kt} \mathrm{SO}_{2}$ year ${ }^{-1}$ with the top ten sources in the region exceeding $165 \mathrm{kt} \mathrm{SO}_{2}$ year $^{-1}$ [Ibid.]. The highest concentrations of anthropogenic $\mathrm{SO}_{2}$ recorded by the P3-B and the C-130 aircraft were in the Yellow Sea. Elevated $\mathrm{SO}_{2}$ concentrations were also identified south of Japan where Asian outflow is advected beyond the East China Sea toward the Northwest Pacific. The Sea of Japan was 
also heavily impacted by the outflow from Asia and by the strong source regions near the South Korean cities of Seoul and Pusan. In addition to the anthropogenic sources of $\mathrm{SO}_{2}$ in the region several active volcanoes are substantial sources of regional $\mathrm{SO}_{2}$. Miyakejima, located south of Tokyo, and Sakurajima, located in Southern Kyushu, emit 8400 and $470 \mathrm{kt}$ $\mathrm{SO}_{2}$ year ${ }^{-1}$. These volcanoes are plotted as scaled black triangles in figure 4.1.

The upper panels in figure 4.1 show the spatial extent of all events recorded by the ACE-Asia rDMA where size-distributions measured on the $\mathrm{C}-130$ show evidence of particles with diameter $<0.063 \mu \mathrm{m}$ and with particle concentrations $>1,000 \mathrm{~cm}^{-3}$. This approach makes it possible to identify secondary aerosols originating from nucleation events within the previous 24 hours. Each data point has been colour coded by $\mathrm{SO}_{2}$ concentration at the time of observation. The right hand column shows the same data plotted with a meridional view to show the vertical distribution of these nucleation mode particles. The middle panels in figure 4.1 show where the PHA-UCN's concentration of 3-8 nm particles exceeded 100 particles $\mathrm{cm}^{-3}$ during TRACE-P. This measurement emphasizes recently nucleated aerosol expected to be less than a few hours old. The lower panels show the TRACE-P nucleation events as measured by the rDMA board the P3-B. Because the rDMA and PHA-UCN measure particles of different sizes locations where nucleation events were observed are also slightly different. For example, during TRACE-P flight 17 the rDMA system recorded elevated concentrations of nucleation mode particles downwind of the Miyakejima volcano (cluster of points near $135^{\circ} \mathrm{E}, 33^{\circ} \mathrm{N}$ ). Despite strong evidence of a nucleation event from the rDMA system the PHA-UCN data shows concentrations of 3-8 nm particles were less than $100 \mathrm{~cm}^{-3}$. Closer examination of the rDMA size distributions show these nucleation mode particles are larger than 3-8 nm which accounts for their absence in the PHA-UCN data.

Both instruments demonstrate that the majority of newly formed secondary aerosols were found below $2500 \mathrm{~m}$ (typical maximum height of the MBL) and that they are associated with $\mathrm{SO}_{2}$ concentrations in excess of $1 \mathrm{ppbv}$. Nucleation mode particles appear to be less prevalent in the free troposphere (FT) where $\mathrm{SO}_{2}$ concentrations rarely exceed $1 \mathrm{ppbv}$.

We will now look closer at several specific cases in order to determine when, i.e. under what meteorological conditions, these events were observed and whether the observations support a binary or a ternary nucleation process for the formation of these secondary aerosols. 
ACE-Asia rDMA
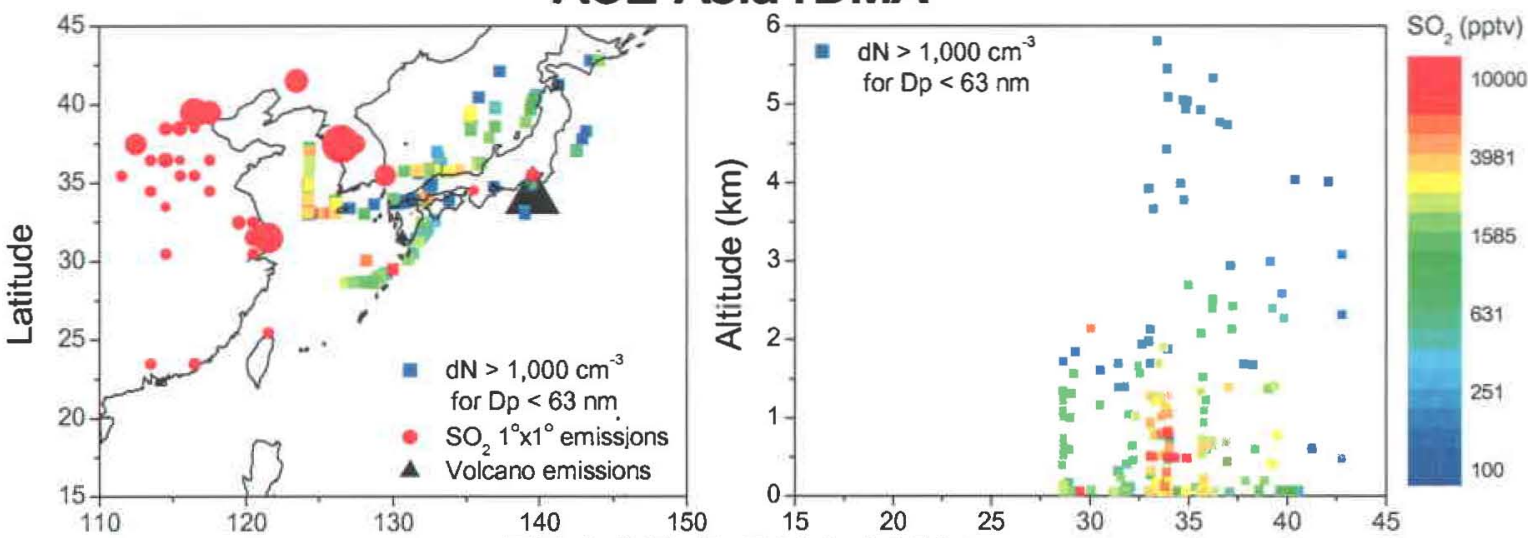

TRACE-P PHA-UCN
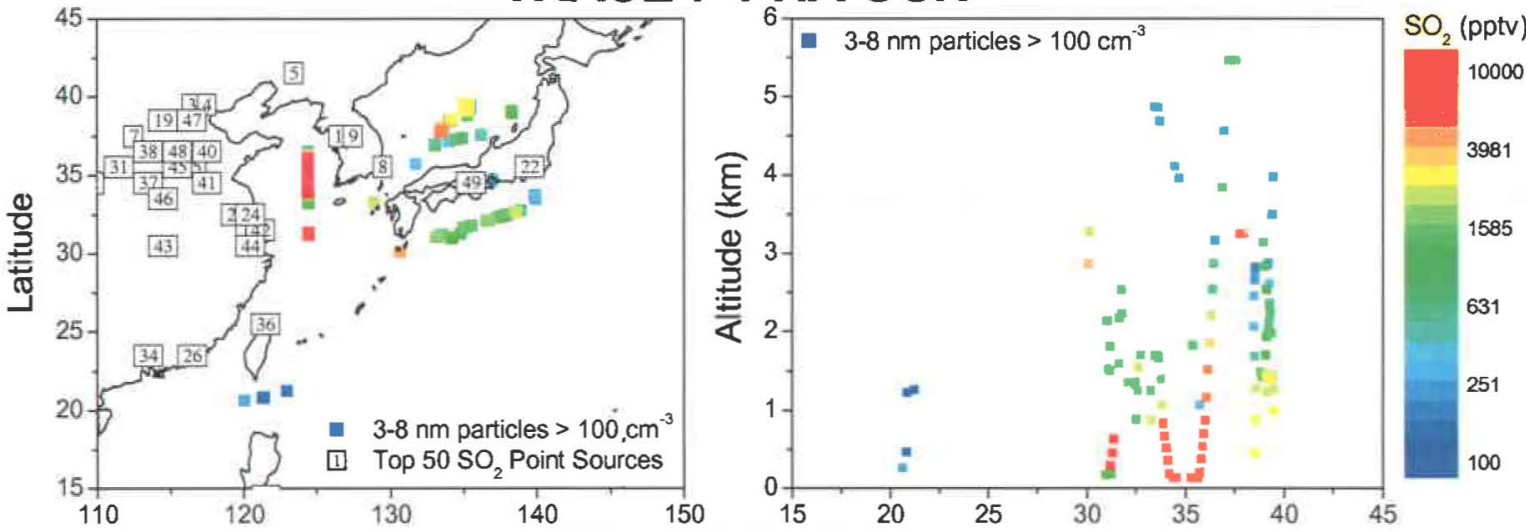

\section{TRACE-P rDMA}
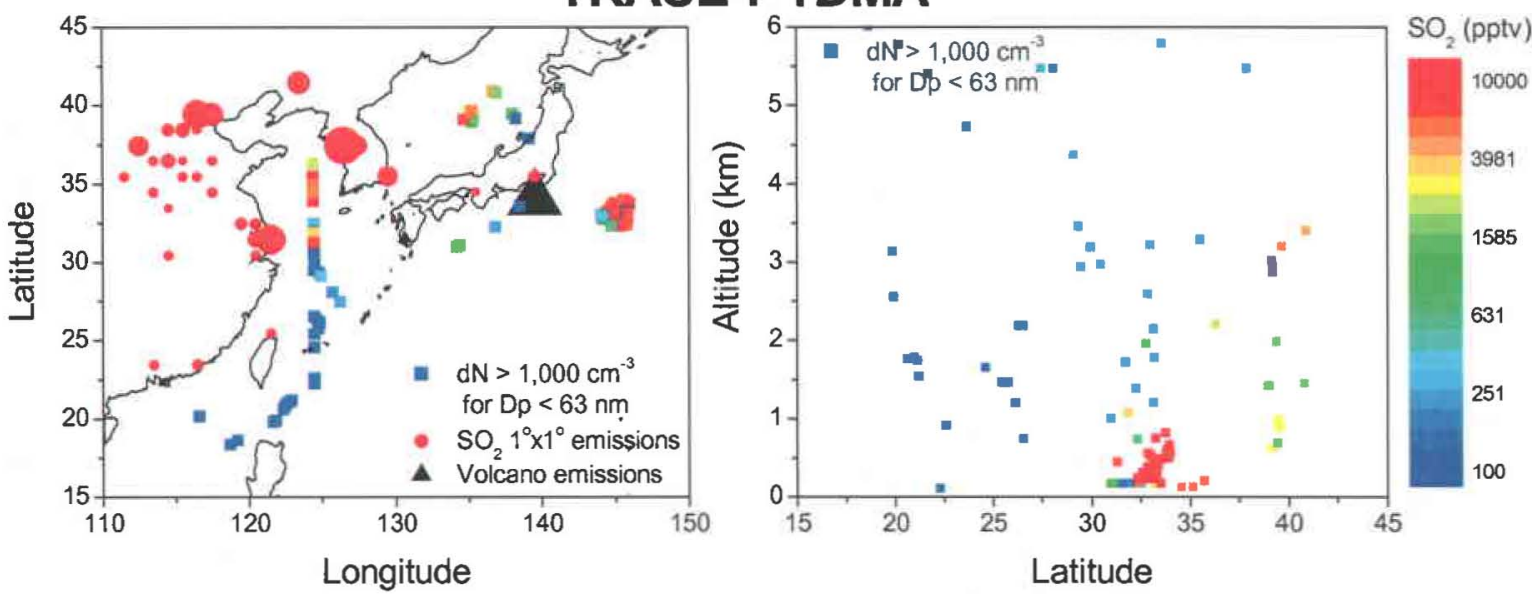

Figure 4.1 - Plan and meridional views of nucleation events for ACE-Asia from rDMA analysis (first row), for TRACE-P from PHA-UCN analysis (second row), and for TRACE-P from rDMA analysis (last row). 


\subsection{Outflow during March $18^{\text {th }}-$ TRACE-P Flight 14}

On March $18^{\text {th }}$ meteorological data indicated that surface flow brought air over the industrialized areas of Beijing, Tianjin and Qingdao into the Yellow Sea at approximately 5$10 \mathrm{~m} \mathrm{~s}^{-1}$. The outflow was due to a low pressure system centered east of Honshu Japan and a second northeast of Harbin China (near the border of Northeastern China and Siberia). These two low-pressure systems were backed by a high-pressure system located above Wuhan, to the west of Shanghai China (Figure 4.2). TRACE-P flight 14 (RF14) was designed to intercept this airmass as it was advected from the industrialized regions of Northeastern China out over the Yellow Sea. The first column of figure 4.3 shows the flight path of the NASA P3-B, location of three profiles, as well as back trajectories generated by the US National Ocean and Atmospheric Administration (NOAA) Air Resources Laboratory's HYSPLIT model (http://www.arl.noaa.gov/ready/hysplit4.html).

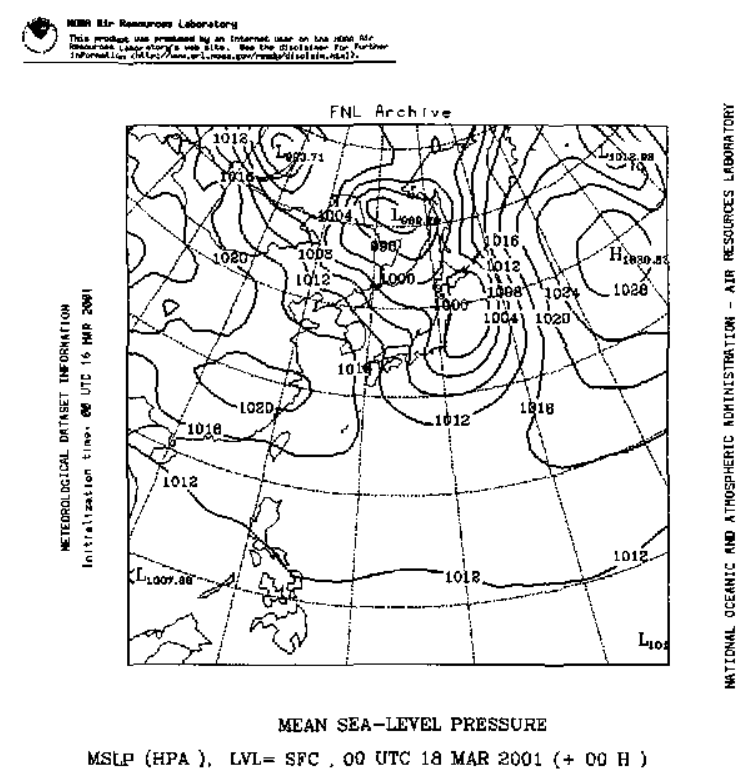

Figure 4.2 - Meteorology for the Northwest Pacific during TRACE-P RF14 on March $18^{\text {th }}, 2001$. 

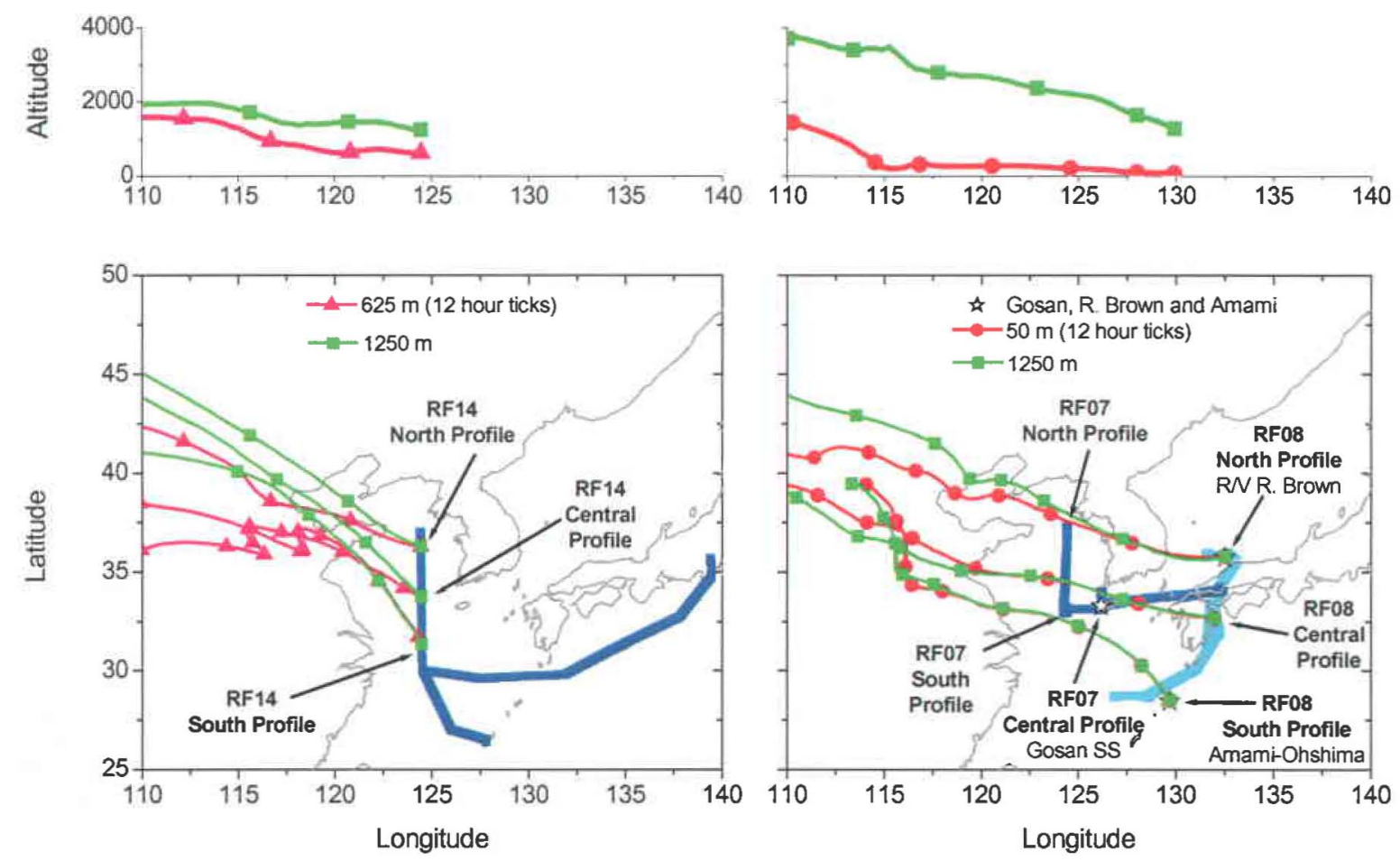

Figure 4.3 - Back trajectories for profiles from TRACE-P RF14 on March $18^{\text {th }}, 2001$ (left) and ACE-Asia RF07 and RF08 on April 12-13 ${ }^{\text {th }}, 2001$ (right).

4.2 Outflow during April $12^{\text {th }}$ and $13^{\text {th }}-$ ACE-Asia Flights 7 and 8

From April $6^{\text {th }}-$ April $13^{\text {th }}$ of 2001 a major dust storm swept through the ACE-Asia study region. On the $12^{\text {th }}$ the C-130 conducted field operations in the Yellow Sea including an intercomparison with the Gosan surface site at Jeju Island South Korea $\left(33.28^{\circ} \mathrm{N}\right.$, $126.17^{\circ} \mathrm{E}$, alt. $\left.70 \mathrm{~m}\right)$. A subsequent flight on April $13^{\text {th }}$ involved an intercomparison with the $\mathrm{R} / \mathrm{V}$ Ron Brown stationed in the Sea of Japan $\left(35.74^{\circ} \mathrm{N}, 132.50^{\circ} \mathrm{E}\right)$ followed by an intercomparison at Amami-Ohshima south of Kyushu Japan $\left(28.44^{\circ} \mathrm{N}, 129.70^{\circ} \mathrm{E}\right)$. The flight path for ACE-Asia RF07 and RF08, the relevant profiles, the location of the R/V Ron Brown, and each of the surface sites are contained in the second column of figure 4.3.

April $12^{\text {th }}$ is characterized as a post-frontal air mass undergoing synoptic scale subsidence in the wake of the passing front. The advancing cold front passed the Gosan surface site at about 16:00 UTC on April 11 $1^{\text {th }}\left(01: 00 \mathrm{JST}\right.$, April 12 $\left.2^{\text {th }}\right)$. Meteorological conditions show that 5-8 $\mathrm{m} \mathrm{s}^{-1}$ winds at the $925 \mathrm{mb}$ level were from the Northwest (Figure 4.4). The dust storm passed over the industrialized areas of Beijing, Tianjin and Qingdao and 
into the Yellow and East China Seas on its way toward the Pacific. The same passing cold front moved over the R/V Ron Brown, located in the Sea of Japan, at approximately 06:00 UTC April $12^{\text {th }}\left(15: 00 \mathrm{JST}\right.$, April $\left.12^{\text {th }}\right)$. For a second day the C-130 was able to sample the aerosol in the cloud free wake of the advancing front. After the Ron Brown flyby the C-130 passed over the Japanese archipelago and flew Southwest of Kyushu to the LIDAR installation at Amami-Ohshima. HYSPLIT back trajectories show that the airmass, particularly near the surface, passed over the strong point source emissions of Mainland China. Based on the back trajectories from RF08 we see that the air sampled on April $13^{\text {th }}$ appears to have been the same air mass sampled during April $12^{\text {th }}$. The time frame for transport of the airmass was fortuitously spaced at approximately 24 hours. This situation is similar to the case outlined on March $18^{\text {th }}$ during TRACE-P. However, unlike the March $18^{\text {th }}$ case the northwesterly flow behind the April $6^{\text {th }}-13^{\text {th }}$ cold front also brought mineral dust from the desert regions China.

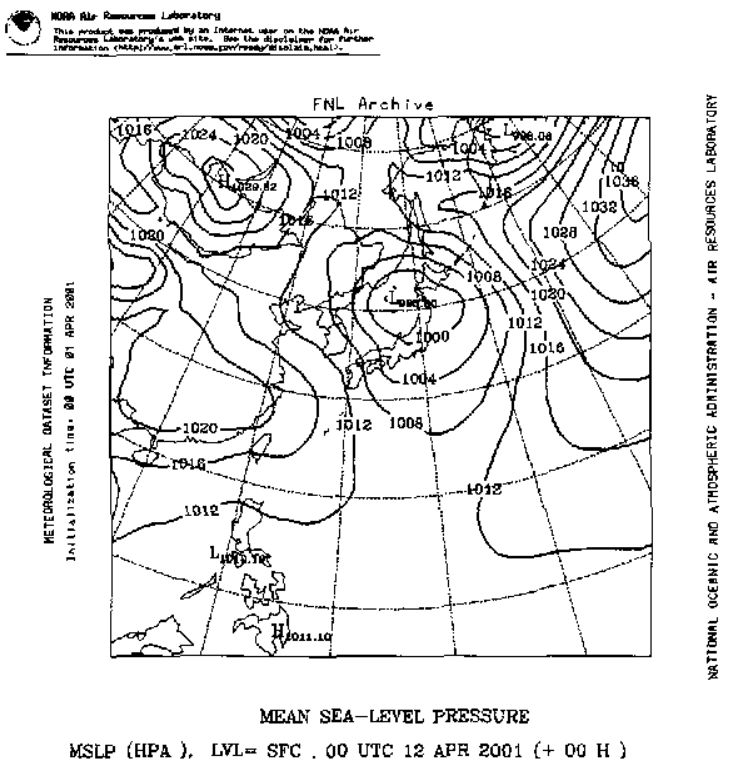

Figure 4.4 - Meteorology for the Northwest Pacific during ACE-Asia RF07 on April $12^{\mathrm{th}}, 2001$. 


\subsection{Aircraft Profiles for March $18^{\text {th }}$ and April $12^{\text {th }}, 13^{\text {th }}$ Cases}

The P3-B and the C-130 can cover 1000's of kilometers during each $\sim 9$ hour flight and often complete vertical profiles anywhere between 50 and 7000 meters. Variability of thermodynamic properties as well as gas and aerosol phase parameters were routinely observed on the scale of 10's to 100's of meters during these vertical profiles. Thermodynamic variables often reveal features that help interpret structure in the gas and aerosol fields. Figures 4.5 through 4.7 illustrate some measured thermodynamic, gas, aerosol and optical properties observed during TRACE-P RF14 and ACE-Asia flights RF07 and RF08. The first column of each figure contains water vapour mixing ratio $\left(\mathrm{g} \mathrm{H}_{2} \mathrm{O} \mathrm{kg} \mathrm{Air}{ }^{-1}\right)$ as well as ambient and potential temperature $\left({ }^{\circ} \mathrm{C}\right)$. The second column of figure 4.5 shows $\mathrm{SO}_{2}, \mathrm{H}_{2} \mathrm{SO}_{4}$ and calculations of $\mathrm{C}_{\text {crit. }}$ The second column of figures 4.6 and 4.7 show $\mathrm{SO}_{2}$ as well as total and sub-micron scattering $\left(\mathrm{Mm}^{-1}\right.$ at $\left.550 \mathrm{~nm}\right)$ because gas phase measurements of $\mathrm{H}_{2} \mathrm{SO}_{4}$ were not available aboard the NCAR C-130. The last column of figure 4.5 contains total scattering $(550 \mathrm{~nm})$ and particle concentrations $(>10 \mathrm{~nm})$ measured aboard the P3-B. The final columns of figures 4.6 and 4.7 include ultrafine $(>3 \mathrm{~nm})$ particle concentrations, particle concentrations $>\sim 12 \mathrm{~nm}$ as well as their difference in order to estimate the total concentration of $3-12 \mathrm{~nm}$ particles. Each row of the three figures corresponds to the North, Central and Southern profiles indicated in figure 4.3 for TRACE-P RF14 as well as ACEAsia RF07 and RF08. The characteristics of each profile are closely linked to the history of the airmass so when viewing figures 4.5 through 4.7 the reader will find it helpful to refer to figure 4.3 .

\subsubsection{TRACE-P - Flight 14 - North Profile}

Back trajectories show the airmass has advected from the Beijing and Tianjin urban/industrial complex, out over the Gulf of Bo Hai and into the Yellow Sea during the previous 24 hours (left panel of Figure 4.3). A layer of elevated water vapour mixing ratio and depressed ambient and potential temperature near the surface extends to $360 \mathrm{~m}$ (top of Figure 4.5). Lowest particle concentrations $\left(25,000 \mathrm{~cm}^{-3}\right)$ were coincident with lowest values of water vapour mixing ratio, $\mathrm{SO}_{2}$ and total scattering. Highest concentrations of $\mathrm{SO}_{2}$ are 
positively correlated with the peak in particle concentrations $\left(50,000 \mathrm{~cm}^{-3}\right)$ and water vapour mixing ratio at $692 \mathrm{~m}$. The stable stratification (increasing potential temperature with height) and little variation in particle concentrations above $692 \mathrm{~m}$ suggests that new particle formation might be taking place over the entire depth of the MBL even though certain regions, such as those near the peaks in $\mathrm{SO}_{2}$ and water vapour mixing ratio $(692 \mathrm{~m})$ have conditions that appear more favorable for new particle formation.

\subsubsection{TRACE-P - Flight 14 - Central Profile}

A layer of evaporative cooling, or an "ocean boundary layer" (OBL), exists between the surface and 507 meters (middle of Figure 4.5). The peak concentrations of aerosol number, $\mathrm{SO}_{2}$ and $\mathrm{H}_{2} \mathrm{SO}_{4}$ occurred above the interface between the $\mathrm{OBL}$ and the remainder of the marine boundary layer (MBL). Total scattering increases within the OBL suggesting that pollution from the Asian landmass and/or shipping lanes as well as sea salt from the ocean surface may be trapped below the OBL. Steep gradients of aerosol surface area, relative humidity and temperature near the OBL inversion are associated with high concentrations of $\mathrm{H}_{2} \mathrm{SO}_{4}$. The low value for $\mathrm{C}_{\text {crit }}$ (Eqn. 2.1) at the ocean surface indicates the most likely site for secondary aerosol formation is the high relative humidity environment over the ocean. However, the highest particle concentrations are observed at the OBL/MBL interface where the values of $\mathrm{C}_{\text {crit }}$ remains $\sim 5$ times larger than the observed concentrations of $\mathrm{H}_{2} \mathrm{SO}_{4}$. This suggests that the available $\mathrm{H}_{2} \mathrm{SO}_{4}$ is insufficient to support a binary homogeneous nucleation process at the time of observation. Particle concentrations, $\mathrm{SO}_{2}$ and $\mathrm{H}_{2} \mathrm{SO}_{4}$ decrease sharply from their peaks at $500 \mathrm{~m}$ toward the surface. In contrast water vapour mixing ratio and total scattering increase sharply over the same interval. This suggests that a process linked to aerosol surface area and relative humidity is responsible for the depletion of gas phase precursors and aerosols within the OBL.

\subsubsection{TRACE-P - Flight 14 - South Profile}

A pronounced OBL layer exists to a height of $615 \mathrm{~m}$ during the southern profile (bottom of Figure 4.5) similar to the structure observed in the central profile. Peak concentrations of $\mathrm{SO}_{2}$ are found within the $\mathrm{OBL}$ but particle concentrations peak at the 
interface between the layer of evaporative cooling and the remainder of the MBL. Within the OBL scattering is at least a factor of 4 higher than the overlying air which appears to be relatively clean. On either side of the cleanest layer ( $615-1066$ meters) particle concentrations show small peaks suggesting that gradients in aerosol surface area, relative humidity and temperature create microphysical environments where new particle production is favored. Gas concentrations and aerosol number concentrations are reduced just above the ocean surface where total scattering and water vapour mixing ratio are highest. This suggests that the removal of both the gas phase precursors and aerosols is occurring in the same process and that the process appears to be linked to aerosol surface area and relative humidity. 


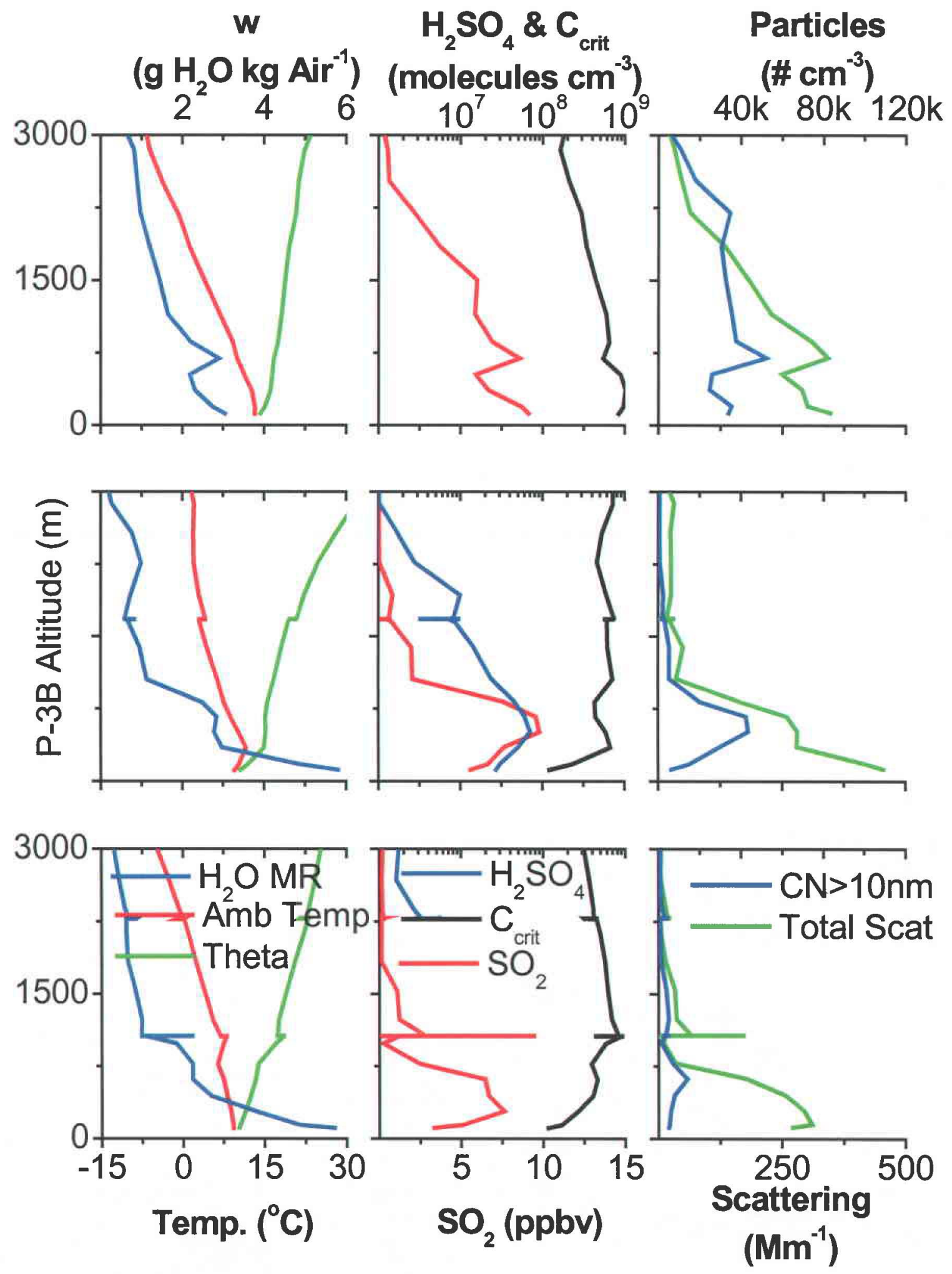

Figure 4.5 - Thermodynamic, gas phase and aerosol properties during the North (top), Central (middle) and Southern (bottom) profiles of TRACE-P RF 14 on March $18^{\text {th }}, 2001$. 


\subsubsection{ACE-Asia - Flight 07 - North Profile}

The northern end of this flight into the Yellow Sea (Figure 4.3) revealed a complex layered structure where submicrometer scattering increases towards the surface nearly doubling in the lowest $594 \mathrm{~m}$ (top of Figure 4.6). Increasing water vapour mixing ratio and near surface gradient in potential temperature suggests that the OBL $(<594 \mathrm{~m})$ is once again de-coupled from the remainder of the MBL. Lowest concentrations (still high) of $3-12 \mathrm{~nm}$ particles (less than $35,000 \mathrm{~cm}^{-3}$ ) occur in the OBL, however, concentrations for particles greater than $12 \mathrm{~nm}$ are a factor of 1.3 higher than the overlying layers (75,000 versus 56,000 $\mathrm{cm}^{-3}$ ). Five rDMA size distributions obtained within the MBL during the profile show the nucleation mode particles have a mode diameter between 26 and $18 \mathrm{~nm}$ with the smallest mode diameters being associated with the lowest aerosol surface area and $\mathrm{SO}_{2}$ concentrations aloft. Based on the size distribution information we conclude that by the time of this profile (13:30 JST) the majority of the newly formed secondary aerosols have grown beyond $12 \mathrm{~nm}$ in size due to condensational growth in a layer with peak $\mathrm{SO}_{2}$ concentration of $12 \mathrm{ppbv}$.

\subsubsection{ACE-Asia - Flight 07 - Central Profile}

This descent profile occurred directly above Jeju Island, South Korea between 10:15 and 10:35 am JST (1:15 - 1:30 UTC). Scattering increases from below the inversion (2400 meters) towards the surface and is dominated by the presence of supermicrometer dust in the wake of the passing cold front (middle of Figure 4.6). In the upper MBL sub-micron scattering, $\mathrm{SO}_{2}$ and total particle concentrations increase toward the surface. Below $\sim 1200 \mathrm{~m}$ these parameters remain relatively constant. The number of particles in the $3-12 \mathrm{~nm}$ size range remains relatively constant at $40,000 \mathrm{~cm}^{-3}$ in both the upper and lower MBL. Within

the lowest 700 meters the water vapour mixing ratio fluctuates between 1.90 and $3.80 \mathrm{~g} \mathrm{~kg}^{-1}$ corresponding to oscillations in relative humidity between $27 \%$ and $47 \%$. Secondary aerosols are distributed more evenly due to the absence of the miniature OBL inversion and secondary aerosol formation appears to be occurring throughout the MBL. 


\subsubsection{ACE-Asia - Flight 07 - South Profile}

This profile $\left(33.1^{\circ} \mathrm{N}, 124.4^{\circ} \mathrm{E}\right)$ occurred between the geographic locations of the central and southern TRACE-P profiles under a similar pattern of outflow from the Chinese Mainland (Figure 4.3). A temperature inversion and layer of evaporative cooling exists below $314 \mathrm{~m}$ (bottom of Figure 4.6). Sharp increases in water vapour mixing ratio as well as total and submicrometer scattering are in phase with sharp decreases in $\mathrm{SO}_{2}$ and particle concentrations near the surface. $\mathrm{SO}_{2}$ and 3-12 nm particle concentrations peak $(8.69 \mathrm{ppbv}$, $\left.40,800 \mathrm{~cm}^{-3}\right)$ at the OBL/MBL interface $(268 \mathrm{~m})$ and drop by about a factor of 2 near the surface $\left(3.4 \mathrm{ppbv}, 21,400 \mathrm{~cm}^{-3}\right)$. Particle concentrations above the $\mathrm{OBL}$ are above 30,000 $\mathrm{cm}^{-3}$ but are separated from the OBL by a local minimum. An additional profile near this location later in the day shows $3-12 \mathrm{~nm}$ particle concentrations were elevated throughout the remainder of the MBL decreasing to $18,000 \mathrm{~cm}^{-3}$ at the MBL inversion (not shown). This profile shows that new particle production is probably occurring throughout the MBL. High aerosol surface area and relative humidity within the layer of evaporative cooling appears linked to reduced concentrations of newly formed secondary aerosols. Three to twelve nanometer particles peak at the transition in aerosol surface area located at 314 meters. This microphysical environment allows a greater number of the nucleation mode particles to survive compared to the layer directly below. For the remainder of the MBL a probable level where these secondary aerosols were formed could not be identified suggesting the secondary aerosols are forming throughout the MBL and surviving because of decreasing aerosol surface area with height. 


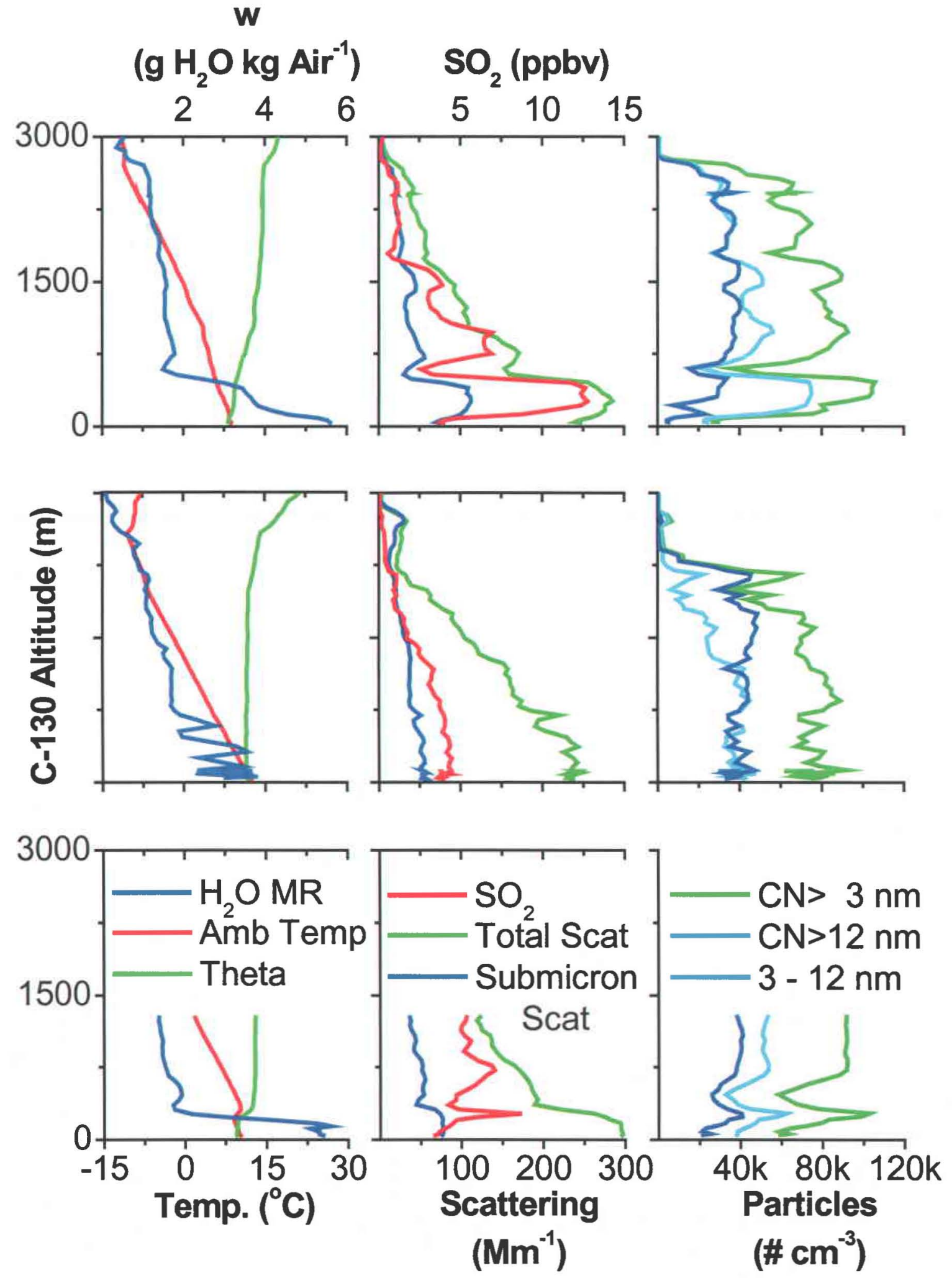

Figure 4.6 - Thermodynamic, gas phase and aerosol properties during the North (top), Central (middle) and Southern (bottom) profiles of ACE-Asia RF07 on April $12^{\text {th }}, 2001$. 


\subsubsection{ACE-Asia - Flight 08 - North Profile}

Back trajectories in figure 4.3 show the northern profile for RF08 (top of Figure 4.7) should be similar to the air mass characterized in the north profile from RF07 (top of Figure 4.6). The airmass was transported over South Korea the previous night and the Sea of Japan that morning. The absence of the stable surface layer caused by evaporative cooling and near constant water vapour mixing ratio and potential temperature (top of Figure 4.7) indicates that the column has become well mixed below $1300 \mathrm{~m}$. Both total and submicrometer scattering are nearly constant with height below 1300 meters which also suggests mixing. However total scattering, and to a lesser extent submicrometer scattering, values are lower than those observed during RF07. This suggests removal of the coarse mode aerosol during transport over South Korea or that this is a slightly different airmass to that characterized upwind the previous day. Concentrations of $\mathrm{SO}_{2}$ are approximately one half to one third the previous day's values $(2.0+/-0.5$ versus $5.9+/-1.1 \mathrm{ppbv})$ between the 500 and $1000 \mathrm{~m}$ level. These peaks are well correlated $\left(\mathrm{R}^{2}=0.7395\right)$ to $3-12 \mathrm{~nm}$ particle concentrations that are a factor of 4 lower than those recorded the previous day $\left(10,000 \mathrm{~cm}^{-3} \mathrm{vs.} 40,000 \mathrm{~cm}^{-3}\right)$.

\subsubsection{ACE-Asia - Flight 08 - Central Profile}

Back trajectories (Figure 4.3) for the RF08 central profile (middle of Figure 4.7) show this airmass should have characteristics similar to the middle profile for RF07 (middle of Figure 4.6). However, the air has just crossed the Japanese island of Kyushu and the profile exhibits a layered structure. Some of these features may be due to orographic effects and/or anthropogenic gas and aerosol sources on Kyushu. A surface layer does appear to exist below $500 \mathrm{~m}$ and is associated with high water vapour mixing ratio and lower total and $3-12 \mathrm{~nm}$ particle concentrations. Concentrations of $\mathrm{SO}_{2}$, total and submicrometer scattering are nearly constant to the top of the MBL. This suggests the air below $500 \mathrm{~m}$ has a different history or is decoupled from the layers above. This is supported by the plots of $3-12 \mathrm{~nm}$ particles which show that concentrations are much higher aloft and possibly formed near the local maximum in water vapour mixing ratio at $\sim 1700 \mathrm{~m}$ or at the $\mathrm{MBL}$ inversion $(\sim 2300 \mathrm{~m})$. 


\subsubsection{ACE-Asia - Flight 08 - Southern Profile}

Back trajectories from the northern and central profiles from RF08 show that at some point the airmass passed over land. In contrast, back trajectories for the southern profile show that this air remained over the Yellow Sea and East China Sea before moving out towards the Pacific (Figure 4.3). This air should be similar to the airmass observed during the southern profile of RF07 (bottom of Figure 4.6). There is no hint of the OBL observed the previous day. In fact, every parameter measured during this profile suggests that the airmass has been completely mixed between the surface and the top of the MBL located at 1800 meters (bottom of Figure 4.7). If we re-examine the RF08 northern profile (top of Figure 4.7) it suggests that after leaving the Korean mainland the airmass appears to be evolving from having characteristics like those seen in the central profile (near land) towards those seen in the southern profile (open ocean). This suggests that as the airmass moves out over the Pacific we can expect its structure to become more homogeneous as convective cells and diurnal cycles turn the airmasses over. At this location the airmass has also encountered the warm Kuroshio current (Figure 4.8). During RF07 sea surface temperatures (SST) in the Yellow Sea were $8-10^{\circ} \mathrm{C}$. North of Japan SST was $13-15^{\circ} \mathrm{C}$ and East of Kyushu the sea surface temperatures were $18-20^{\circ} \mathrm{C}$. Sea surface temperature was $21-23^{\circ} \mathrm{C}$ at the southern profile near Amami-Ohshima. The Kuroshio seems to have provided a strong source of heat and water vapour responsible for $\sim 4^{\circ} \mathrm{C}$ increase in potential temperature $\left(6^{\circ} \mathrm{C}\right.$ at the surface) and a water vapour mixing ratio above $4.2 \mathrm{~g} \mathrm{~kg}^{-1}$ for the entire MBL. During the southern profile of RF07 the water vapour mixing ratio only exceeded $4.2 \mathrm{~g} \mathrm{~kg}^{-1}$ below $205 \mathrm{~m}$ in the shallow layer of evaporative cooling (OBL). This suggests that heating of the airmass by the warm surface turned the column over and is responsible for the well-mixed structure observed in the profile. Concentrations of $3-12 \mathrm{~nm}$ particles are highest $\left(4400 \mathrm{~cm}^{-3}\right)$ near the inversion $(1800 \mathrm{~m})$ where there is a steep gradient in aerosol surface area, $\mathrm{RH}$ and temperature. $\mathrm{SO}_{2}$ concentrations have dropped from values of $8.69 \mathrm{ppbv}$ at $250 \mathrm{~m}$ during RF07 to values near $1.40 \mathrm{ppbv}$ for RF08. 

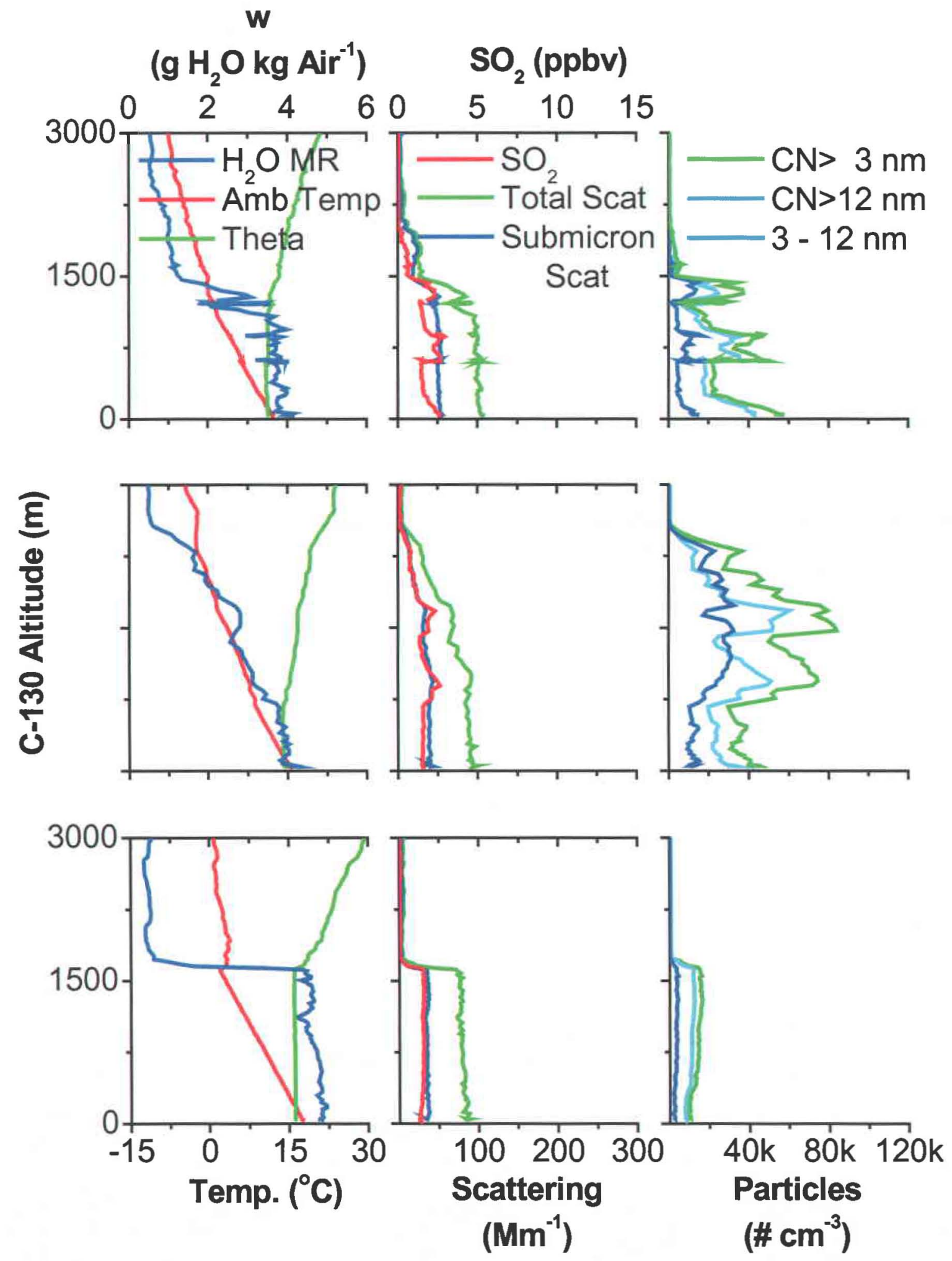

Figure 4.7 - Thermodynamic, gas phase and aerosol properties during the North (top), Central (middle) and Southern (bottom) profiles of ACE-Asia RF08 on April $13^{\text {th }}, 2001$. 

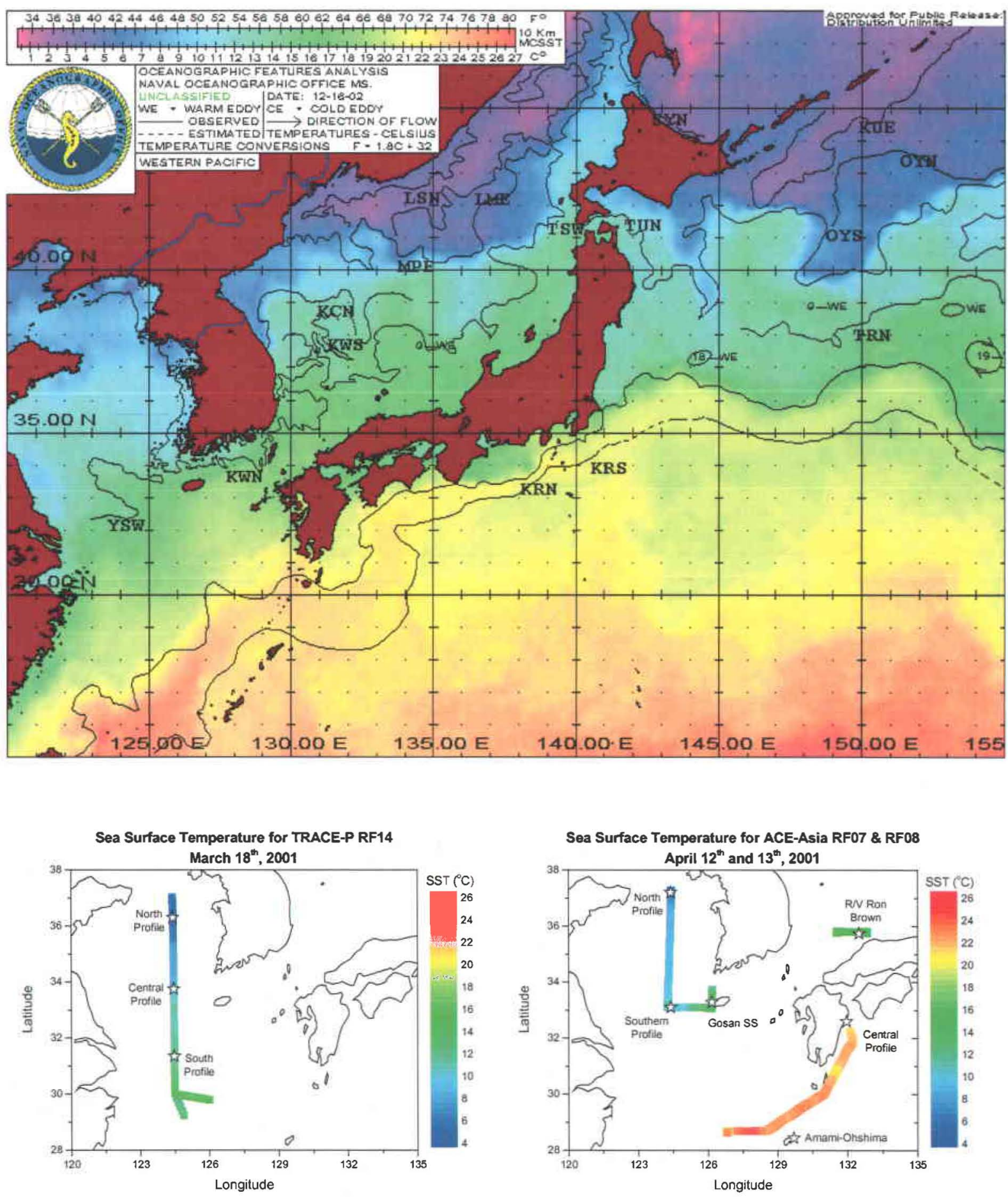

Figure 4.8 - Sea Surface Temperatures for April $12^{\text {th }}$ (top) as well as SST's measured by infrared (IR) sensors aboard the P3-B (left) and C-130 (right) during TRACE-P RF14 on March $18^{\text {th }}$ and ACE-Asia RF07 and RF08 on April $12^{\text {th }}$ and 13 $3^{\text {th }}, 2001$. 


\subsection{Size Distributions Measured Aboard the Aircraft}

Size distributions are dynamic and evolve over time in response to processes linked to aerosol formation and removal. Changes in the size distributions can provide greater insight into processes than concentrations alone. Number, area and volume distributions at dry ambient temperature, $150^{\circ} \mathrm{C}$ and $300^{\circ} \mathrm{C}$ can be calculated by combining the thermally resolved size distributions measured by the University of Hawai ${ }^{\circ}$ rDMA and the OPC. Recall that the rDMA measures particle size using mobility while the OPC is an optical method (see section 3.4 and 3.5). Simple MATLAB functions were written in order to join the size distributions over their region of overlap $(0.100-0.213 \mu \mathrm{m})$ and then to smooth the output. The MATLAB functions are contained in Appendix B. The size distributions are presented within the thesis as either single distributions at a particular altitude (Figures 5.1 5.3 and 5.5) or as contour plots to show structure over a vertical profile (Figures $5.4 \& 5.6$ ). Size distributions associated with TRACE-P flight RF14 and ACE-Asia flights RF07 and RF08 are presented in the following sections.

\subsection{Size distributions from TRACE-P RF14}

On March $18^{\text {th }}$ during the central TRACE-P descent profile an rDMA size distribution was obtained at $663 \mathrm{~m}$ allowing us to evaluate the size distribution directly above the observed $\mathrm{OBL}$. The $\mathrm{SO}_{2}$ concentration at the time of observation was $9.60 \mathrm{ppbv}$, the sulfuric acid concentration was $6.03 \times 10^{7}$ molecules $\mathrm{cm}^{-3}$ and $\mathrm{C}_{\text {crit }}$ was $4.40 \times 10^{8}$ molecules $\mathrm{cm}^{-3}$. This indicates that the concentration of $\mathrm{H}_{2} \mathrm{SO}_{4}$ required for binary homogeneous nucleation is low by a factor of $\sim 7$ according to Wexler et al. [1994].

Figure 5.1 shows the number, area and volume distributions obtained during this scan. Dry ambient distributions are shown in blue, distributions at $150^{\circ} \mathrm{C}$ are red, while the black lines correspond to scans completed at $300^{\circ} \mathrm{C}$. The number distribution shows a clear nucleation mode aerosol centered at $9 \mathrm{~nm}$ but that after heating to $150^{\circ} \mathrm{C}$ nearly all the volume for this mode has been eliminated. This is consistent with the nucleation mode aerosol being composed primarily of sulfuric acid or another compound volatile at temperatures below $150^{\circ} \mathrm{C}$. The accumulation mode aerosol shows a distinct pollution 
signature with low volatility consistent with near complete neutralization of the sulfuric acid by ammonium. The Particle-Into-Liquid Sampling system (PILS) operated by Georgia Institute of Technology primarily measures the soluble ionic species in the accumulation mode aerosol [Orsini and Weber, 2002; Weber et al., 2001b]. The molar equivalents ratio $\left(\left[\mathrm{NH}_{4}{ }^{+}\right]: 2\left[\mathrm{SO}_{4}{ }^{2-}\right]+\left[\mathrm{NO}_{3}{ }^{-}\right]\right)$as measured by the PILS instrument was 1.17. This demonstrates there is an abundant local source of ammonia and confirms our inferred near complete neutralization of the accumulation mode sulfuric acid by ammonia. This also suggests a possible ternary nucleation mechanism in the formation of the secondary aerosol due to the insufficient concentration of $\mathrm{H}_{2} \mathrm{SO}_{4}$ as calculated using the $\mathrm{C}_{\mathrm{crit}}$ parameterization.

After the descent profile the P3-B completed a level leg at $118 \mathrm{~m}$ (Figure 5.2) where the size distribution looks much different than that obtained above the OBL. Nucleation mode particles are smaller and exist at reduced concentrations compared to those above the OBL (note change of scale for $\mathrm{dN} / \mathrm{d}_{\log } \mathrm{Dp}$ by 1 order of magnitude between figures 5.1 and 5.2). Total aerosol surface area has doubled with all of the increase in the accumulation mode aerosol. Molar ratios of $\left[\mathrm{NH}_{4}{ }^{+}\right]:\left(2\left[\mathrm{SO}_{4}{ }^{2-}\right]+\left[\mathrm{NO}_{3}{ }^{-}\right]\right)$averaged $0.87(+/-0.06)$ supporting the volatility analysis which shows accumulation mode aerosol has been neutralized to a lesser degree than the accumulation mode aerosol at $663 \mathrm{~m} . \mathrm{SO}_{2}$ concentrations have dropped but remain high at $5.07 \mathrm{ppbv}(+/-1.5 \mathrm{ppbv}), \mathrm{H}_{2} \mathrm{SO}_{4}$ has dropped to $2.15 \times 10^{7}$ molecules $\mathrm{cm}^{-3}(+/-0.80)$ indicating that the concentration of $\mathrm{H}_{2} \mathrm{SO}_{4}$ is still about a factor of 7 lower than that required for binary nucleation $\left(\mathrm{C}_{\text {crit }}=1.47 \times 10^{8}+1-0.69\right.$ molecules $\left.\mathrm{cm}^{-3}\right)$. $\mathrm{SO}_{2}$ and $\mathrm{H}_{2} \mathrm{SO}_{4}$ concentrations drop by factors of 1.89 and 2.80 while total aerosol surface area increases by a factor of 1.90 compared to the region above. The nature of the $\mathrm{C}_{\mathrm{crit}}$ parameterization (Eqn. 2.1) suggests that high relative humidity conditions would deplete $\mathrm{H}_{2} \mathrm{SO}_{4}$ but produce a vast number of nucleation mode particles. Within the OBL a process that simultaneously depletes gas phase precursors $\left(\mathrm{H}_{2} \mathrm{SO}_{4}\right.$ and $\left.\mathrm{SO}_{2}\right)$ as well as nucleation mode particles is required in order to explain the observations. 

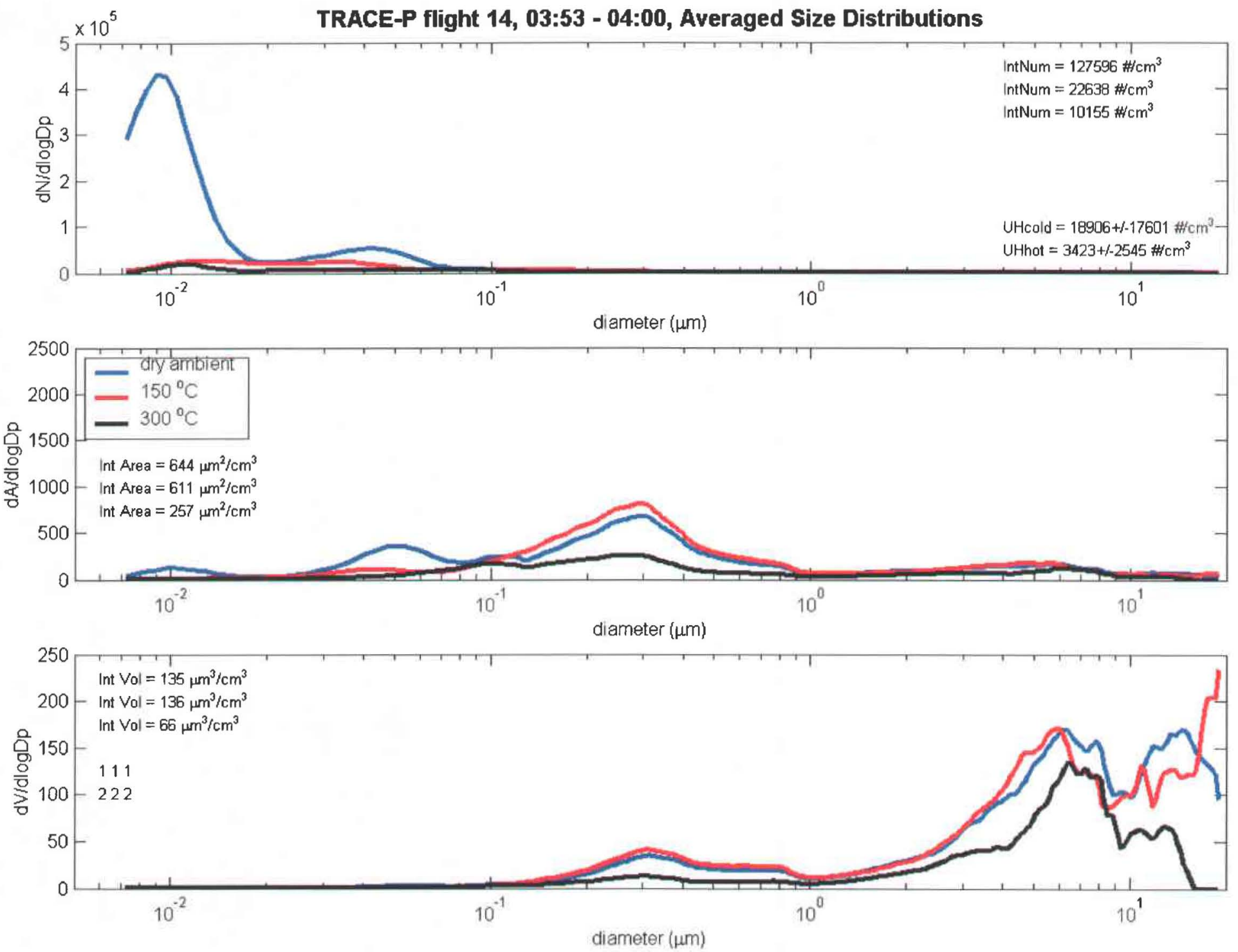

Figure 5.1 - Aerosol number (top), area (middle) and volume (bottom) distributions recorded at $663 \mathbf{m}$ above the Yellow Sea along $124.4^{\circ} \mathrm{E}$ during TRACE-P RF14, March $18^{\text {th }}, 2001$. Distribution highlights the presence of nucleation mode particles just above a shallow layer of evaporative cooling. Accumulation mode aerosol shows near complete neutralization. 

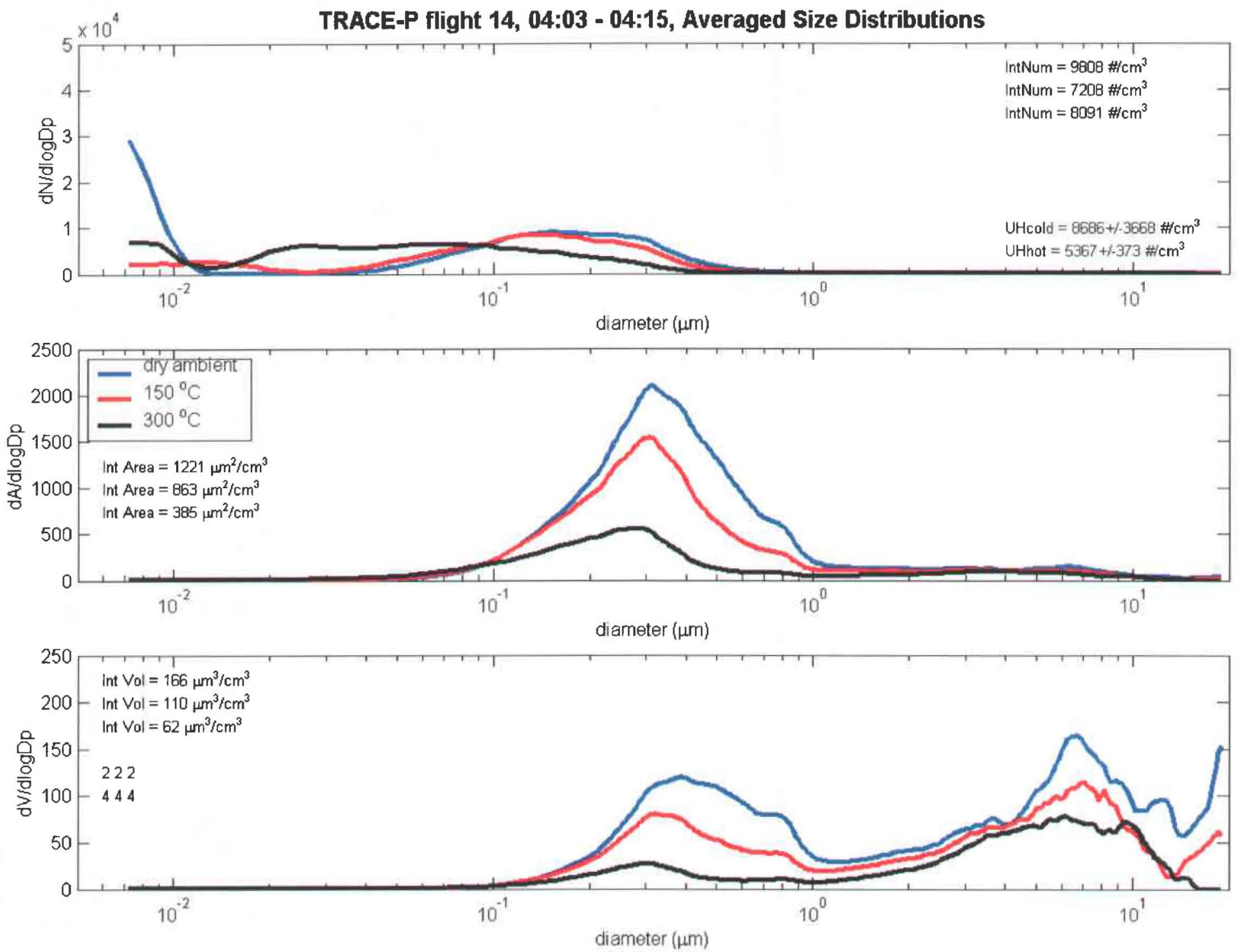

Figure 5.2 - Aerosol number (top), area (middle) and volume (bottom) distributions recorded at $118 \mathbf{m}$ above the Yellow Sea along $124.4^{\circ} \mathrm{E}$ during TRACE-P RF14, March $18^{\text {th }}, 2001$. Distributions show doubling of surface area and reduced number (note scale change compared to Figure 5.1) and diameter of nucleation mode particles within the layer of evaporative cooling. 


\subsection{Size distributions from ACE-Asia RF07}

ACE-Asia RF07 on April 12 ${ }^{\text {th }}$ involved an intercomparison with the Gosan surface site located at Jeju Island, South Korea (Figure 4.3). At 1:30 UTC (10:30 am JST) the C-130 flew west of the surface site at $40 \mathrm{~m}$ (the sea cliffs at Jeju are $\sim 70 \mathrm{~m}$ high). Nucleation mode particle sizes at this time were centered at $13 \mathrm{~nm}$ (Figure 5.3). Concurrent DMA scans completed at the surface site show the peak diameter for the nucleation mode particles to be $11 \mathrm{~nm}$ [Buzorius et al., submitted 2003]. As described during TRACE-P RF14 most of the nucleation mode particles are again eliminated after heating to $150^{\circ} \mathrm{C}$ but the accumulation mode aerosol shows volatility consistent with partial neutralization to ammonium sulfate/bisulfate. This suggests that an abundant source of ammonia is present for secondary aerosols to form via a ternary nucleation mechanism though the presence of $\mathrm{NH}_{4}{ }^{+}$in the accumulation mode does not directly imply a ternary nucleation mechanism. The PILS instrument also aboard the NCAR C-130 showing a molar ratio of 0.70 supports partial neutralization of the accumulation mode aerosol. Additional evidence for the participation of ammonia in the formation of secondary aerosols comes from the Gosan surface site. Operating a humidified tandem differential mobility analyzer (HTDMA) the research group from Brookhaven National Laboratory determined that the hygroscopic growth of $25 \mathrm{~nm}$ particles was best explained by an ammonium sulfate/ammonium bisulfate type composition [Buzorius et al., submitted 2003].

The back trajectory analysis and profile data from ACE-Asia RF07 indicate the atmospheric structure and pattern of outflow for TRACE-P RF14 and ACE-Asia RF07 are nearly identical particularly with regard to the OBL. The main difference between these cases is the absence of the coarse mode dust during March $18^{\text {th }}$ (TRACE-P RF14). Size distributions from RF14 confirm that "dry" aerosol surface area in the OBL (Figure 5.2) was much higher than in the remainder of the MBL (Figure 5.1). Figure 5.4 shows combined DMA and OPC area distributions from ACE-Asia RF07 during the vertical profiles along $124.4^{\circ} \mathrm{E}$ on April $12^{\text {th }}$. These show few nucleation mode particles below 500 meters as seen in the more limited number of distributions from TRACE-P RF14. The accumulation mode area also has a larger mode diameter within the surface layer and is present in conjunction with coarse dust near the surface. Nucleation mode particles have their highest 
concentrations above the $\mathrm{OBL}$ and are associated with smaller coarse and accumulation mode surface area. $\mathrm{C}_{\text {crit }}$ predicts that the region of secondary aerosol formation is within the OBL yet 3-12 nm particle concentrations are lowest within the shallow layer. It appears that nucleation mode particles (as well as $\mathrm{SO}_{2}$ - see top and bottom of Figure 4.6) in the OBL have been depleted but that just above the layer of evaporative cooling these species still exist at peak concentrations. There is also a second peak in nucleation mode particles near the MBL inversion. $\mathrm{C}_{\text {crit }}$ predicts that the cold, high relative humidity environment near the inversion favours the formation of nucleation mode particles. Also, entrainment could play an important role in secondary aerosol formation by reducing aerosol surface area through dilution of MBL air with low surface area free troposphere air [Nilsson and Kulmala, 1998].

At 7:00 UTC (16:00 JST) the C-130 made a second pass by the Gosan surface site. Once again the size distributions measured on the ground were nearly identical to those measured aboard the aircraft. Nucleation mode particles aboard the aircraft were centered at $28 \mathrm{~nm}$ (Figure 5.5). The surface site showed a peak diameter centered at $33 \mathrm{~nm}$. Integral number (as measured by the size distributions) had decreased from $32,800 \mathrm{~cm}^{-3}$ to $18,900 \mathrm{~cm}^{-}$ ${ }^{3}$ (a factor of 1.74) and total particle concentrations measured by the ultrafine particle counter $(>3 \mathrm{~nm})$ were lower by a factor of 3 . The size distributions measured at the Gosan site by the $\mathrm{C}-130$ were not part of the same air parcel (a Lagrangian analysis) because winds from the Northwest were $5-8 \mathrm{~m} \mathrm{~s}^{-1}$. Airmass heterogeneity could therefore be responsible for the differences observed at Gosan between 1:30 UTC (10:30 am JST) and 7:00 UTC (16:00 JST). While airmass heterogeneity could play a role the reduction of particle number and shifts to larger size classes suggests that instead particles are growing through condensation while particle number is being reduced through coagulation with the accumulation and coarse mode aerosols. 

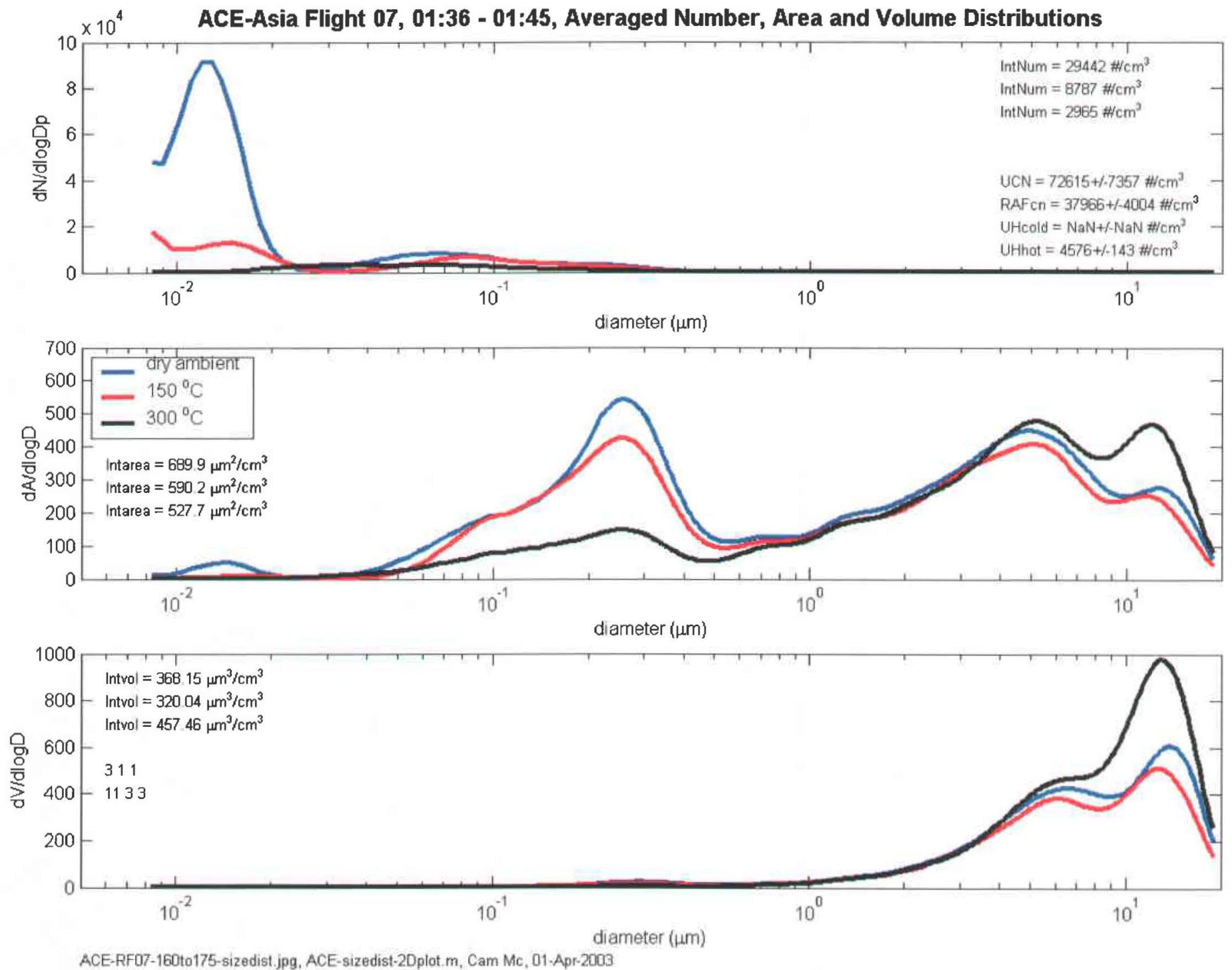

Figure 5.3 - Aerosol number (top), area (middle), and volume (bottom) distributions measured during the morning fly-by of the Gosan surface site during ACE-Asia RF07, April $12^{\text {th }}, 2001$. Nucleation mode particles are identical to those observed at the ground station. 

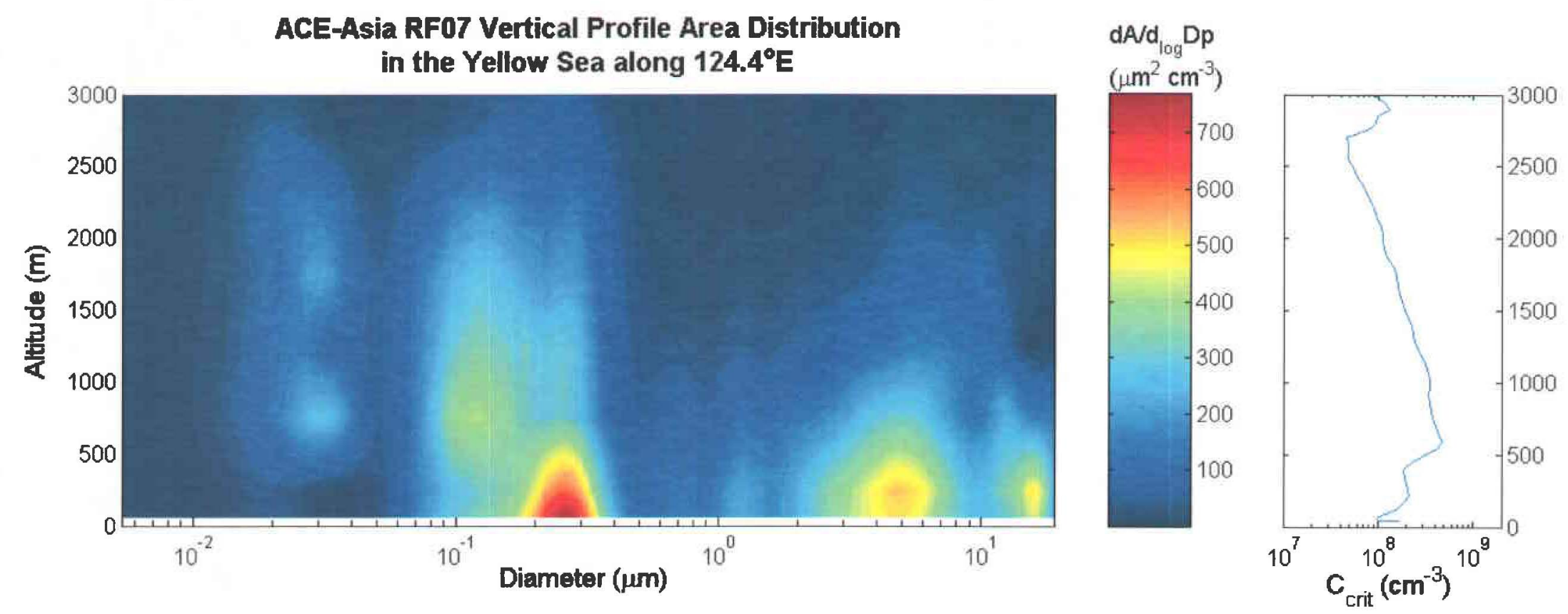

Figure 5.4 - Vertical structure of aerosol surface area over the Yellow Sea along $124.4^{\circ} \mathrm{E}$ during ACE-Asia RF07 on April $12^{\text {th }}, 2001$. Aerosol surface area is highest within the shallow layer of evaporative cooling. Larger accumulation mode sizes and mineral dust account for approximately $60 \%$ and $40 \%$ of the surface area within the OBL. Nucleation mode particles are present in highest concentrations above the OBL where total surface area is lower and the accumulation mode area is centered at smaller particle diameters. 

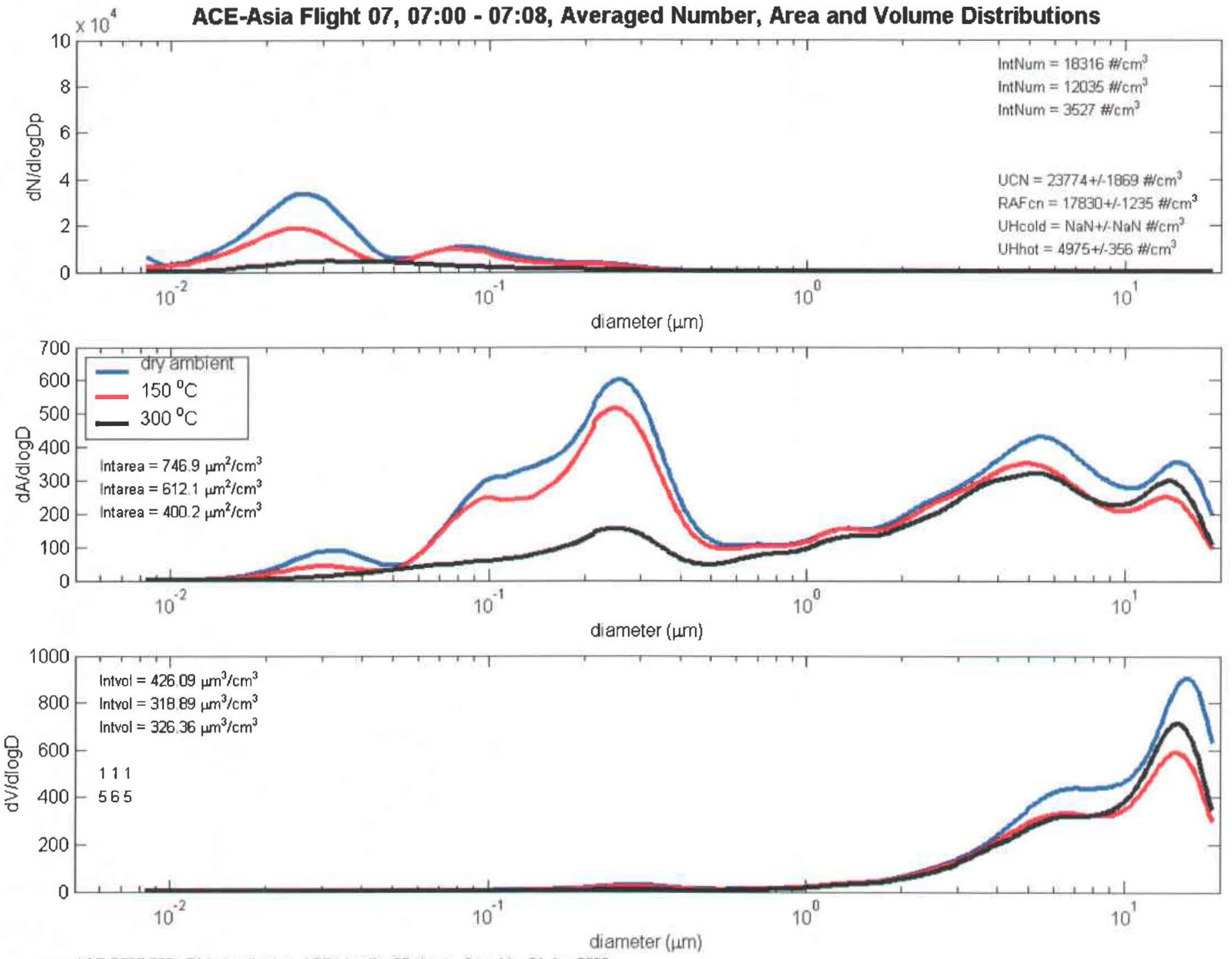

ACE-FFO7-700to714-sizedist.jpg, ACE-sizedist-2Dplot,m, Carn Mc, 01-Apr-2003

Figure 5.5 - Aerosol number (top), area (middle) and volume (bottom) distributions measured during the afternoon fly-by of the Gosan surface site during ACE-Asia RF07, April 12 $2^{\text {th }}, 2001$. Nucleation mode particles are identical to those observed at the ground station and have shifted to larger size classes than those recorded during the morning fly-by (Figure 5.3). 


\subsection{Size distributions from ACE-Asia RF08}

From 1:35 - 2:05 UTC on April $13^{\text {th }}$ the C-130 completed an intercomparison with $\mathrm{R} / \mathrm{V}$ Ron Brown located at $35.74^{\circ} \mathrm{N}, 132.50^{\circ} \mathrm{E}$. The $\mathrm{C}-130$ recorded nucleation mode particles with a peak diameter of $14 \mathrm{~nm}$ compared to a peak diameter of $13 \mathrm{~nm}$ measured aboard the Ron Brown (D. Covert, U. of Washington). The Ron Brown recorded evolving size distributions during April $13^{\text {th }}$ similar to the Gosan surface site the previous day. The C130 continued to operate in the postfrontal airmass on April $13^{\text {th }}$ observing nucleation mode particles in the MBL North and South of the Japanese archipelago. The C-130 completed two vertical profiles at 7:00 UTC above the LIDAR installation at Amami-Ohshima. In figure 5.6 we show the composite size distribution for these profiles from the surface to 3000 meters. $\mathrm{C}_{\text {crit }}$ reaches it's minimum value of $4.5 \times 10^{7} \mathrm{~cm}^{-3}$ just below the inversion located at $\sim 1800 \mathrm{~m}$. Values of $\mathrm{C}_{\text {crit }}$ suggest that the cold high relative humidity condition near the MBL inversion is the most favoured site for the formation of secondary aerosols via binary nucleation. Unfortunately $\mathrm{H}_{2} \mathrm{SO}_{4}$ measurements were not available aboard the $\mathrm{C}-130$ so a relative comparison to $\mathrm{C}_{\text {crit }}$ as an indicator of binary nucleation is not possible. However, PILS data show that the molar ratios of $\left[\mathrm{NH}_{4}{ }^{+}\right]:\left(\left[\mathrm{SO}_{4}{ }^{2-}\right]+\left[\mathrm{NO}_{3}{ }^{-}\right]\right)$are still between 0.83 and 0.68 for these profiles suggesting the presence of ammonia during the southern profile of RF08. The presence of nucleation mode particles (bottom of Figure 4.7) throughout the MBL suggests that in fact aerosols are forming throughout the column but that the strongest driving force arising from the highest relative acidity should be near the MBL inversion as evident by the relative minima in $\mathrm{C}_{\text {crit }}$ (Figure 5.6). 

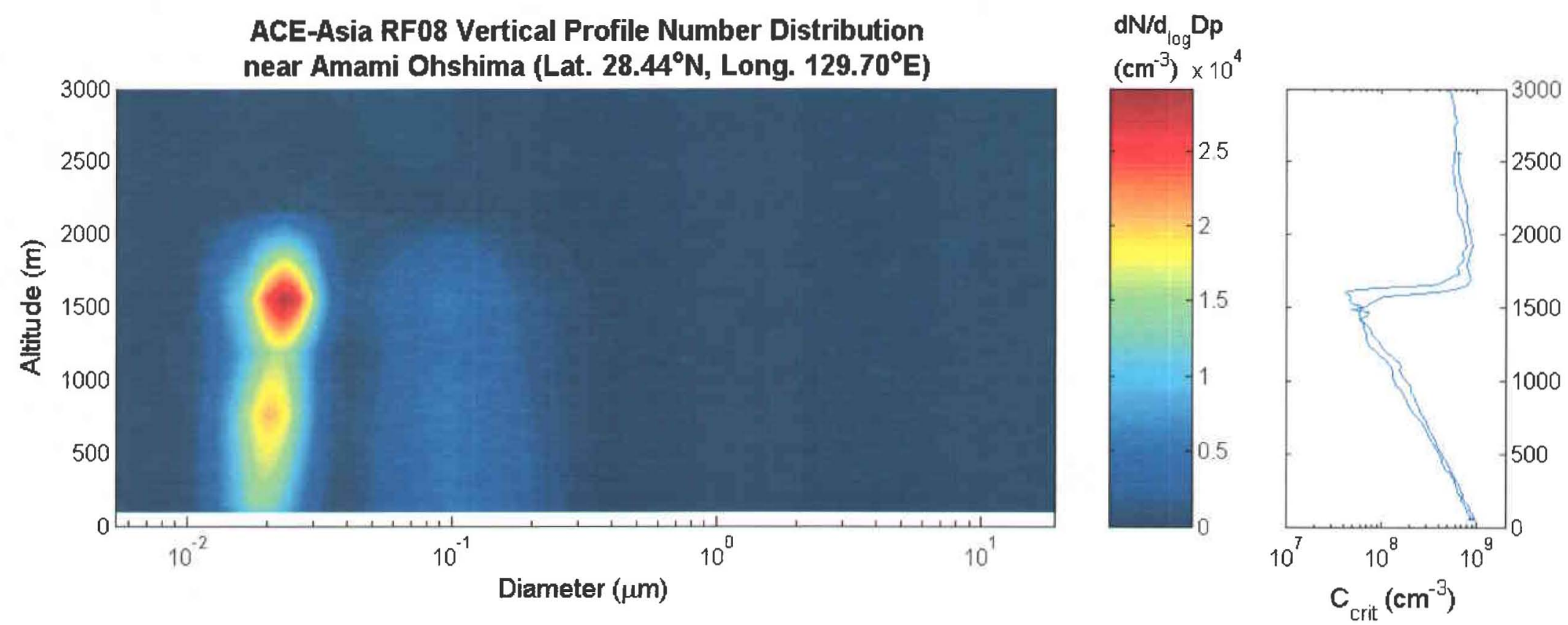

Figure 5.6 - Vertical structure of the aerosol number distribution near Amami-Ohshima during ACE-Asia RF08 on April $13^{\text {th }}$, 2001. Highest concentrations of nucleation mode particles exist near the $\mathrm{MBL}$ inversion where the $\mathrm{C}_{\text {erit }}$ parameterization indicates gas-to-particle conversion of sulfuric acid is favoured. Presence of nucleation mode particles throughout the marine boundary layer suggests that they are forming throughout the column or that they are being mixed after forming near the inversion. 


\subsection{Particle growth rates for April $12^{\text {th }}$ and April $13^{\text {th }}$}

The C-130 observed nucleation mode particles throughout the MBL on April $12^{\text {th }}$ while traveling across 8 degrees of longitude $(\sim 720 \mathrm{~km})$ and 4 degrees of latitude $(\sim 40 \mathrm{~km})$. Moreover, the following day, while conducting operations in essentially the same airmass the C-130 again observed nucleation mode particles throughout the MBL while covering 6 degrees of longitude $(\sim 540 \mathrm{~km})$ and 7 degrees of latitude $(\sim 770 \mathrm{~km})$. These observations show that formation of secondary aerosols occurred on a scale of about $200,000 \mathrm{~km}^{2}$ over a two-day period. High secondary aerosol concentrations in the wake of a passing cold front appears to be associated with steep vertical gradients in aerosol surface area, relative humidity and temperature (Figures 4.5, 4.6, 4.7, 5.4 and 5.6). Other publications [Easter and Peters, 1994; Nilsson and Kulmala, 1998] suggest that nucleation events can occur in regions where airmasses of slightly different character (e.g. relative humidity, temperature, $\mathrm{H}_{2} \mathrm{SO}_{4}$, $\mathrm{SO}_{2}$, aerosol surface area etc.) can mix. Our observations appear to confirm that steep gradients in thermodynamic variables, gas concentrations and aerosol surface area, particularly those associated with atmospheric layers (OBL and the MBL inversion), can enhance new particle production on a synoptic scale [Nilsson et al., 2001].

\subsection{Growth rates as observed by the C-130}

While ACE-Asia flights RF07 and RF08 were not designed as Lagrangian experiments the back trajectories suggest that the aircraft remained within the same air mass over a two-day period. If the $\mathrm{C}-130$ observations reflect widespread secondary aerosol formation and growth throughout the MBL during these two days then a plot of nucleation mode diameter vs. UTC time should reveal this. All recent nucleation peaks evident below $63 \mathrm{~nm}$ were identified for these flights and plotted vs. time of day. The top row of figure 6.1 shows the peak diameter of the nucleation peak for the dry ambient size distributions from RF07 and RF08 along with a linear fit estimate indicative of the growth rate. The graphs show remarkable agreement between the two days with linear growth rates of 2.4 and $1.7 \mathrm{~nm}$ $\mathrm{hr}^{-1}$ for flights seven and eight with $\mathrm{R}^{2}$ statistics of 0.6294 and 0.8314 . These values are consistent with other observed growth rates [Aalto et al., 2001; Birmili and Wiedensohler, 2000; Birmili et al., 2000; Verheggen and Mozurkewich, 2002; Weber et al., 1997; Weber et 
al., 1998a] summarized in table 6.1. The data shows a slightly higher growth rate in the Yellow Sea (RF07) as compared to the Sea of Japan and East China Sea (RF08). Intercepts for both growth plots suggest that at 00:00 UTC (9:00 JST) the particles had sizes of about $\sim 10 \mathrm{~nm}$. However, extrapolation of the growth rate indicates formation of nucleating clusters $(1 \mathrm{~nm})$ at 05:00 or 04:00 JST. Sunrise on the two days occurred at 06:13 and 06:11 JST indicating our linear extrapolation of particle growth is not accurate at or near the time of formation when particles are very small $(<10 \mathrm{~nm})$.

RF07 - 04/12/01

Nucleation Mode Peak Diam. vs. Observation Time
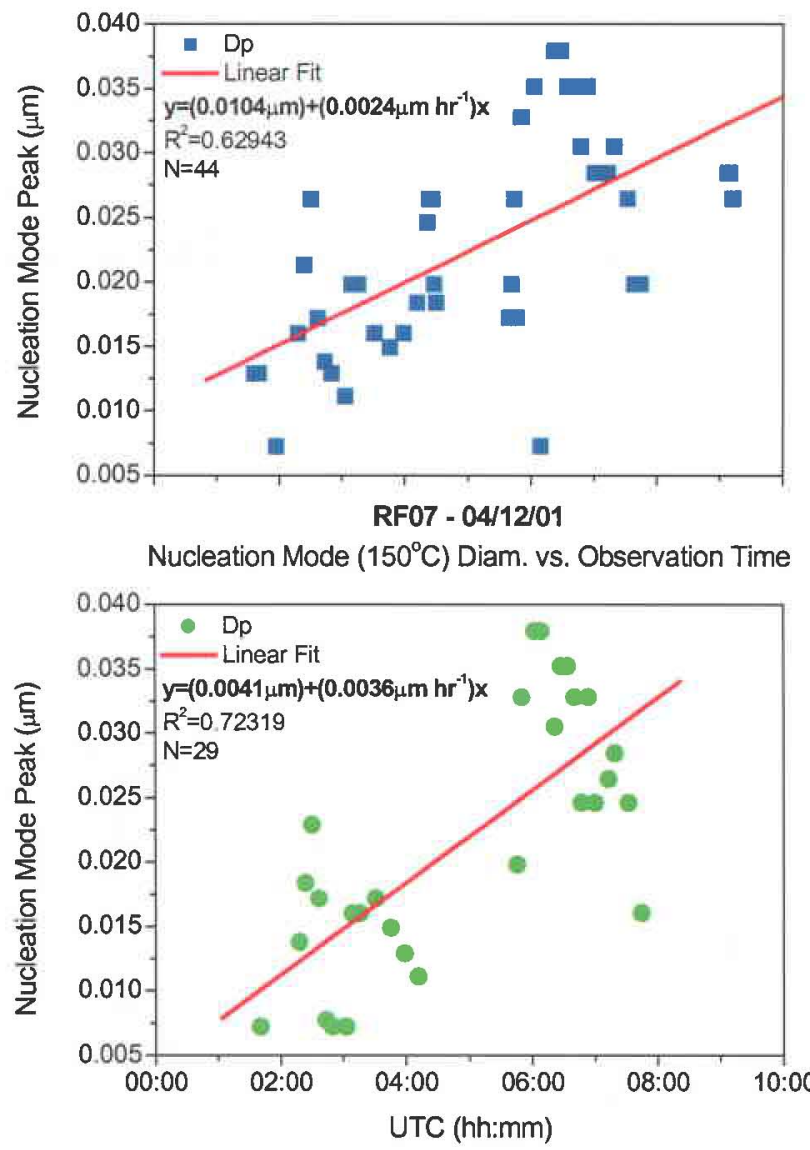

RF08 - 04/13/01

Nucleation Mode Peak Diam. vs. Observation Time
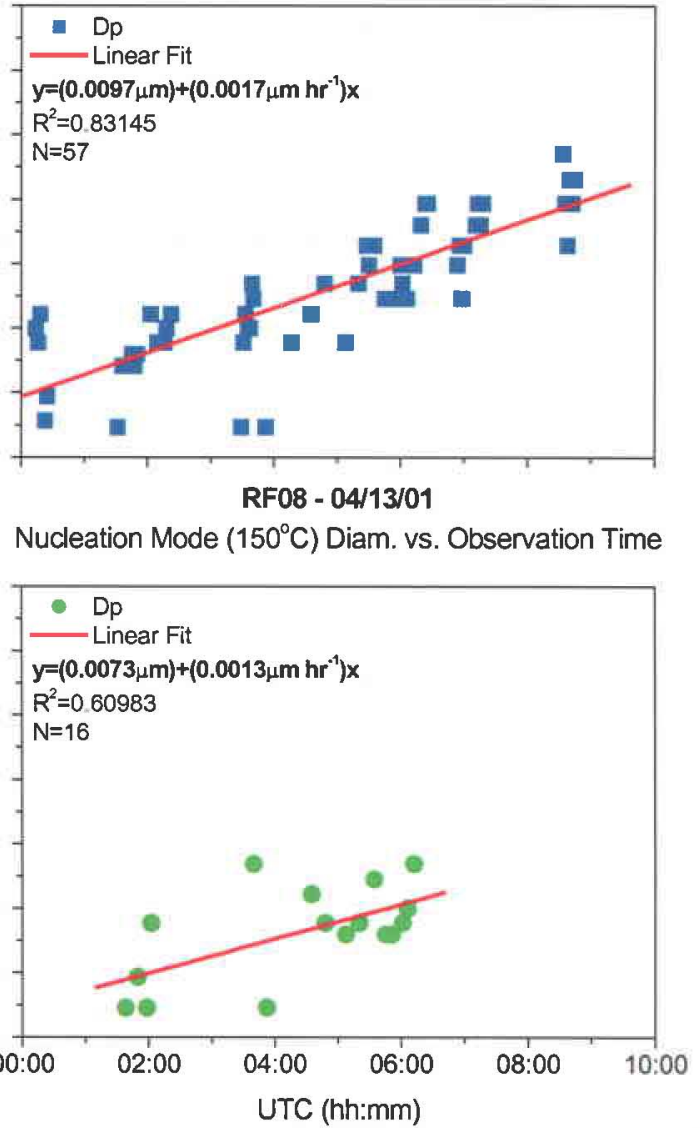

Figure 6.1 - Evolution of the nucleation mode aerosols observed over a synoptic scale during ACE-Asia flights RF07 and RF08 flown on April 12 $2^{\text {th }}$ and $13^{\text {th }}$ of 2001. The top row indicates the size of the peak diameter of nucleation mode particles as measured at dry conditions. Bottom row indicates the peak diameter of neutralized nucleation mode after heating to $150^{\circ} \mathrm{C}$. 
Table 6.1 - Particle growth rates published for other regions and environmental conditions.

\begin{tabular}{|c|c|c|}
\hline Publication & Growth Rate & Environment/Location \\
\hline Weber et al., 1997 & $1.2+/-0.4 \mathrm{~nm} \mathrm{hr}^{-1}$ & alpine, clean continental \\
\hline Weber et al., 1998 & 2 to $5 \mathrm{~nm} \mathrm{hr}^{-1}$ & $\begin{array}{r}\text { biogenically impacted } \\
\text { clean marine }\end{array}$ \\
\hline Birmili and Wiedensohler, 2000 & $4.1+/-2.3 \mathrm{~nm} \mathrm{hr}^{-1}$ & polluted continental \\
\hline Birmili et al., 2000 & $2.1+/-0.1 \mathrm{~nm} \mathrm{hr}^{-1}$ & alpine, clean continental \\
\hline Aalto et al., 2001 & 3 to $4 \mathrm{~nm} \mathrm{hr}^{-1}$ & boreal forest \\
\hline Verheggen and Mozurkewich, 2002 & $4.2+/-0.8 \mathrm{~nm} \mathrm{hr}^{-1}$ & polluted continental \\
\hline M'Naughton et al., 2003 & 1.7 to $2.4 \mathrm{~nm} \mathrm{hr}^{-1}$ & \\
\hline
\end{tabular}

If sulfuric acid were the only gas phase compound condensing on the aerosol size distribution then we expect that after sunset (19:10 JST April $12^{\text {th }}$ ) photochemical production of $\mathrm{OH}$ radicals necessary for converting $\mathrm{SO}_{2}$ to $\mathrm{H}_{2} \mathrm{SO}_{4}$ would stop and condensational growth of the nucleation mode particles would be suspended until the following morning. Since it is likely that ammonia and low vapour pressure organics ${ }^{4}$ continue to condense after sunset, nucleation mode particles may continue to grow overnight. Continued growth of the nucleation mode particles occurs in conjunction with the coagulation process which will deplete the total number of nucleation mode aerosols transferring their mass to larger size classes.

On April $13^{\text {th }}$ the airmass North and South of Japan was the same airmass characterized the previous day over the Yellow Sea (Figure 4.3). April $13^{\text {th }}$ size distributions show no distinct evidence of the nucleation mode particles formed on April $12^{\text {th }}$. The data suggests that overnight condensational growth rates are not high enough to shift the nucleation mode particles far enough into the Aitken mode size classes such that they appear as a distinct mode in the aerosol size distribution $16-24$ hours after their formation. Thus the nucleation events on April $12^{\text {th }}$ and $13^{\text {th }}$ appear to represent a daily cycle of new particle production in the region. Modeling of the coagulation rate for the nucleation mode particles is discussed in Section 7.3.

\footnotetext{
${ }^{4}$ Mass of organic carbon $(\mathrm{OC})$ is approximately equal to the mass of sulfates for the accumulation mode aerosol in this environment (B. Huebert, A. Clarke, personal communication).
} 
6.2 Evidence for Partial Neutralization of the Nucleation Mode Particles

The data obtained from the size distributions recorded at $150^{\circ} \mathrm{C}$ (second row of Figure 6.1) is also of interest since it reveals the development of a component refractory at $150^{\circ} \mathrm{C}$ as the secondary aerosols age. The data shows the nucleation mode aerosol to be less volatile at $150^{\circ} \mathrm{C}$ over time indicating that ternary species (ammonia and/or organics with a boiling point $>150^{\circ} \mathrm{C}$ ) are being incorporated through condensation into the nucleation mode aerosols. However, the different slopes drawn through this data are uncertain in view of the scatter in the data.

Size distributions during RF07 and during RF08 also suggest neutralization of the nucleation mode aerosol. Examples of these size distributions are shown in figures 6.2 and 6.3. Five distributions from RF07 show $46.9 \%+/-14.8 \%$ of the nucleation mode volume is refractory after heating to $150^{\circ} \mathrm{C}$ (Table 6.2). Four distributions from RF08 show $25.6 \%+/$ $8.3 \%$ of the nucleation mode volume is refractory (Table 6.3). Size distributions from RF07 were obtained near the Gosan surface site in the Yellow Sea. Size distributions from RF08 were obtained South of Kyushu and near Amami. This analysis shows that the nucleation mode aerosol is becoming less volatile over time and suggests that the ternary species participating in neutralization of the particles might also participate in secondary aerosol formation during gas-to-particle conversion.

Table 6.2 - Percent neutralization of nucleation mode volume at $150^{\circ} \mathrm{C}$ as inferred from volatility and size distributions near Jeju Island (Yellow Sea) during ACE-Asia RF07 on April 12 $2^{\text {th }}, 2001$.

\begin{tabular}{l|c|c|c} 
Scan Time & $\begin{array}{c}\text { Dry ambient } \\
\text { peak DP }\end{array}$ & $\begin{array}{c}150^{\circ} \mathrm{C} \\
\text { peak Dp }\end{array}$ & $\begin{array}{c}\text { \% Volume } \\
\text { Neutralization }\end{array}$ \\
\hline $7: 00-7: 08$ & 28.4 & 24.6 & 48.0 \\
$7: 08-7: 17$ & 26.4 & 24.6 & 55.3 \\
$7: 18-7: 25$ & 30.5 & 28.4 & 63.3 \\
$7: 33-7: 41$ & 19.8 & 13.8 & 32.3 \\
$7: 41-7: 49$ & 19.8 & 16.0 & 36.8 \\
\hline Mean & 24.1 & 20.7 & 46.9 \\
Stdev & 5.3 & 6.9 & 14.8
\end{tabular}


Table 6.3 - Percent neutralization of nucleation mode volume at $150^{\circ} \mathrm{C}$ as inferred from volatility and size distributions near Amami-Ohshima (East China Sea) during ACE-Asia RF08 on April $18^{\text {th }}, 2001$.

\begin{tabular}{l|c|c|c} 
Scan Time & $\begin{array}{c}\text { Dry ambient } \\
\text { peak DP }\end{array}$ & $\begin{array}{c}150^{\circ} \mathrm{C} \\
\text { peak Dp }\end{array}$ & $\begin{array}{c}\text { \% Volume } \\
\text { Neutralization }\end{array}$ \\
\hline $4: 33-4: 41$ & 16.0 & 15.0 & 37.2 \\
$4: 41-5: 00$ & 16.6 & 12.5 & 25.7 \\
$5: 01-5: 15$ & 13.8 & 12.0 & 21.4 \\
$5: 15-5: 31$ & 19.8 & 14.0 & 18.3 \\
\hline mean & 16.6 & 13.4 & 25.6 \\
stdev & 2.5 & 1.4 & 8.3
\end{tabular}



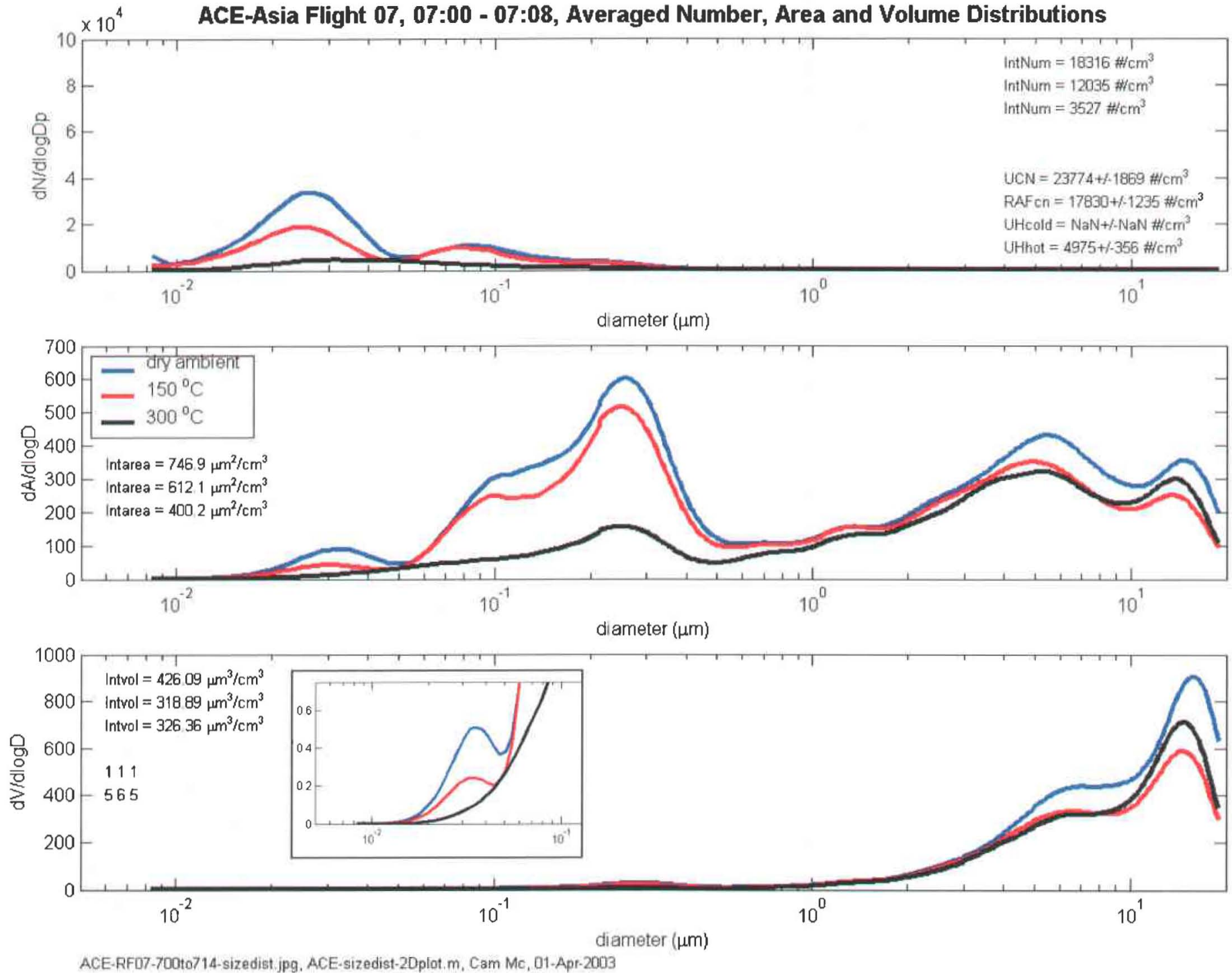

Figure 6.2 - Aerosol number (top), area (middle) and volume (bottom) distributions near Gosan during ACE-Asia flight RF07 shows $48.0 \%$ neutralization (inset) of the nucleation mode volume after heating to $150^{\circ} \mathrm{C}$ and suggests the participation of ternary species $\left(\mathrm{NH}_{3}\right.$ or organics) during gas-to-particle conversion. 

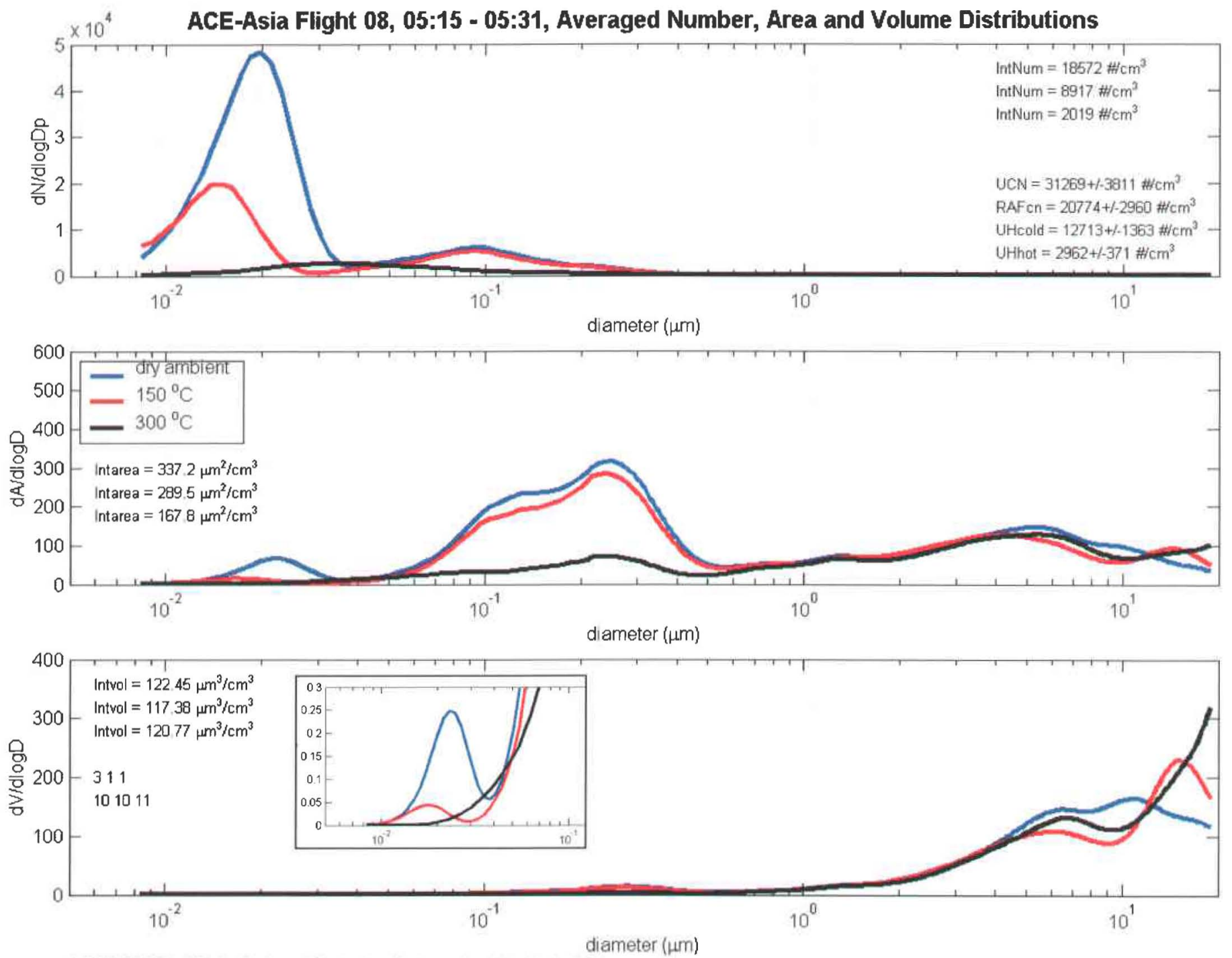

ACE-RF08-525to552-sizedist.jpg, ACE-sizedist-20plot m, Cam Mc, 01-Apr-2003

Figure 6.3 - Aerosol number (top), area (middle) and volume (bottom) distributions near Amami during ACE-Asia flight RF08 shows $18.3 \%$ neutralization (inset) of the nucleation mode volume after heating to $150^{\circ} \mathrm{C}$ and suggests the participation of ternary species $\left(\mathrm{NH}_{3}\right.$ or organics) during gas-to-particle conversion. 


\subsection{Evolution of the size distribution at the surface}

The ubiquity with which nucleation mode particles were observed within the MBL on April $12^{\text {th }}$ and $13^{\text {th }}$ show that, on average, growth rates for the nucleation mode aerosols was between 2.4 and $1.7 \mathrm{~nm} \mathrm{hr}^{-1}$. The Gosan field site and the $\mathrm{R} / \mathrm{V}$ Ron Brown also obtained size distributions at the surface using differential mobility analyzers. These platforms essentially occupied a Eulerian reference frame. If the production of secondary aerosols was occurring at a single location and is then advected to the platforms we would not expect to see the same evolution in the size distributions obtained near the surface. Also if airmass heterogeneity was responsible for differences in the aerosol size distribution than the stationary surface sites should record this with better temporal resolution.

In fact, both the Gosan surface site and the R/V Ron Brown observed evolving size distributions during April $12^{\text {th }}$ and April $13^{\text {th }}$ (Figure 6.4). This data is consistent with our interpretation of aerosol growth from the C-130 data. The C-130, with its broad spatial resolution, demonstrates that the formation of secondary aerosol in this region occurred throughout the airmass on a synoptic scale and over a two-day period. The surface sites demonstrate condensational growth of the nucleation mode aerosol as well as reductions in total particle number over time indicating scavenging of nucleation mode aerosols by the accumulation and coarse mode aerosol. Figure 6.4 also shows that the growth rates from the C-130 are broadly consistent with those measured at the surface but that near 0:00 UTC (9:00 JST) the C-130 estimates over-predict nucleation mode diameters. The ground stations both show that near 0:00 UTC growth rates appear to be higher than $2 \mathrm{~nm} \mathrm{hr}^{-1}$. The comparison confirms that our earlier extrapolation of the intercepts (at $10 \mathrm{~nm}$ ) to a $1 \mathrm{~nm}$ cluster size is inaccurate. 

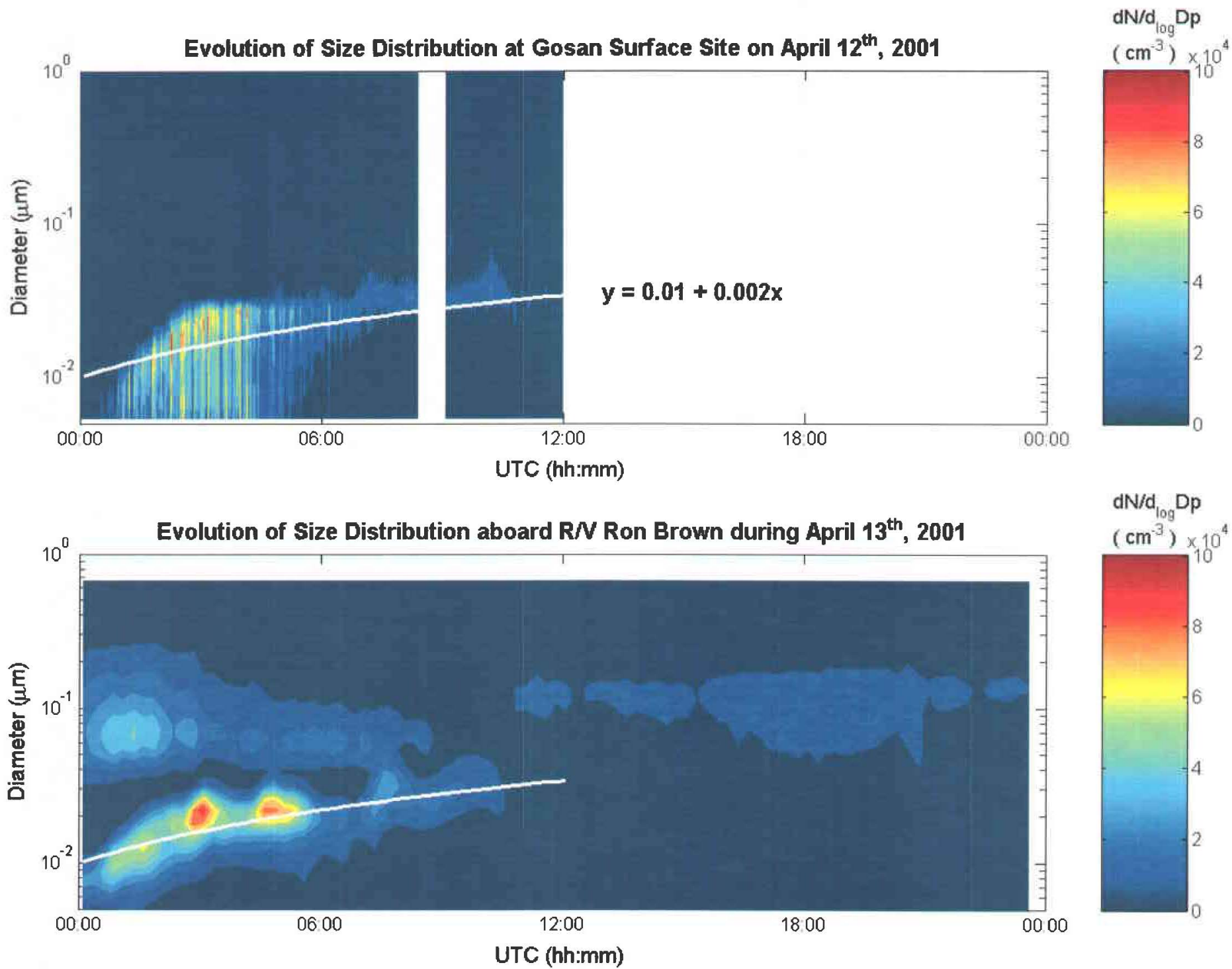

Figure 6.4 - Evolution of the nucleation mode aerosols as observed by the Gosan surface site on April $12^{\text {th }}, 2001$ and observed by the R/V Ron Brown on April 13 $3^{\text {th }}, 2001$. Growth rates are broadly consistent with the linear regression of nucleation mode growth rates calculated from the $\mathrm{C}-130$ while surveying the regional airmass. 


\subsection{Discussion}

Although measurements of $\mathrm{H}_{2} \mathrm{SO}_{4}$ were limited during TRACE-P flight 14 and were not available during $\mathrm{ACE}-\mathrm{Asia}$, the $\mathrm{C}_{\text {crit }}$ parameterization indicates the concentration of $\mathrm{H}_{2} \mathrm{SO}_{4}$ during TRACE-P RF14 was insufficient to explain secondary aerosol formation at the time of observation. And, although no measurements of $\mathrm{NH}_{3}$ gas were made aboard the NASA P3-B or NCAR C-130, it is likely that the large urban centers and agricultural facilities in the region have $\mathrm{NH}_{3}$ emission rates of the same order of magnitude as the emission rates for $\mathrm{SO}_{2}$ [Huebert et al., submitted 2003; Streets et al., submitted 2002]. This information suggests that $\mathrm{NH}_{3}$ was available for a ternary nucleation mechanism.

In laboratory experiments Ball et al. [1999] showed that 80 pptv of $\mathrm{NH}_{3}$ (g) increases nucleation rates in the $\mathrm{H}_{2} \mathrm{SO}_{4}-\mathrm{H}_{2} \mathrm{O}-\mathrm{NH}_{3}$ system by up to an order of magnitude at $15 \% \mathrm{RH}$. These findings are also consistent with Hanson and Eisele [2002] who show ammonia and sulfuric acid can play an important role in forming new particles in the atmosphere and that the ternary system has a strong dependence on relative humidity.

Field measurements of aerosols collected at Qingdao China $\left(36.0^{\circ} \mathrm{N}, 120.3^{\circ} \mathrm{E}\right)$ in October 1996 indicated that morphology and composition of particle droplets in the $0.04-$ $0.11 \mu \mathrm{m}$ size range consisted of sulfuric acid and/or partially neutralized sulfate species [Zhang et al., 1999]. Particle-into-Liquid samplers operated aboard the NASA P3-B and the NCAR C-130 show equivalent mole fractions consistent with accumulation mode aerosol dominated by neutralized sulfuric acid species. Finally, partial neutralization of the nucleation mode aerosols suggests that a plausible explanation for the observations is new particle production via a ternary nucleation mechanism involving $\mathrm{H}_{2} \mathrm{SO}_{4}, \mathrm{H}_{2} \mathrm{O}$ and $\mathrm{NH}_{3}$.

\subsection{Fog Formation Over the Yellow Sea}

Although the discussion in Section 6.0 emphasized a synoptic scale nucleation event this is due in part to large-scale similarity in air mass characteristics. It is important to keep in mind that processes that favor formation and evolution of aerosol can depend upon smallscale variations in these characteristics (microphysical environments). A marked event of boundary layer nucleation and the role of boundary layer processes on aerosol evolution was evident in TRACE-P measurements made over the Yellow Sea [Weber et al., submitted 
2002]. They attribute the formation of secondary aerosols to a pollution "plume" being advected from Mainland China to the Yellow Sea by the regional Southeasterly flow. In the central and southern profiles of TRACE-P flight 14 (middle and bottom rows of Figure 4.5) ambient and potential temperature as well as water vapour mixing ratio indicate that a shallow layer of evaporative cooling exists below $\sim 500 \mathrm{~m}$. After the descent at the central profile the P3-B flew at $118 \mathrm{~m}$ heading north between $34.25^{\circ} \mathrm{N}$ and $35.75^{\circ} \mathrm{N}$ and then ascending to complete the northern profile (top of Figure 7.1). In the northern profile (first row of Figure 4.5) the layer of evaporative cooling is less apparent and particle concentrations remain high throughout the MBL. In contrast particle concentrations are lowest in the central and southern profiles within the layer of evaporative cooling.

Relatively low variability (7-10\%) was observed in unreactive gas and aerosol combustion indicators including refractory $\mathrm{CN}(\mathrm{RCN})$ and $\mathrm{CO}$ during the horizontal leg near the surface (top of Figure 7.1). However, reactive aerosol precursors $\mathrm{SO}_{2}$ and $\mathrm{H}_{2} \mathrm{SO}_{4}$ as well as volatile $\mathrm{CN}(\mathrm{VCN})$, drop by factors of $3.6,6.2$ and $~ 30$ between their maximum at $507 \mathrm{~m}$ and their minimum during the level leg (center and bottom of Figure 7.1). The Wexler et al. [1994] formulation for $\mathrm{C}_{\text {crit }}$ predicts that increasing relative humidity favours nucleation, however, the high relative humidity environment at the surface, prior to 4:15 UTC, shows the least number of volatile CN. Relative humidity and VCN both increase after 4:15 UTC $\left(>35.25^{\circ} \mathrm{N}\right)$ on the approach to the northern profiles' ascent. This is the region with a less pronounced OBL.

Figure 7.2 illustrates the relationship between relative humidity and $\mathrm{SO}_{2}, \mathrm{H}_{2} \mathrm{SO}_{4}$ and VCN below $1.0 \mathrm{~km}$ for the central profile, the level leg at 118 meters and the northern profile shown in figure 7.1. Outside of the OBL $\left(\mathrm{w}<2.9 \mathrm{~g} \mathrm{~kg}^{-1}\right)$ each parameter is positively correlated to relative humidity (black lines). This suggests that the source of $\mathrm{SO}_{2}$ is near the surface and that the production of sulfuric acid and new particle number are favoured in the high relative humidity environment. This observation is consistent with the $\mathrm{C}_{\text {crit }}$ formulation of Wexler et al. Within the $\mathrm{OBL}\left(\mathrm{w}>2.9 \mathrm{~g} \mathrm{~kg}^{-1}\right)$ the relationship between $\mathrm{SO}_{2}, \mathrm{H}_{2} \mathrm{SO}_{4}$ and VCN becomes negative (red lines) with $\mathrm{R}^{2}$ statistics of $0.9095,0.9004$ and 0.9138 . Such a close coupling between gas phase precursors, volatile aerosol and RH suggest that airmass history, with regard to relative humidity, may have influenced the formation of nucleation mode aerosols. 


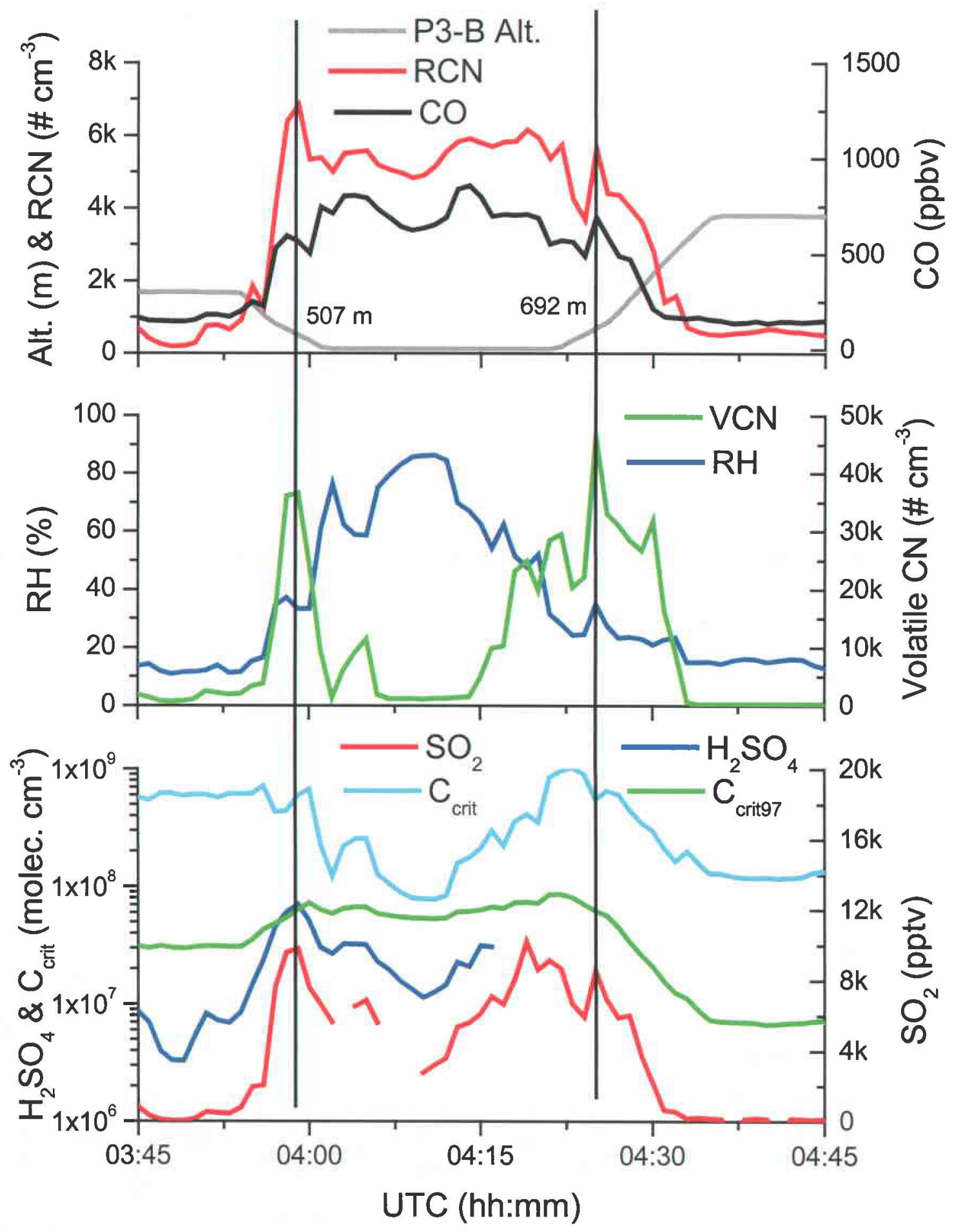

Figure 7.1 - Altitude and non-reactive tracers along $124.4^{\circ} \mathrm{E}$ during TRACE-P flight 14 (top). Volatile $\mathrm{CN}$ (VCN), $\mathrm{SO}_{2}$ and $\mathrm{H}_{2} \mathrm{SO}_{4}$ are negatively correlated to relative humidity during the boundary layer run (middle and bottom). Calculations of $\mathrm{C}_{\text {crit }}$ at ambient RH indicated binary nucleation is not possible. However, calculations at $97 \% \mathrm{RH}\left(\mathrm{C}_{\text {crit97}}\right)$ suggest binary nucleation was possible during the initial descent over a shallow layer of fog that may have existed earlier in the day. 

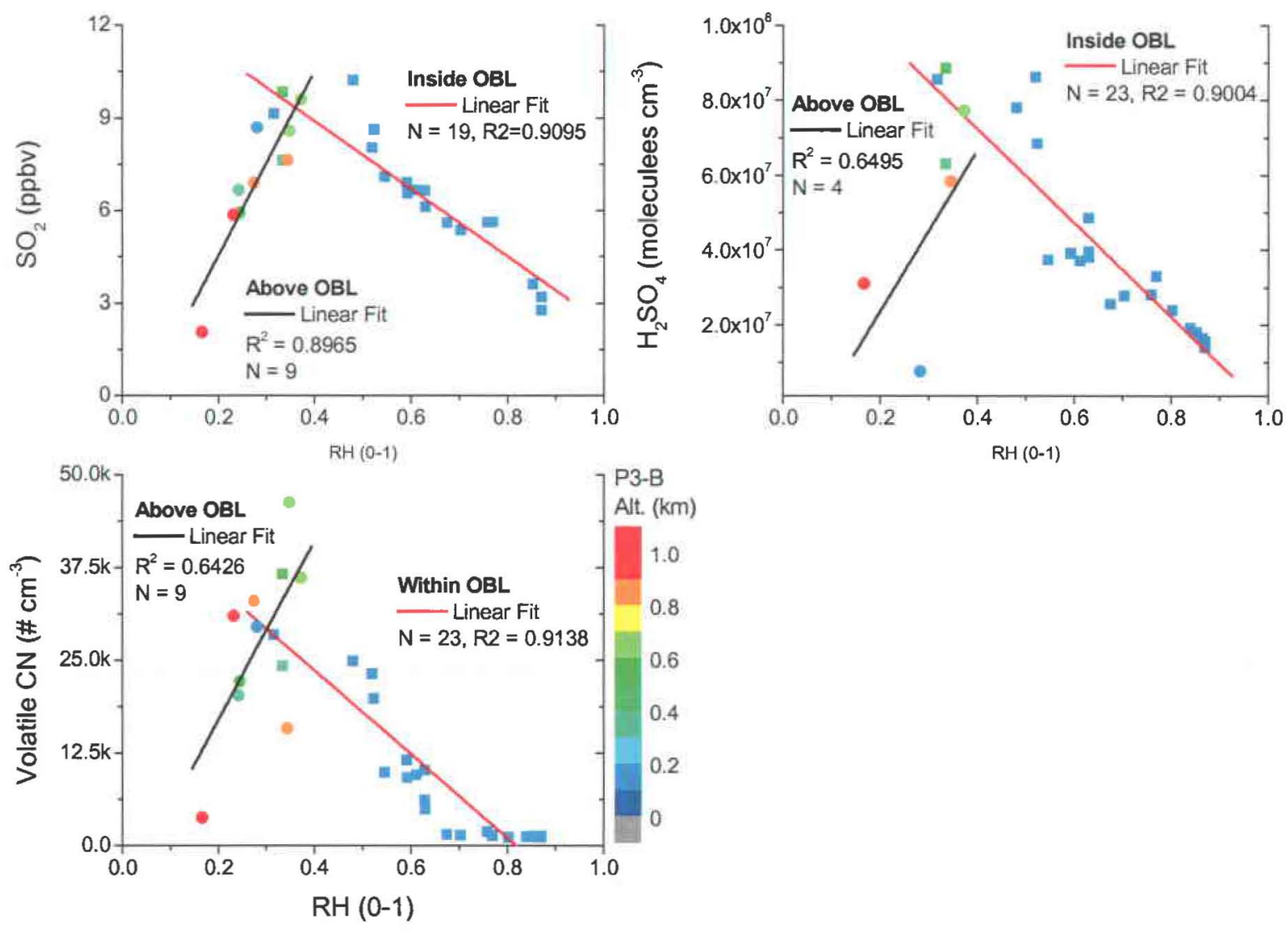

Figure 7.2 - Linear regressions of the relationship between $\mathrm{SO}_{2}$ (top left), $\mathrm{H}_{2} \mathrm{SO}_{4}$ (top right), volatile $\mathrm{CN}$ (bottom left) and relative humidity. Positive correlations outside the OBL (black lines) indicate production of sulfuric acid and secondary aerosols is favoured in the high RH environment. Within the OBL (red lines) the formation of surface fog has depleted gas phase precursors and new particle number through aqueous phase chemistry and coagulation.

Returning to figure 4.5 we note that by extrapolating the values of water vapour mixing ratio and ambient temperature from $118 \mathrm{~m}$ to the surface $(25 \mathrm{~m}$ and $101.325 \mathrm{kPa}) \mathrm{RH}$ values for the southern and central profiles exceed $100 \%$ (Table 7.1). The extrapolations of relative humidity show that fog may have existed over the Yellow Sea earlier in the day. $C_{\text {crit }}$ calculations were made at $97 \%$ relative humidity $\left(\mathrm{C}_{\text {crit97 }}\right)$ to estimate the potential for nucleation under near cloud (fog) conditions. This is plotted in the bottom panel of figure 7.1 and suggests that sulfuric acid concentrations at this RH could have sustained binary homogeneous nucleation at the $507 \mathrm{~m}$ level. 
Table 7.1 - Extrapolation of thermodynamic parameters from TRACE-P RF14 on March $18^{\text {th }}, 2001$ from $\sim 115 \mathrm{~m}$ to $25 \mathrm{~m}$. Coastal fog appears likely in the OBL for the Central and Southern profiles but is absent from the Northern profile (see also Figures $4.5,7.1$ and 7.2).

\begin{tabular}{|c|c|c|c|c|}
\hline & Parameter & $\begin{array}{c}\text { RF14 } \\
\text { North } \\
\text { Profile } \\
\end{array}$ & $\begin{array}{c}\text { RF14 } \\
\text { Central } \\
\text { Profile }\end{array}$ & $\begin{array}{l}\text { RF14 } \\
\text { South } \\
\text { Profile } \\
\end{array}$ \\
\hline \multirow{10}{*}{ Original Data } & $P(m b)$ & 986.93 & 987.10 & 987.42 \\
\hline & Alt. (m) & 117.9 & 115.6 & 112.0 \\
\hline & $w\left(\mathrm{~g} \mathrm{~kg}^{-1}\right)$ & 3.04 & 5.80 & 5.69 \\
\hline & Theta $\left({ }^{\circ} \mathrm{C}\right)$ & 14.3 & 10.7 & 10.3 \\
\hline & $\mathrm{T}\left({ }^{\circ} \mathrm{C}\right)$ & 13.3 & 9.6 & 9.2 \\
\hline & es $(m b)$ & 15.23 & 11.97 & 11.66 \\
\hline & ws $\left(\mathrm{g} \mathrm{kg}^{-1}\right)$ & 9.45 & 7.45 & 7.26 \\
\hline & $\mathrm{RH}(\%)$ & $32.1 \%$ & $77.9 \%$ & $78.4 \%$ \\
\hline & $\mathrm{H}_{2} \mathrm{SO}_{4}$ (molecules $\mathrm{cm}^{-3}$ ) & - & $2.68 \mathrm{E}+07$ & - \\
\hline & $\mathrm{C}_{\text {crit }}$ & $8.38 \mathrm{E}+08$ & $1.22 \mathrm{E}+08$ & $1.15 \mathrm{E}+08$ \\
\hline \multirow{7}{*}{$\begin{array}{l}\text { Extrapolation to } \\
25 \text { meters }\end{array}$} & $P(m b)$ & 1013.25 & 1013.25 & 1013.25 \\
\hline & $w\left(\mathrm{~g} \mathrm{~kg}^{-1}\right)$ & 3.34 & 7.01 & 7.24 \\
\hline & $\mathrm{T}\left({ }^{\circ} \mathrm{C}\right)$ & 13.4 & 8.7 & 9.4 \\
\hline & ws $\left(\mathrm{g} \mathrm{kg}^{-1}\right)$ & 9.29 & 6.84 & 7.15 \\
\hline & es $(m b)$ & 15.36 & 11.27 & 11.78 \\
\hline & $\mathrm{RH}(\%)$ & $36.0 \%$ & $102.4 \%$ & $101.3 \%$ \\
\hline & $\mathrm{C}_{\text {crit }}$ & $7.24 \mathrm{E}+08$ & $4.43 E+07$ & $4.95 \mathrm{E}+07$ \\
\hline
\end{tabular}

Highest concentrations of nucleation mode particle were observed above the OBL (Figure 5.1) but a small nuclei mode was also evident within the layer (Figure 5.2). This indicates that nucleation was occurring in both locations under the high relative humidity conditions. However, the large reduction in $\mathrm{SO}_{2}, \mathrm{H}_{2} \mathrm{SO}_{4}$ and $\mathrm{VCN}$ compared to unreactive $\mathrm{CO}$ and $\mathrm{RCN}$ while flying at $118 \mathrm{~m}$ suggests enhanced relative removal of these species within the ocean boundary layer. This presents the possibility that preferential scavenging might have occurred for $\mathrm{SO}_{2}$ and $\mathrm{H}_{2} \mathrm{SO}_{4}$ relative to $\mathrm{CO}$ and the primary aerosol through cloud or fog conditions where enhanced surface area and rapid aqueous reactions can accelerate the production of sulfates [Hegg and Hobbs, 1981]. If formation of secondary aerosols within the fog layer occurred then the surface area provided by the fog droplets $\left(D_{p}\right.$ between 5 and $50 \mu \mathrm{m}$ ) could result in rapid coagulation of the nucleation mode aerosol. The 
nucleation mode particles observed in the size distribution at $118 \mathrm{~m}$ (Figure 5.2) either survived the coagulation process or formed after the dissipation of the fog similar to observations by Kerminen and Wexler [1994b]. The smaller size of particles within the OBL could be a result of a lower rate of sulfuric acid condensation in a region where the sulfur dioxide and sulfuric acid precursors have been drawn down by aqueous phase chemistry. Cloud scavenging and enhanced production of sulfuric acid in the fog layer may also provide an explanation for less neutralization of the larger accumulation mode aerosols at $118 \mathrm{~m}$ (Figure 5.2) compared to the size distribution obtained at $663 \mathrm{~m}$ and presumed to be above the layer of morning fog (Figure 5.1).

Flight operations in the Yellow Sea during TRACE-P RF14 were centered on 4:00 UTC (1:00 pm JST) on March $18^{\text {th }}, 2001$. No clouds were evident and the crew aboard the NASA P3-B did not report observations of fog during the flight. However, local meteorology stations reported "heavy fog", "fog", "smoke" and "haze" across the Eastern and Western coasts of the Gulf of Bo Hai and Yellow Sea and extended past Shanghai to as far south as Hong Kong at 0:00 UTC (9:00 am JST). Figures 4.6 and 5.4 show that the OBL structure during ACE-Asia RF07 (April 12 $2^{\text {th }}, 2001$ ) was similar to the conditions observed on March $18^{\text {th }}$ during TRACE-P flight 14. Less extensive reports of "heavy fog", "smoke", "fog" and "haze" were recorded North and South of the Shandong Peninsula, at coastal sites in North Korea and as far South as Shanghai on April $12^{\text {th }}$ despite the fact that fog was not reported by the crew aboard the NCAR C-130. Archived sea surface temperature (SST) from April $12^{\text {th }}$ (a detailed map for March $18^{\text {th }}$ was not available) show upwind coastal SST appear $1-5$ degrees cooler than SST at the observation points during the ACE-Asia RF07 on April $12^{\text {th }}$ (see Figure 4.8 ).

Spring fog over the Yellow Sea is not unusual. Chung et al. [1999] report that the 6year average of foggy days (visibility < 1 km) from 1991 to 1996 for an inland site in South Korea are 5.2 days for March and 3.8 days for April. The number of misty or hazy (associated with pollution) days was 19.8 and 20.0. They report that radiative cooling in the cloud free regions of synoptic scale subsidence and that differences in air-sea temperatures can result in fog formation in the Yellow Sea that can then be advected inland. Synoptic scale nucleation events were only observed on 2 out of 10 flights into the Yellow Sea. Taken as a representative sample we expect this phenomenon could be occurring on $\sim 6$ days per 
month in the spring. This is also consistent with ground station data from Gosan which showed strong nucleation events occurred on at least eight days during April of 2001.

These observations indicate that cooler conditions prevailed earlier in the day (as investigated in Table 7.1) and formation of fog enhanced the transfer of gas phase precursors to the aerosol size distribution [Kerminen and Wexler, 1995]. Within and directly above the fog layer, binary and/or ternary nucleation created the high concentrations of nucleation mode particles consistent with the post-fog nucleation of Kerminen and Wexler [1994b] and similar to conditions associated with nucleation near cloud outflow [Clarke et al., 1999; Clarke et al., 1998; Weber et al., 2001a]. Hence, the nucleation mode particles observed just above the OBL and present at reduced concentrations and smaller sizes within the OBL are consistent with fog formation that would lower rates of condensation growth while depleting their number due to scavenging by the elevated aerosol surface area.

Because of the common presence of fog it is clear the production and growth of nuclei will vary greatly in the region even when precursors remain at similar levels. Consequently, although high RH and colder temperatures create more favorable conditions for nucleation of sulfuric acid aerosol, if these conditions lead to fog formation then the increase in surface area both scavenges gas precursors and many of the nuclei formed. This example can also be applied to conditions near the MBL inversion a common site of cloud formation for the region. Colder temperatures and higher $\mathrm{RH}$ at altitude tend to favor nucleation, however these secondary aerosols are expected to have very short lifetimes once clouds begin to form.

\subsection{Flux Rate of Sulfuric Acid to the Size Distribution}

Typical mid-day growth rates for the nucleation mode aerosols during RF07 and RF08 were estimated at 2.4 and $1.7 \mathrm{~nm} \mathrm{hr}^{-1}$. Size distributions at the Gosan surface site and aboard the R/V Ron Brown also reflect this with better temporal resolution. Figure 6.4 shows that the growth rates from the $\mathrm{C}-130$ are broadly consistent with those measured at the surface but near 0:00 UTC (9:00 am JST) the C-130 estimates tend to over-predict nucleation mode diameters. Using the change of particle diameter with respect to time, $\mathrm{dDp} / \mathrm{dt}$, we can calculate the condensation and coagulation sink (CS and CoagS) by adopting the method of Kulmala et al. [2001] (see Section 2.0). These calculations will allow us not only to estimate 
the flux rate of vapour (believed to be dominated by sulfuric acid) to the size distribution but also to estimate the coagulation rate of the nucleation mode particles and thus their atmospheric lifetime. The MATLAB code created to evaluate the condensation and coagulation sinks as well as those used to estimate flux rates and volume of sulfuric acid added to the aerosols is contained in Appendix C.

The values for the condensation sink (CS) and the vapour flux (Q) are summarized in table 7.2. Growth rates of $2 \mathrm{~nm} \mathrm{hr}^{-1}$ were used based on three size distributions from TRACE-P RF14, four size distributions from ACE-Asia RF07 and three distributions from ACE-Asia RF08. Where the nucleation mode particle concentrations were highest, calculations at $1 \mathrm{~nm} \mathrm{hr}^{-1}$ and $4 \mathrm{~nm} \mathrm{hr}^{-1}$ have also been included. The mean vapour flux, based on a $2 \mathrm{~nm} \mathrm{hr}{ }^{-1}$ growth rate is $2.4 \times 10^{6}$ molecules $\mathrm{cm}^{-3} \mathrm{~s}^{-1}+/-1.2 \times 10^{6}$ molecules $\mathrm{cm}^{-3} \mathrm{~s}^{-1}$. These values compare favourably with sulfuric acid production rates of $0.5-2.0 \times 10^{6}$ molecules $\mathrm{cm}^{-3} \mathrm{~s}^{-1}$ calculated by Weber et al. [submitted 2002] for TRACE-P RF14. This indicates that our steady state assumption for equation 2.2 appears reasonable.

Using the Weber et al. [submitted 2002] estimates for sulfuric acid production and the dry ambient size distributions measured aboard the NASA P3-B and the NCAR C-130 it is possible to estimate the mass added to the submicrometer and supermicrometer aerosol. We provide estimates for addition of mass based on three different aerosol size distribution scenarios. The first is a pollution dominated case from TRACE-P RF14 where total aerosol surface area is $1221 \mathrm{um}^{2} \mathrm{~cm}^{-3}$ with $89 \%$ of the area in sizes $<1.0 \mathrm{um}$. The second case is a mixed dust/pollution scenario from ACE-Asia RF07. Total aerosol surface area is $690 \mathrm{um}^{2}$ $\mathrm{cm}^{-3}$ with $47 \%$ of the area in the submicrometer mode. The last case is a dust-dominated case during ACE-Asia RF06. During this case total surface area is $1278 \mathrm{um}^{2} \mathrm{~cm}^{-3}$ with $76 \%$ of the area in the coarse ( $>1.0 \mathrm{um}$ ) mode. The results in table 7.3 were obtained assuming condensation to the size distribution is simply related to the available aerosol surface area and using production rates of $0.5,1.0$ and $2.0 \times 10^{6}$ molecules $\mathrm{cm}^{-3} \mathrm{sec}^{-1}$ for eight hours. The calculations indicate that after eight hours $1.8-7.22 \mathrm{um}^{3} \mathrm{~cm}^{-3}$ of sulfuric acid can be added to the size distribution. Depending on the partitioning of surface area for each scenario this amounts to between 2.4 and $24.3 \%$ increases in submicrometer volume and between 0.1 and $1.1 \%$ increases in coarse mode volume. 
Table 7.2 - Sulfuric acid flux rate to size distributions observed during TRACE-P RF14 on March $18^{\text {th }}, 2001$ and ACE-Asia RF07 and RF08 on April $12^{\text {th }}$ and $13^{\text {th }}$, 2001.

\begin{tabular}{l|c|c|c|c|c|c|} 
Flight & $\begin{array}{c}\text { UTC Time } \\
(\mathrm{hh}: \mathrm{mm})\end{array}$ & $\begin{array}{c}\text { Altitude } \\
(\mathrm{m})\end{array}$ & $\begin{array}{c}\mathrm{SA} \\
\left(\mu \mathrm{m}^{2} \mathrm{~cm}^{-3}\right)\end{array}$ & $\begin{array}{c}\mathrm{dDp} / \mathrm{dt} \\
\left.(\mathrm{nm} \mathrm{hr})^{-1}\right)\end{array}$ & $\begin{array}{c}\mathrm{CS} \\
\left(\mathrm{s}^{-1}\right)\end{array}$ & $\begin{array}{c}\mathrm{Q} \\
\left(\text { molecules } \mathrm{cm}^{-3} \mathrm{~s}^{-1}\right)\end{array}$ \\
\hline \multirow{5}{*}{ TP RF14 } & $3: 53-4: 00$ & 663 & 644 & 1 & $3.76 \mathrm{E}-02$ & $1.66 \mathrm{E}+06$ \\
& $3: 53-4: 00$ & 663 & 644 & 2 & $3.76 \mathrm{E}-02$ & $3.32 \mathrm{E}+06$ \\
& $3: 53-4: 00$ & 663 & 644 & 4 & $3.76 \mathrm{E}-02$ & $6.63 \mathrm{E}+06$ \\
\cline { 2 - 7 } & $4: 03-4: 15$ & 118 & 1221 & 2 & $3.59 \mathrm{E}-02$ & $3.16 \mathrm{E}+06$ \\
& $4: 19-4: 25$ & 155 & 1144 & 2 & $4.90 \mathrm{E}-02$ & $4.32 \mathrm{E}+06$ \\
\hline \multirow{5}{*}{ AA RF07 } & $1: 36-1: 45$ & 97 & 690 & 2 & $1.81 \mathrm{E}-02$ & $1.60 \mathrm{E}+06$ \\
& $4: 09-4: 12$ & 48 & 774 & 2 & $2.07 \mathrm{E}-02$ & $1.83 \mathrm{E}+06$ \\
\cline { 2 - 7 } & $4: 19-4: 22$ & 677 & 609 & 1 & $3.81 \mathrm{E}-02$ & $1.68 \mathrm{E}+06$ \\
& $4: 19-4: 22$ & 677 & 609 & 2 & $3.81 \mathrm{E}-02$ & $3.36 \mathrm{E}+06$ \\
& $4: 19-4: 22$ & 677 & 609 & 4 & $3.81 \mathrm{E}-02$ & $6.73 \mathrm{E}+06$ \\
\cline { 2 - 7 } & $5: 42-5: 44$ & 512 & 667 & 2 & $2.82 \mathrm{E}-02$ & $2.49 \mathrm{E}+06$ \\
\hline \multirow{5}{*}{ AA RF08 } & $1: 48-2: 05$ & 61 & 426 & 2 & $1.50 \mathrm{E}-02$ & $1.32 \mathrm{E}+06$ \\
& $6: 59-7: 01$ & 93 & 389 & 2 & $1.27 \mathrm{E}-02$ & $1.12 \mathrm{E}+06$ \\
\cline { 2 - 7 } & $7: 12-7: 14$ & 1295 & 295 & 1 & $1.11 \mathrm{E}-02$ & $4.91 \mathrm{E}+05$ \\
& $7: 12-7: 14$ & 1295 & 295 & 2 & $1.11 \mathrm{E}-02$ & $9.82 \mathrm{E}+05$ \\
& $7: 12-7: 14$ & 1295 & 295 & 4 & $1.11 \mathrm{E}-02$ & $1.96 \mathrm{E}+06$ \\
\hline
\end{tabular}


Table 7.3 - Volumetric increases to three types of aerosol size distributions based on the calculated sulfuric acid flux rates. The three distributions represent airmasses dominated by pollution (TRACE-P RF14), pollution with dust (ACE-Asia RF07) and dust (ACE-Asia RF06) as illustrated by the proportions of accumulation and coarse mode surface areas.

\begin{tabular}{|c|c|c|c|c|c|c|c|c|c|c|}
\hline Flight & Time & $\begin{array}{c}\mathrm{H}_{2} \mathrm{SO}_{4} \mathrm{Flux} \\
\left.\text { (molec. } \mathrm{cm}^{-3} \mathrm{~s}^{-1}\right)\end{array}$ & $\begin{array}{c}\text { Acc. SA } \\
\left(\mu \mathrm{m}^{2} \mathrm{~cm}^{-3}\right)\end{array}$ & $\begin{array}{c}\text { Coa. SA } \\
\left(\mu \mathrm{m}^{2} \mathrm{~cm}^{-3}\right)\end{array}$ & $\begin{array}{l}\text { Acc. Vol. } \\
\left(\mu \mathrm{m}^{3} \mathrm{~cm}^{-3}\right)\end{array}$ & $\begin{array}{l}\text { Coa. Vol. } \\
\left(\mu \mathrm{m}^{3} \mathrm{~cm}^{-3}\right)\end{array}$ & $\begin{array}{c}\text { New Acc. } \\
\text { Vol. } \\
\left(\mu \mathrm{m}^{3} \mathrm{~cm}^{-3}\right)\end{array}$ & $\begin{array}{c}\text { New Coa. } \\
\text { Vol. } \\
\left(\mu \mathrm{m}^{3} \mathrm{~cm}^{-3}\right)\end{array}$ & $\begin{array}{c}\% \text { Acc. Vol. } \\
\text { Increase }\end{array}$ & $\begin{array}{l}\% \text { Coa. Vol } \\
\text { Increase }\end{array}$ \\
\hline \multirow{3}{*}{ TP RF14 } & \multirow{3}{*}{$\begin{array}{l}4: 03 \\
-4: 15\end{array}$} & $5.00 \mathrm{E}+05$ & \multirow{3}{*}{1085} & \multirow{3}{*}{135.5} & \multirow{3}{*}{65.57} & \multirow{3}{*}{100.4} & 1.60 & 0.20 & 2.4 & 0.2 \\
\hline & & $1.00 E+06$ & & & & & 3.21 & 0.40 & 4.9 & 0.4 \\
\hline & & $2.00 \mathrm{E}+06$ & & & & & 6.42 & 0.80 & 9.8 & 0.8 \\
\hline \multirow{3}{*}{ AA RF07 } & \multirow{3}{*}{$\begin{array}{r}1: 36 \\
-1: 45\end{array}$} & $5.00 \mathrm{E}+05$ & \multirow{3}{*}{325.0} & \multirow{3}{*}{365.0} & \multirow{3}{*}{14.73} & \multirow{3}{*}{353.6} & 0.85 & 0.95 & 5.8 & 0.3 \\
\hline & & $1.00 E+06$ & & & & & 1.70 & 1.91 & 11.6 & 0.5 \\
\hline & & $2.00 \mathrm{E}+06$ & & & & & 3.40 & 3.82 & 23.2 & 1.1 \\
\hline \multirow{3}{*}{ AA RF06 } & \multirow{3}{*}{$\begin{array}{l}2: 00 \\
-2: 30\end{array}$} & $5.00 \mathrm{E}+05$ & \multirow{3}{*}{305.5} & \multirow{3}{*}{972.7} & \multirow{3}{*}{19.31} & \multirow{3}{*}{946.1} & 0.43 & 1.37 & 2.3 & 0.1 \\
\hline & & $1.00 E+06$ & & & & & 0.86 & 2.75 & 4.5 & 0.3 \\
\hline & & $2.00 \mathrm{E}+06$ & & & & & 1.73 & 5.49 & 9.1 & 0.6 \\
\hline
\end{tabular}




\subsection{Coagulation Rate of Nucleation Mode Particles}

In order to estimate particle losses due to coagulation we have selected the peak diameter of the nucleation mode particles and the maximum diameter of the nucleation mode particles to provide a measure of particle lifetime. The maximum nucleation mode diameter was chosen as the local minima between the nucleation mode particles and the remainder of the Aitken mode particles. We note that many of the particles will have substantially smaller coagulation rates as condensation shifts the size distribution to the right. More accurate modeling of the combined condensation/coagulation processes using a discreet or modal parameterization is needed and may be the focus of future work. Results for the calculation of CoagS for the same ten size distributions as used in the estimates for the condensational sink (Table 7.2) are summarized in table 7.4. The data shows that in the high surface area environment during ACE-Asia and TRACE-P the pollution derived accumulation mode aerosols and the naturally produced dust aerosols are effective at scavenging the observed nucleation mode particles on the order of one to two days. However, the lower surface area conditions in the East China Sea observed during ACE-Asia RF08 show that these secondary aerosols could persist in significant concentrations up to 72 hours after their formation.

In section 6.1 we mention that none of the nucleation mode particles observed over the Yellow Sea during ACE-Asia RF07 appear as distinct modes in the size distributions of RF08 despite our suggestion that we remained within the same airmass over the two-day period. Peak diameters of the nucleation mode particles at 10:00 UTC (19:00 JST) ${ }^{5}$ are between 25 and $40 \mathrm{~nm}$ (Figure 6.1). Size distributions from the Gosan surface site suggest that at 12:00 UTC (21:00 JST) the nucleation mode particles are $30-40 \mathrm{~nm}$ in diameter. If condensation overnight continued at a rate of $2 \mathrm{~nm} \mathrm{hr}^{-1}$ then at 0:00 UTC on April $13^{\text {th }}$ the same $30-40 \mathrm{~nm}$ particles should be $54-64 \mathrm{~nm}$ in diameter. No particles $50-70 \mathrm{~nm}$ in diameter form a distinct mode in the aerosol size distributions on April $13^{\text {th }}$.

In table 7.4 we see that particles smaller than $\sim 40 \mathrm{~nm}$ in diameter will be eliminated by coagulation within $\sim 24$ hours but that particles near $\sim 60 \mathrm{~nm}$ in diameter could exist for up to 48 hours for the size distributions measured on April $12^{\text {th }}$. We suggest two possible reasons for the absence of a distinct set of Aitken mode particles in the size distributions

\footnotetext{
${ }^{5}$ Sunset occurred at 19:10 and 19:11 JST for April $12^{\text {th }}$ and $13^{\text {th }}, 2001$.
} 
from April 13 ${ }^{\text {th }}$. Back trajectory analysis (Figure 4.3) shows most of the regional airmass sampled on April $13^{\text {th }}$ passed over the landmasses of South Korea or Japan. We suggest that mixing due to topography, nighttime clouds, as well as local inputs of primary aerosols and gas phase precursors have the potential to modify the aerosol size distribution affecting the survivorship of the newly formed secondary aerosols. Second, condensational growth rates overnight could not be estimated. Condensational growth could have been lower than $2 \mathrm{~nm}$ $\mathrm{hr}^{-1}$ and may even have been suspended overnight. If these particles remained small then the coagulation rates of the new secondary aerosols will remain high resulting in faster removal and their relative absence from the size distributions on April $13^{\text {th }}$.

Observationally we saw no evidence of the particles formed on April $12^{\text {th }}$ surviving to contribute a distinct population of new particle number in size distributions on April $13^{\text {th }}$. This suggests that the coagulation rate of these particles is sufficiently high to eliminate these particles in 16-24 hours. This is broadly consistent with the modeled e-folding times for size distribution in the Yellow Sea summarized in table 7.4. A more detailed analysis using a modal parameterization of the size distribution that incorporates condensation and coagulation in order to evaluate particle dynamics is necessary to make more conclusive statements about the fate of these secondary aerosols. 
Table 7.4 - Coagulation rates and e-folding times for the nucleation mode particles observed in size distributions from TRACE-P RF14 on March $18^{\text {th }}, 2001$ and for ACE-Asia RF07 and RF08 on April $12^{\text {th }}$ and $13^{\text {th }}, 2001$.

\begin{tabular}{|c|c|c|c|c|c|c|c|c|c|}
\hline \multirow[b]{2}{*}{ Flight } & \multirow[b]{2}{*}{$\begin{array}{c}\text { UTC Time } \\
\text { (hh:mm) }\end{array}$} & \multirow[b]{2}{*}{$\begin{array}{c}\text { Altitude } \\
\text { (m) }\end{array}$} & \multirow[b]{2}{*}{$\begin{array}{c}\text { Dry } \\
\text { ambient } \\
\mathrm{SA} \\
\left(\mu \mathrm{m}^{2} \mathrm{~cm}^{-3}\right)\end{array}$} & \multicolumn{3}{|c|}{$\mathrm{RH}=25 \%$} & \multicolumn{3}{|c|}{$\mathrm{RH}=75 \%$} \\
\hline & & & & $\begin{array}{c}\text { Dp } \\
(\mu \mathrm{m})\end{array}$ & $\begin{array}{c}\text { Coags for } \\
\text { peak Dp } \\
\left(\mathrm{s}^{-1}\right)\end{array}$ & $\begin{array}{c}\text { Dp e-fold } \\
\text { (hr) } \\
\end{array}$ & $\begin{array}{c}\text { Dp } \\
(\mu \mathrm{m}) \\
\end{array}$ & $\begin{array}{c}\text { Coags for } \\
\text { peak Dp } \\
\left(\mathrm{s}^{-1}\right)\end{array}$ & $\begin{array}{c}\text { Dp e-fold } \\
(h r)\end{array}$ \\
\hline \multirow{7}{*}{ TP RF14 } & \multirow{3}{*}{ 3:53-4:00 } & \multirow{3}{*}{663} & \multirow{5}{*}{1221} & 0.010 & $2.25 \mathrm{E}-04$ & 1.23 & 0.013 & $1.98 \mathrm{E}-04$ & 1.40 \\
\hline & & & & 0.021 & 5.33E-05 & 5.21 & 0.028 & 4.52E-05 & 6.15 \\
\hline & & & & 0.044 & 1.67E-05 & 16.6 & 0.058 & $1.31 \mathrm{E}-05$ & 21.2 \\
\hline & \multirow{2}{*}{$4: 03-4: 15$} & \multirow{2}{*}{118} & & 0.008 & $2.96 \mathrm{E}-04$ & 0.94 & 0.010 & $2.61 \mathrm{E}-04$ & 1.06 \\
\hline & & & & 0.025 & $3.74 \mathrm{E}-05$ & 7.43 & 0.028 & $3.66 \mathrm{E}-05$ & 7.58 \\
\hline & \multirow{2}{*}{$4: 19-4: 25$} & \multirow{2}{*}{155} & \multirow{2}{*}{1144} & 0.010 & $2.56 \mathrm{E}-04$ & 1.09 & 0.013 & $2.49 \mathrm{E}-04$ & 1.12 \\
\hline & & & & 0.021 & $6.88 \mathrm{E}-05$ & 4.04 & 0.028 & $5.65 \mathrm{E}-05$ & 4.91 \\
\hline \multirow{8}{*}{ AA RF07 } & \multirow{2}{*}{$1: 36-1: 45$} & \multirow{2}{*}{97} & \multirow{2}{*}{690} & 0.013 & $6.19 E-05$ & 4.49 & 0.016 & $5.82 \mathrm{E}-05$ & 4.77 \\
\hline & & & & 0.026 & $1.57 \mathrm{E}-05$ & 17.7 & 0.035 & 1.24E-05 & 22.5 \\
\hline & \multirow{2}{*}{ 4:09-4:12 } & \multirow{2}{*}{48} & \multirow{2}{*}{774} & 0.016 & $4.55 E-05$ & 6.11 & 0.021 & $3.63 E-05$ & 7.66 \\
\hline & & & & 0.035 & 1.19E-05 & 23.3 & 0.044 & $1.05 E-05$ & 26.6 \\
\hline & \multirow{2}{*}{$4: 19-4: 22$} & \multirow{2}{*}{677} & \multirow{2}{*}{609} & 0.023 & $5.48 \mathrm{E}-05$ & 5.07 & 0.028 & 5.42E-05 & 5.13 \\
\hline & & & & 0.058 & $5.36 \mathrm{E}-06$ & 51.8 & 0.063 & $6.11 \mathrm{E}-06$ & 45.5 \\
\hline & \multirow{2}{*}{$5: 42-5: 44$} & \multirow{2}{*}{512} & \multirow{2}{*}{667} & 0.026 & 3.24E-05 & 8.58 & 0.033 & $3.10 \mathrm{E}-05$ & 8.97 \\
\hline & & & & 0.054 & $6.42 \mathrm{E}-06$ & 43.2 & 0.063 & $6.45 \mathrm{E}-06$ & 43.0 \\
\hline \multirow{6}{*}{ AA RF08 } & \multirow{2}{*}{ 1:48-2:05 } & \multirow{2}{*}{61} & \multirow{2}{*}{426} & 0.014 & $4.35 E-05$ & 6.38 & 0.017 & $4.01 \mathrm{E}-05$ & 6.93 \\
\hline & & & & 0.028 & $1.21 \mathrm{E}-05$ & 22.9 & 0.035 & $1.08 \mathrm{E}-05$ & 25.8 \\
\hline & $6: 59-7: 01$ & 93 & 389 & 0.020 & $2.06 \mathrm{E}-05$ & 13.5 & 0.026 & $1.66 \mathrm{E}-05$ & 16.8 \\
\hline & $0.00-1.01$ & 50 & & 0.041 & $5.43 E-06$ & 51.2 & 0.054 & 4.31E-06 & 64.4 \\
\hline & $7 \cdot 12-7 \cdot 14$ & 1295 & 295 & 0.023 & 1.44E-05 & 19.4 & 0.028 & 1.34E-05 & 20.7 \\
\hline & & & & 0.041 & $4.80 \mathrm{E}-06$ & 57.9 & 0.054 & $3.86 \mathrm{E}-06$ & 72.0 \\
\hline
\end{tabular}




\subsection{Conclusions}

The ACE-Asia and TRACE-P aircraft observations provide the opportunity to study aerosol nucleation and growth over broad spatial and vertical scales. As the profiles show, these observations provide a different perspective from ground or ship based data obtained almost exclusively within $500 \mathrm{~m}$ thick "ocean boundary layer". After studying the profiles and their associated back trajectories, a number of "characteristics" related to secondary aerosol formation can be stated in regard to the "Asian outflow".

- As air is advected from the Asian mainland a shallow layer of evaporative cooling, termed the ocean boundary layer (OBL), often forms over the Yellow Sea and Sea of Japan. This layer may be associated with low-level fog over the ocean surface due to radiative cooling during cloud free subsidence events or due to differences in air and sea-surface temperatures.

- The OBL appears stably stratified and tends to trap local pollution along with gas phase precursors $\left(\mathrm{SO}_{2}, \mathrm{H}_{2} \mathrm{SO}_{4}\right.$, and possibly $\mathrm{NH}_{3}$ ) below $\sim 500 \mathrm{~m}$.

- At the steep gradient of aerosol surface area, relative humidity and temperature associated with the OBL/MBL interface, peak concentrations of $\mathrm{SO}_{2}$ and nucleation mode $(3-12 \mathrm{~nm})$ particles are often observed. The high concentrations of secondary aerosols are consistent with binary nucleation or ternary nucleation in high relative humidity conditions near the OBL/MBL interface.

- Somewhat lower concentrations of nucleation mode particles are often present throughout the MBL. These particles appear well mixed and linked to one or more of the following conditions.

a) Particles formed at the OBL/MBL interface are transported by mixing from the surface throughout the MBL due to convective cells and turbulent eddies.

b) Formation of secondary aerosols by a ternary nucleation mechanism is occurring throughout the MBL. Reductions in precursor concentrations with altitude appear somewhat offset by decreasing ambient temperature and increasing relative humidity allowing secondary aerosol formation to occur throughout the column. 
c) Particle formation is favoured near the MBL inversion in cool, high relative humidity conditions.

- Secondary aerosol formation was observed on a synoptic scale over a two-day period after up to 48 hours of transport from the gas phase precursor source regions.

Under post-frontal outflow conditions we observed growth rates for the nucleation mode particles of 2.4 and $1.7 \mathrm{~nm} \mathrm{hr}^{-1}$ aboard the C-130 during ACE-Asia flights 7 and 8 . These were consistent with ground based and ship based measurements for the same time period. Applying this growth rate to a subset of size distributions from TRACE-P and ACEAsia an average sulfuric acid flux rate of $2.4+/-1.2 \times 10^{6}$ molecules $\mathrm{cm}^{-3} \mathrm{~s}^{-1}$ was obtained. This value represents an upper bound for the estimate of sulfuric acid flux as the accumulation mode aerosol suggests that ammonia and possibly low vapour pressure organics may also condense on the aerosol size distribution. This value is within a factor of two of Weber et al. [submitted 2002] who estimated sulfuric acid production rates of 0.5 $2.0 \times 10^{6}$ molecules $\mathrm{cm}^{-3} \mathrm{~s}^{-1}$ during TRACE-P flight 14. Calculations using the Weber et al. flux rates correspond to increases of the accumulation aerosol volume of $2.4-9.8 \%$ and 2.3 $-9.1 \%$ for area distributions dominated by accumulation mode and coarse mode aerosols respectively. Coarse mode aerosol shows volume increases of $0.2-0.8 \%$ and $0.1-0.6 \%$ for the same two scenarios.

The influence of fog and high $\mathrm{RH}$ was also shown to dramatically influence the formation, growth and survival of new nuclei. Figures 8.1 and 8.2 are conceptual diagrams of the processes believed to cause and/or influence the formation of secondary aerosols in the ACE-Asia and TRACE-P study regions. The figures are representative in nature and aerosol particles and atmospheric structure are not drawn to scale. 


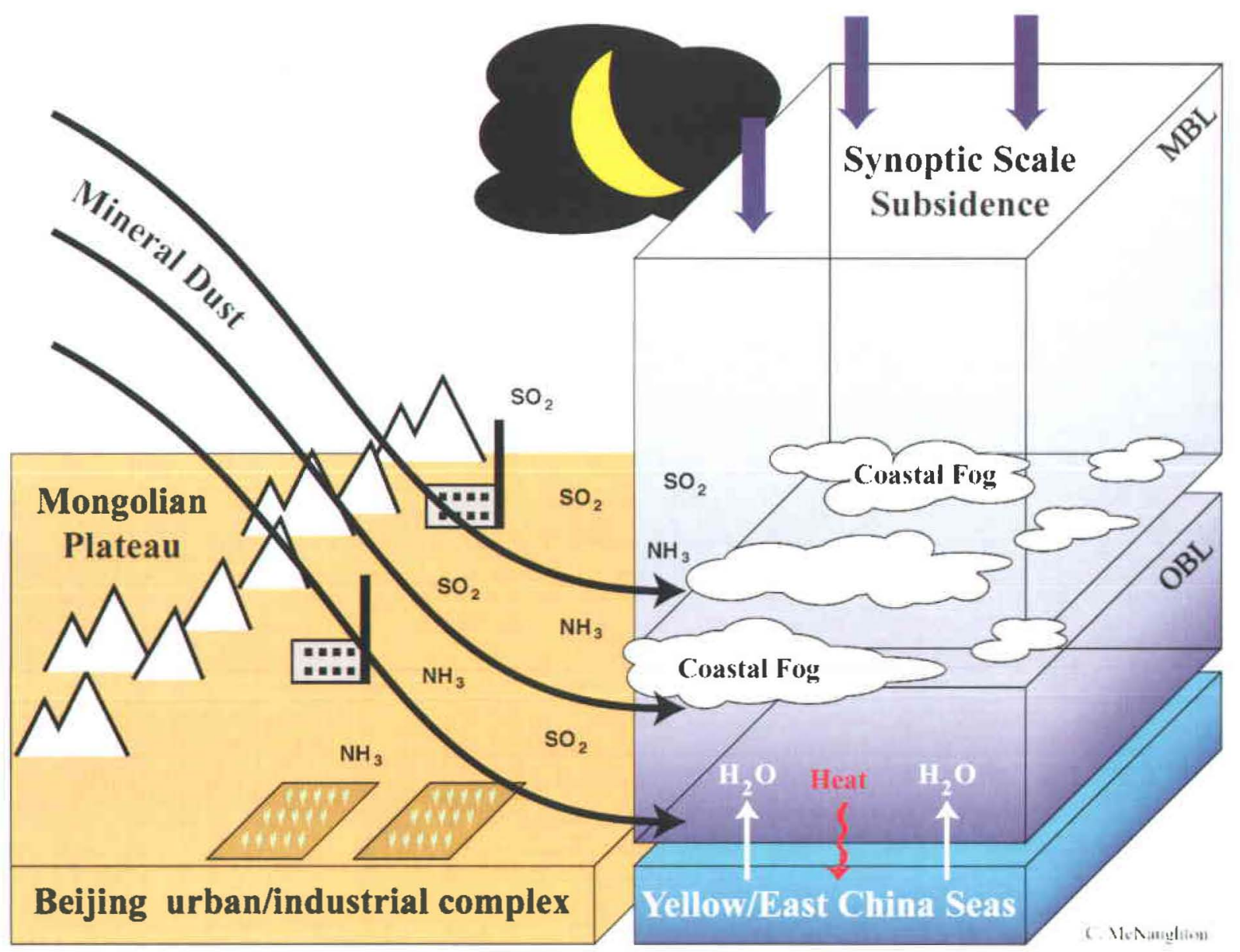

Figure 8.1 - Physical and meteorological conditions leading to synoptic scale secondary aerosol formation during spring in East Asia.

1. Cool dry continental air from Central Asia warms and dries further as it descends into the coastal plains of Mainland China.

2. The Beijing-Tianjin urban/industrial complex supplies $\mathrm{SO}_{2}$ and $\mathrm{NH}_{3}$ gases to the atmosphere through burning of high sulfur coal (power production and heating) and urban/agricultural activities. These gases are the dominant precursors for secondary aerosol formation.

3. Synoptic scale subsidence in the wake of passing cold fronts leads to cloud free conditions and a well-defined marine boundary layer inversion located at $2000 \mathrm{~m} \mathrm{(+/-}$ $500 \mathrm{~m})$.

4. The extremely dry air moves out over coastal water bodies with sea surface temperatures lower than the ambient air temperatures. Overnight the formation of coastal fog creates an isolated layer of evaporative cooling between the surface and $500 \mathrm{~m}(+/-200 \mathrm{~m})$. The OBL is separated from the remainder of the MBL by a miniature inversion in potential temperature. 


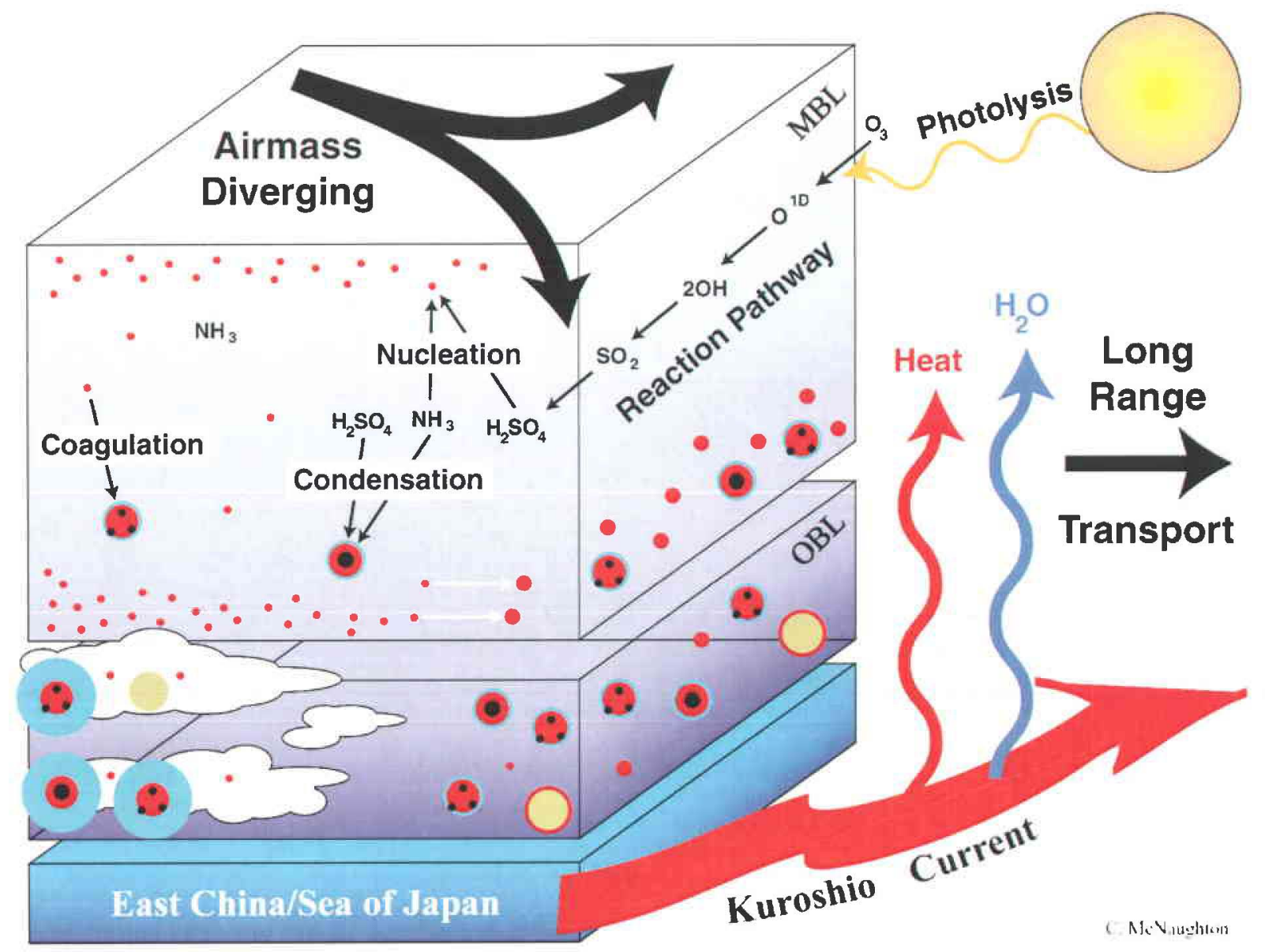

Figure 8.2 - Interactions between primary and secondary aerosols in continental outflow from East Asia.

5. At sunrise $\mathrm{SO}_{2}$ is oxidized to $\mathrm{H}_{2} \mathrm{SO}_{4}$ through photochemically produced $\mathrm{OH}$. The high $\mathrm{RH}$ environment above the fog and near the MBL inversion leads to new particle production and rapid condensational grow of both new particles and existing primary aerosols.

6. While fog persists gas phase precursors are directly converted to aerosol mass by aqueous phase chemistry within the fog layer. Any nucleation mode particles are quickly scavenged in the high surface area, high relative humidity environment. By late morning/early afternoon the fog has dissipated leaving high aerosol surface areas and low concentrations of nucleation mode particles and gas phase precursors.

7. The $\mathrm{OBL}$ and MBL appear to remain intact until reaching warm surface waters associated with the Kuroshio Current. The high heat and vapour flux from the ocean surface to the atmosphere destabilizes the OBL and leads to mixing and increased homogeneity throughout the MBL.

8. New secondary aerosols can form after up to 48 hours of transport from Mainland China and may be important for up to 72 hours after forming. Cloud formation and precipitation are the dominant mechanisms for removing new particles that do not coagulate with the primary aerosol before growing (through condensation) to accumulation mode sizes. 
Using a simple Brownian coagulation scheme, e-folding times for the peak diameters of the nucleation mode particles was 1-21 hours under cloud free conditions in the pollution dominated environment encountered on March $18^{\text {th }}, 2001$ during TRACE-P flight 14 . Efolding times for nucleation mode particles under cloud free conditions were between 4.5 and 52 hours for ACE-Asia flight 7 (April 12 $2^{\text {th }}$ ) and between 6.5 and 72 hours for flight 8 (April $13^{\text {th }}$ ). As airmasses are advected away from Asian source regions and while gas phase precursor concentrations are sufficient to trigger nucleation events, coagulation rates of secondary aerosols will continue to decline and secondary aerosols have increasing potential to survive as new aerosol number over the Pacific Ocean. 


\subsection{References}

Aalto, P., K. Hameri, E. Becker, R.J. Weber, J. Salm, J.M. Makela, C. Hoell, C.D. O'Dowd, H. Karlsson, H.-C. Hansson, M. Vakeva, I.K. Koponen, and G. Buzorius, Physical characterization of aerosol particles during nucleation events, Tellus, 53B, 344-358, 2001.

Albrecht, B.A., Aerosols, Cloud Microphysics, and Fractional Cloudiness, Science, 245, 1227-1230, 1989.

Anderson, T.L., D.S. Covert, S.F. Marshall, M. L. Laucks, R.J. Charlson, A.P. Waggoner, J.A. Ogren, R. Caldow, R. Holm, F. Qyant, G. Sem, A. Wiedensohler, N.A. Ahlquist, and T.S. Bates, Performance characteristics of a high-sensitivity, three-wavelength, total scatter/backscatter nephelometer, Journal of Atmospheric Oceanic Technology, 13, 967-986, 1996.

Anderson, T.L., and J.A. Ogren, Determining aerosol radiative properties using a TSI 3563 integrating nephelometer, Aerosol Science and Technology, 29, 57-69, 1998.

Ball, S.M., D.R. Hanson, F. Eisele, and P.H. McMurry, Laboratory studies of particle nucleation: Initial results for $\mathrm{H}_{2} \mathrm{SO}_{4}, \mathrm{H}_{2} \mathrm{O}$, and $\mathrm{NH}_{3}$ vapors, Journal of Geophysical Research, 104 (D19), 23709-23718, 1999.

Birmili, W., and A. Wiedensohler, New particle formation in the continental boundary layer: Meteorological and gas phase parameter influence, Geophysical Research Letters, 27 (20), 3325-3328, 2000.

Birmili, W., A. Wiedensohler, C. Plass-Dulmer, and H. Berresheim, Evolution of newly formed aerosol particles in the continental boundary layer: a case study including $\mathrm{OH}$ and $\mathrm{H}_{2} \mathrm{SO}_{4}$ measurements, Geophysical Research Letters, 27 (15), 2205-2208, 2000.

Buzorius, G., C.S. McNaughton, A.D. Clarke, D.S. Covert, B.W. Blomquist, K. Nielsen, S.C. Yoon, A. Zelenyuk, D. Imre, and F. Brechtel, Secondary aerosol formation in continental outflow conditions during ACE-Asia, submitted 2003.

Buzorius, G., U. Rannik, E.D. Nilsson, and M. Kulmala, Vertical fluxes and micrometeorology during aerosol particle formation events, Tellus, 53B (4), 394-405, 2001.

Carmichael, G.R., Y. Tang, G. Kurata, I. Uno, D.G. Streets, N. Thongboonchoo, J.H. Woo, S. Guttikunda, A. White, T. Wang, D.R. Blake, E. Atlas, A. Fried, B. Potter, M.A. Avery, G.W. Sachse, S.T. Sandholm, Y. Kondo, R.W. Talbot, A.R. Bandy, A.D. Clarke, and Heikes, Evaluating Regional Emissions Estimates using TRACE-P Observations, Journal of Geophysical Research, submitted 2002.

Chung, Y.S., H.S. Kim, and M.B. Yoon, Observations of visibility and chemical compositions related to fog, mist and haze in South Korea, Water, Air and Soil Pollution, 111, 139-157, 1999.

Clarke, A.D., A Thermo-optic technique for in-situ analysis of size-resolved aerosol physicochemistry, Atmospheric Environment, 25A (3/4), 635-644, 1991.

Clarke, A.D., W.G. Collins, P.J. Rasch, C.N. Kapustin, K. Moore, S. Howell, and H.E. Fuelberg, Dust and pollution transport on global scales: Aerosol measurements and model predictions, Journal of Geophysical Research, 106 (D23), 32555-32569, 2001. 
Clarke, A.D., and V.N. Kapustin, A Pacific Aerosol Survey. Part I: A decade of data on particle production, transport, evolution, and mixing in the troposphere, Journal of the Atmospheric Sciences, 59 (3), 363-382, 2002.

Clarke, A.D., V.N. Kapustin, F.L. Eisele, R.J. Weber, and P.H. McMurry, Particle production near marine clouds: Sulfuric acid and predictions from classical binary nucleation, Geophysical Research Letters, 26 (16), 2425-2428, 1999.

Clarke, A.D., J.L. Varner, F. Eisele, R.L. Mauldin, D. Tanner, and M. Litchy, Particle production in the remote marine atmosphere: Cloud outflow and subsidence during ACE-1, Journal of Geophysical Research, 103 (D13), 16397-16409, 1998.

Easter, R.C., and L.K. Peters, Binary Homogeneous Nucleation: Temperature and Relative Humidity Fluctuations, Nonlinearity, and Aspects of New Particle Production in the Atmosphere, Journal of Applied Meteorology, 33, 775-784, 1994.

Eisele, F.L., and D.J. Tanner, Measurements of the gas phase concentration of $\mathrm{H}_{2} \mathrm{SO}_{4}$ and methane sulfonic acid and estimates of $\mathrm{H}_{2} \mathrm{SO}_{4}$ production and loss in the atmosphere., Journal of Geophysical Research, 98, 9001-9010, 1993.

Fuelberg, H.E., C.M. Kiley, J.R. Hannan, D.J. Westberg, M.A. Avery, and R.E. Newell, Meteorological conditions and transport pathways during the Transport and Chemical Evolution over the Pacific (TRACE-P) Experiment, Journal of Geophysical Research, submitted 2002.

Hannan, J.R., H. Fuelberg, E., J.H. Crawford, G.W. Sachse, and D.R. Blake, The Role of Wave Cyclones in Transporting Boundary Layer Air to the Free Troposphere during the Spring 2001 NASA/TRACE-P Experiment, Journal of Geophysical Research, submitted 2002.

Hanson, D.R., and F.L. Eisele, Measurement of prenucleation molecular clusters in the $\mathrm{NH}_{3}$, $\mathrm{H}_{2} \mathrm{SO}_{4}, \mathrm{H}_{2} \mathrm{O}$ system, Journal of Geophysical Research, 107 (D12), 2002.

Hegg, D.A., and P.V. Hobbs, Cloud water chemistry and the production of sulfates in clouds, Atmospheric Environment, 15 (9), 1597-1604, 1981.

Hoppel, W.A., J.W. Fitzgerald, G.M. Frick, R.E. Larson, and B.J. Wattle, Preliminary investigation of the role that DMS and cloud cycles play in the fromation of the aerosol size distribution, Naval Research Laboratory, Washington, DC, 1987.

Hoppel, W.A., G.M. Frick, and R.E. Larson, Effects of non-precipitating clouds on the aerosol size distribution in the marine boundary layer, Geophysical Research Letters, 13, 125-128, 1986.

Huebert, B.J., T.S. Bates, P.B. Russell, G. Shi, Y.J. Kim, K. Kawamura, G.R. Carmichael, and T. Nakajima, An overview of ACE-Asia: strategies for quantifying the relationships between Asian aerosols and their climatic impacts, Journal of Geophysical Research, submitted 2003.

Husar, R.B., D.M. Tratt, B.A. Schichtel, S.R. Falke, F. Li, D. Jaffe, S. Gasso, T. Gill, N.S. Laulainen, F. Lu, M.C. Reheis, Y. Chun, D. Westphal, B.N. Holben, C. Gueymard, I. McKendry, N. Kuring, G.C. Feldman, C. McClain, R.J. Frouin, J.T. Merrill, D. DuBois, F. Vignola, T. Murayama, S. Nickovic, W.E. Wilson, K. Sassen, N. Sugimoto, and W.C. Malm, Asian dust events of April 1998, Journal of Geophysical Research, 106 (D16), 18317-18330, 2001.

IPCC, Third Assessment Report - Climate Change 2001, edited by D.L. Albritton, and L.G.M. Filho, 2001. 
Jacob, D.J., J.H. Crawford, M.M. Kleb, V.E. Connors, R.J. Bendura, J.L. Raper, G.W. Sachse, J.C. Gille, L. Emmons, and C.L. Heald, The Transport and Chemical Evolution over the Pacific (TRACE-P) Aircraft Mission: design, execution and first results, Journal of Geophysical Research, submitted 2002.

Jaecker-Voirol, A., and P. Mirabel, Heteromolecular nucleation in the sulfuric acid-water system, Atmospheric Environment, 23 (9), 2053-2057, 1989.

Janson, R., K. Rosman, A. Karlsson, and H.-C. Hansson, Biogenic emissions and gaseous precursors to forest aerosols, Tellus, 53B (4), 423-440, 2001.

Kerminen, V.-M., and A.S. Wexler, Particle formation due to $\mathrm{SO}_{2}$ oxidation and high relative humidity in the remote marine boundary layer, Journal of Geophysical Research, 99 (D12), 25,607-25614, 1994a.

Kerminen, V.-M., and A.S. Wexler, Post-fog nucleation of $\mathrm{H}_{2} \mathrm{SO}_{4}-\mathrm{H}_{2} \mathrm{O}$ particles in smog, Atmospheric Environment, 28 (15), 2399-2406, 1994 b.

Kerminen, V.-M., and A.S. Wexler, Enhanced formation and development of sulfate particles due to marine boundary layer circulation, Journal of Geophysical Research, 100 (D11), 23,051-23,062, 1995.

Kulmala, M., M. Dal Maso, J.M. Makela, L. Pirjola, M. Vakeva, P. Aalto, P. Miikkulainen, K. Hameri, and C.D. O'Dowd, On the formation, growth and composition of nucleation mode particles, Tellus, $53 B(4), 479-490,2001$.

Kulmala, M., P. Korhonen, I. Napari, A. Karlsson, H. Berresheim, and C.D. O'Dowd, Aerosol formation during PARFORCE: Ternary nucleation of $\mathrm{H}_{2} \mathrm{SO}_{4}, \mathrm{NH}_{3}$, and $\mathrm{H}_{2} \mathrm{O}$, Journal of Geophysical Research, 2002.

Kulmala, M., L. Pirjola, and J.M. Makela, Stable sulphate clusters as a source of new atmospheric particles, Nature, 404 (6773), 66-69, 2000.

Kunz, G.J., G.d. Leeuw, E. Becker, and C.D. O'Dowd, Coastal new particle formation: Environmental conditions and aerosol physicochemical characteristics during nucleation bursts, Journal of Geophysical Research, 2002.

Leaitch, W.R., J.W. Bottenheim, T.A. Biesenthal, S.-M. Li, P.S.K. Liu, K. Asalian, H. Dryfhout-Clark, F. Hopper, and F. Brechtel, A case study of gas-to-particle conversion in an eastern Canadian forest, Journal of Geophysical Research, 104 (D7), 8095-8111, 1999.

Liu, H., D.J. Jacob, I. Bey, R.M. Yantosca, B.N. Duncan, and G.W. Sachse, Transport pathways for Asian combustion outflow over the Pacific: Interannual and seasonal variability, Journal of Geophysical Research, submitted 2002.

Mari, C., M. Evans, P. Palmer, D.J. Jacob, G.W. Sachse, J. Escobar, and D. Gazen, The effect of clean warm conveyor belts on the export of pollution from East Asia, Journal of Geophysical Research, submitted 2002.

Marti, J.J., R.J. Weber, M.T. Saros, J.G. Vasiliou, and P.H. McMurry, Modification of the TSI 3025 condensation particle counter for pulse height analysis, Aerosol Science and Technology, 25 (2), 214-218, 1996.

McNeal, R.J., D.J. Jacob, D.D. Davis, and S.C. Liu, The NASA Global Tropospheric Experiment: recent accomplishments and future plans, IGACtivities Newsletter, 2-18, 1998.

Merrill, J.T., R.E. Newell, and A.S. Bachmeier, A meteorological overview for the Pacific Exploratory Mission-West Phase B, Journal of Geophysical Research, 102 (D23), 28241-28253, 1997. 
Moore, K.G., A.D. Clarke, V.N. Kapustin, C.S. McNaughton, B.E. Anderson, E.L. Winstead, R.J. Weber, Y. Ma, Y.N. Lee, R.W. Talbot, J. Dibb, T. Anderson, S. Masonis, D.S. Covert, and D. Rogers, A comparison of similar aerosol measurements made on the NASA P3-B, DC-8 and NSF C-130 aircraft during TRACE-P and ACE-Asia, Journal of Geophysical Research, submitted 2003.

Nilsson, E.D., and M. Kulmala, The potential for atmospheric mixing to enhance the binary nucleation rate, Journal of Geophysical Research, 103 (D1), 1381-1389, 1998.

Nilsson, E.D., J. Paatera, and M. Boy, Effects of Air Masses and Synoptic Weather on Aerosol Formation in the Continental Boundary Layer, Tellus, 53B, 462-478, 2001.

Orsini, D., and R.J. Weber, A Particle-Into-Liquid Sampler (PILS) for measurements of water soluble fine aerosol chemistry, Atmospheric Environment, 2002.

Pirjola, L., C.D. O'Dowd, I.M. Brooks, and M. Kulmala, Can new particle formation occur in the clean marine boundary layer?, Journal of Geophysical Research, 105 (D21), $26,531-26,546,2000$.

Raes, F., R.V. Dingenen, E. Vignati, J. Wilson, J.P. Putaud, J.H. Seinfeld, and P. Adams, Formation and cycling of aerosols in the global troposphere, Atmospheric Environment, 34, 4215-4240, 2000.

Saros, M.T., R.J. Weber, J.J. Marti, and P.H. McMurry, Ultrafine aerosol measurement using a condensation nucleus counter with pulse height analysis, Aerosol Science and Technology, 25 (2), 200-213, 1996.

Seinfeld, J.H., and S.N. Pandis, Atmospheric Chemistry and Physics, John Wiley \& Sons, Inc., New York, 1998.

Streets, D.G., T.C. Bond, G.R. Carmichael, S.D. Fernandes, Q. Fu, D. He, Z. Klimont, S.M. Nelson, N.Y. Tsai, M.Q. Wang, J.H. Woo, and K.F. Yarber, An inventory of gaseous and primary aerosol emissions in Asia in the year 2000, Journal of Geophysical Research, submitted 2002.

Thornton, D., A.R. Bandy, F.H. Tu, B.W. Blomquist, G.M. Mitchell, W. Nadler, and D.H. Lenschow, Fast airborne sulfur dioxide measurements by atmospheric pressure ionization mass spectrometry (APIMS), Journal of Geophysical Research, In press, 2002.

Tomczak, M., and J.S. Godfrey, Regional Oceanography: An Introduction, Pergamon, New York, 1994.

TSI, I., Model 3760 Condensation Nucleus Counter Instruction Manual, TSI Incorporated, St. Paul, Minnesota, 1986.

TSI, I., Model 3010 Condensation Particle Counter Instruction Manual, TSI Incorporated, St. Paul, Minnesota, 1992.

TSI, I., Model 3025 A Ultrafine Condensation Particle Counter Instruction Manual, TSI Incorporated, St. Paul, Minnesota, 1996.

Twomey, S., Pollution and the Planetary Albedo, Atmospheric Environment, 8, 1251-1256, 1974.

Uno, I., H. Amano, S. Emori, K. Kinoshita, I. Matsui, and N. Sugimoto, Trans-Pacific yellow sand transport observed in April 1998: A numerical simulation, Journal of Geophysical Research, 106 (D16), 18331-18344, 2001.

Verheggen, B., and M. Mozurkewich, Determination of nucleation and growth rates from observation of an $\mathrm{SO}_{2}$ induced atmospheric nucleation event, Journal of Geophysical Research, 107 (D11), 2002. 
Weber, R.J., G. Chen, D.D. Davis, R.L. Mauldin, D.J. Tanner, F.L. Eisele, A.D. Clarke, D.C. Thornton, and A.R. Bandy, Measurements of enhanced $\mathrm{H}_{2} \mathrm{SO}_{4}$ and 3-4 nm particles near a frontal cloud during the First Aerosol Characterization Experiment (ACE-1), Journal of Geophysical Research, 106 (D20), 24107-24117, 2001a.

Weber, R.J., S. Lee, G. Chen, B. Wang, V.N. Kapustin, K. Moore, A.D. Clarke, L. Mauldin, E. Kosciuch, C. Cantrell, F. Eisele, D. Thornton, A.R. Bandy, G.W. Sachse, and H.E. Fuelberg, New Particle Formation in Anthropogenic Plumes Advecting from Asia observed during TRACE-P, Journal of Geophysical Research, submitted 2002.

Weber, R.J., J.J. Marti, P.H. McMurry, F.L. Eisele, D.J. Tanner, and A. Jefferson, Measurements of new particle formation and ultrafine particle growth rates at a clean continental site, Journal of Geophysical Research, 102 (D4), 4375-4385, 1997.

Weber, R.J., P.H. McMurry, R.L. Mauldin, D.J. Tanner, F.L. Eisele, F.J. Brechtel, S.M. Kreidenweis, G.L. Kok, R.D. Schillawski, and D. Baumgardner, A study of new particle formation and growth involving biogenic and trace gas species measured during ACE-1, Journal of Geophysical Research, 103 (D13), 16385-16396, 1998a.

Weber, R.J., P.H. McMurry, R.L. Mauldin, D.J. Tanner, F.L. Eisele, A.D. Clarke, and V.N. Kapustin, New particle formation in the remote troposphere: A comparison of observations at various sites, Geophysical Research Letters, 26 (3), 307-310, 1999.

Weber, R.J., D. Orsini, Y. Duan, Y.N. Lee, P.J. Klotz, and F. Brechtel, A particle-into-liquid collector for rapid measurements of aerosol bulk chemical composition, Aerosol Science and Technology, 35, 718-727, 2001b.

Weber, R.J., M. Stolsenburg, S. Pandis, and P.H. McMurry, Inversion of the UCNC pulse height distributions to obtain ultrafine $(\sim 3-10 \mathrm{~nm})$ particle size distributions, Journal of Aerosol Science, 29, 601 615, $1998 \mathrm{~b}$.

Wexler, A.S., L.F. W., and J.H. Seinfeld, Modeling urban and regional aerosols, 1, Model development, Atmospheric Environment, 28, 531-546, 1994.

Wilemski, G., Composition of the critical nucleus in multicomponent vapor nucleation, Journal of Chemical Physics, 80 (3), 1370-1372, 1984.

Zhang, D., G.-Y. Shi, Y. Iwasaka, and M. Hu, Mixture of sulfate and nitrate in coastal atmospheric aerosols: Individual particle studies in Qingdao $\left(36^{\circ} 04^{\prime} \mathrm{N}, 120^{\circ} 21^{\prime} \mathrm{E}\right)$, China, Atmospheric Environment, 34, 2669-2679, 1999.

Zhang, S.-H., Y. Akutsu, L.M. Russell, R.C. Flagan, and J.H. Seinfeld, Radial Differential Mobility Analyzer, Aerosol Science and Technology, 23, 357-372, 1995. 


\subsection{Appendix A - DMA Corrections}

10.1 Multiplication Factors for Transmission Efficiency

During ACE-Asia RF01 and RF02 the C-130 and the NASA P3-B conducted two intercomparison flights (TRACE-P RF17 \& RF018). DMA and OPC size distributions from the flights showed excellent agreement [Moore et al., submitted 2003]. Corrections to the TRACE-P DMA size distributions were calculated from a field evaluation of the transmission efficiency. Using the TRACE-P values as benchmark a comparison between the size distributions from the $\mathrm{P} 3-\mathrm{B}$ and the $\mathrm{C}-130$ during the intercomparison flight was completed. The results from the intercomparison flights resulted in three possible curves for adjusting the ACE-Asia size distributions to correct for transmission efficiency losses. These curves are shown in figure 10.1 below. The TRACE-P correction curve is shown for comparison.

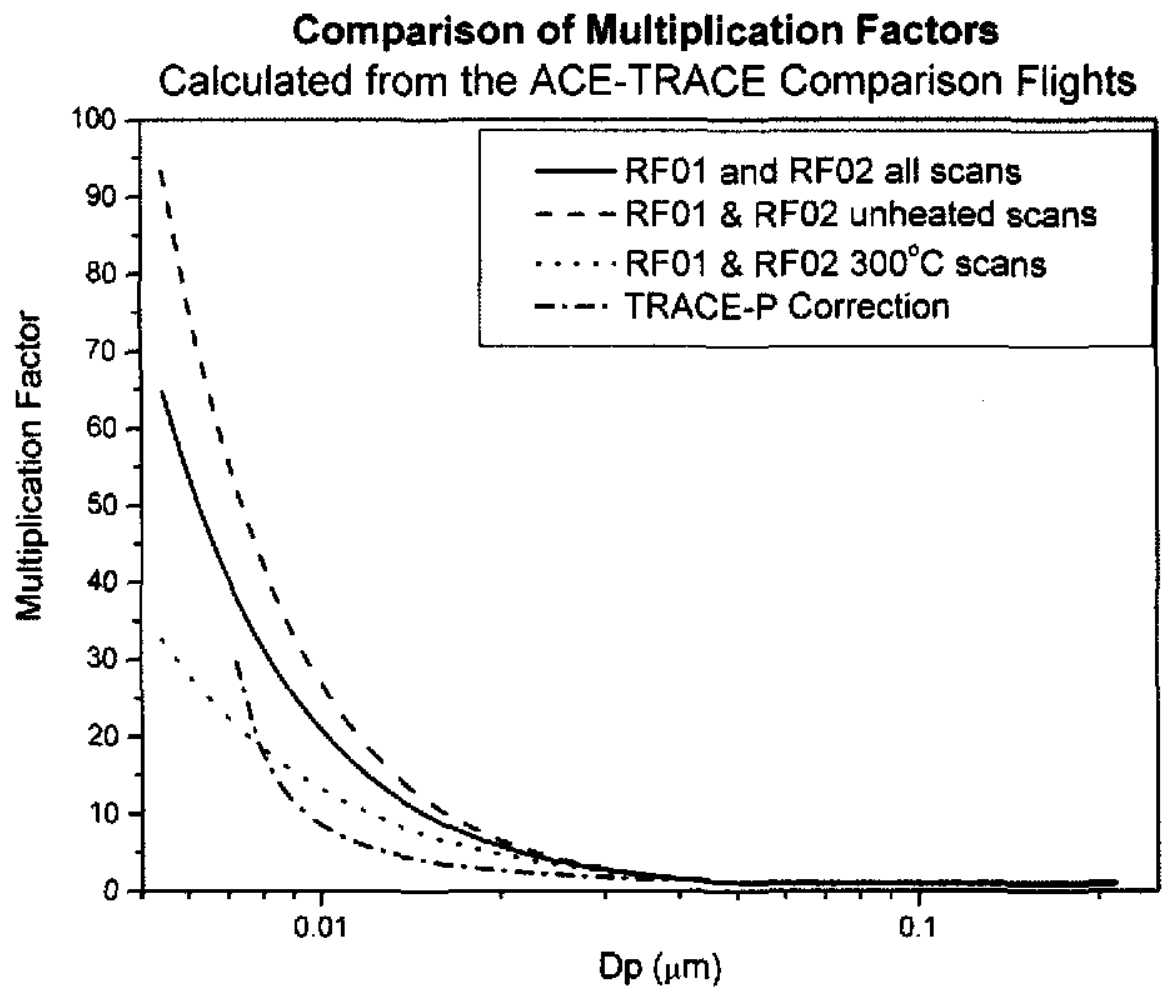

Figure 10.1 - Comparison of the transmission efficiency curves applied to the rDMA data sets for ACE-Asia and TRACE-P. 
Results from histogram analysis of the total concentration using each of the three multiplication factor curves showed that the best fit to the UCN and $\mathrm{CN}$ data was for the "RF01 and RF02 all scans" curve (solid black line). This curve was applied to the dry ambient and $150^{\circ} \mathrm{C}$ scans. The multiplication factor curve was arbitrarily not applied to the $300^{\circ} \mathrm{C}$ due to the relatively large uncertainty of the charge correction after heating to $300^{\circ} \mathrm{C}$. Shifts to the size distribution after heating to $150^{\circ} \mathrm{C}$ are substantially less and the multiplication factor was applied with some confidence. However, since no $\mathrm{CN}$ counter operated at $150^{\circ} \mathrm{C}$ there is no measure of error associated with this calculation. Based on the histograms for the $300^{\circ} \mathrm{C}$ scans (Figures 3.3 and 3.4) we see that the size distribution measurements are undercounting the $\mathrm{UH}$ Hot $\mathrm{CN}$ by about $25 \%$ for both TRACE-P and ACE-Asia. This suggests that some counting efficiency multiplication factor could be applied but that the curves obtained by comparing the two instruments were not adequate. As this portion of the analysis is not important to the discussion of the nucleation mode particles measured at dry ambient conditions no further corrections were made to the $300^{\circ} \mathrm{C}$ scans.

\subsection{Heated Charging Correction}

During October of 2002 a set of laboratory experiments were conducted in order to evaluate how the heated $\left(150^{\circ} \mathrm{C}\right.$ and $\left.300^{\circ} \mathrm{C}\right)$ size distributions were being sized. This investigation was required due to the inability of the DMA inversion program to correct for changes to particle diameters during the heating process. This effect can be summarized as:

- Particle sizing is based on a boltzman distribution of charges being applied by the polonium neutralizer ( $\beta$-source) to the particles entering the DMA.

- For unheated size distributions (dry ambient) this distribution is a known function and is correctly applied.

- Each particle is charged prior to heating to $150^{\circ} \mathrm{C}$ or $300^{\circ} \mathrm{C}$.

- The charge distribution for the heated particles is based on their size before heating and the DMA inversion program assumes that particles have the same charge distribution as the unheated particles.

- Since particles do not lose their charge but do shrink in size (stripped of volatile mass) the particles have a slightly higher charge to mass ratio and the total number counted per channel $(\mathrm{dN} / \mathrm{d} \operatorname{logDp})$ will be higher than some "true" value. 
In order to quantify this effect a number of laboratory experiments were undertaken in order to evaluate this effect on the $150^{\circ} \mathrm{C}$ and $300^{\circ} \mathrm{C}$ scans. Sequentially performing scans with the neutralizer fore and aft of the heating process allowed us to evaluate the effects of heating on the size distribution. Differences between the distributions using the standard configuration ( $\mathrm{dN} / \mathrm{d}_{\log } \mathrm{Dp}$ Orig) and the configuration with the neutralizer aft of the heaters $\left(\mathrm{dN} / \mathrm{d}_{\log } \mathrm{Dp}\right.$ Neut) allow us to empirically derive the correction factor. A fifth-order polynomial fit was calculated and the results are shown in figure 10.2.

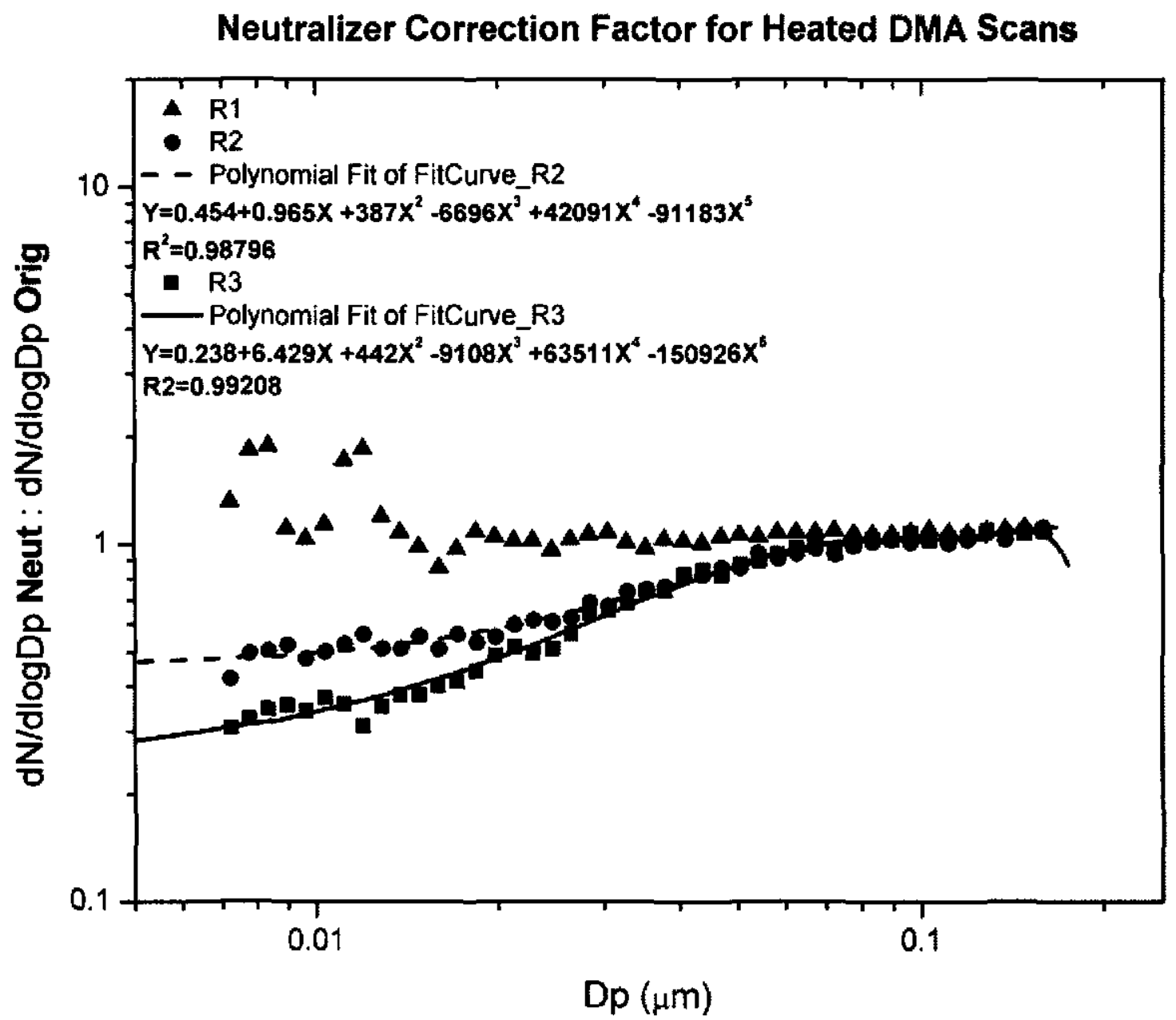

Figure 10.2 - Neutralizer charging correction factor based upon laboratory experiments and applied to the ACE-Asia and TRACE-P rDMA size distributions. 


\subsection{Applying Correction Factors to the DMA Size Distributions}

In addition to the correction factors outlined above, size distributions were corrected to standard atmospheric temperature and pressure (SATP, $298.15^{\circ} \mathrm{K}, 101325 \mathrm{~Pa}$ ). All of the corrections were applied simultaneously to the DMA size distributions using a MATLAB code called $A C E \_d m a \_M F \_v e r 5 b . m$. This code is included below.

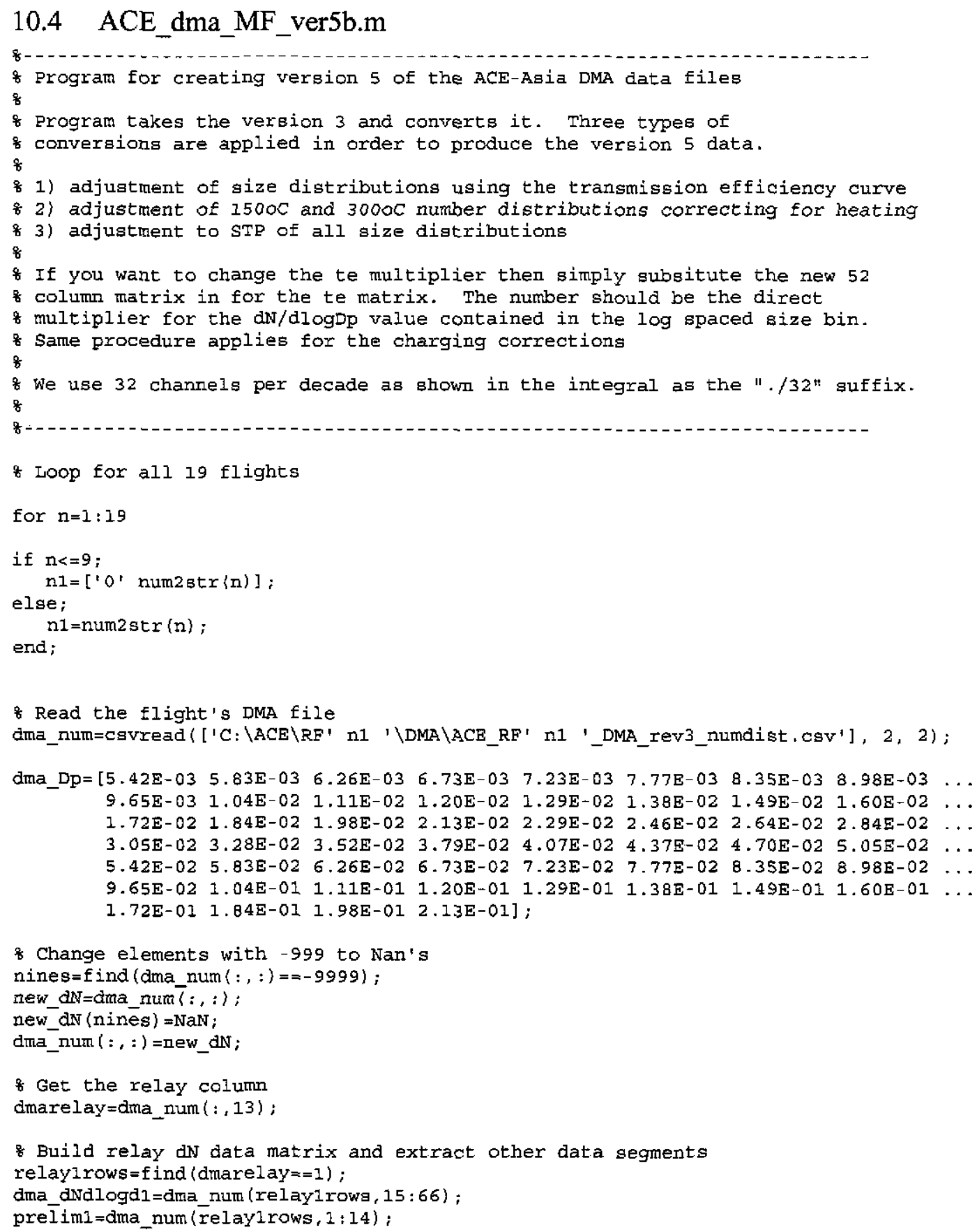


flags1=dma_num (relaylrows , 70);

relay 2 rows $=$ find $($ dmarel $a y==2)$;

dma_dNdlogd2=dma_num (relay2 rows, 15:66) ;

prēim2=dma num (relay2rows, $1: 14)$;

flags2=dma_num (relay2rows, 70);

relay3rows $=$ find (dmare 1 ay $==3$ ) ;

dma_dNdlogd3=dma_num (relay3rows, $15: 66)$;

prēim $3=d m a$ num $($ relay 3 rows , $1: 14)$.

flags $3=d m a \_n u m ~(r e l a y 3 r o w s, ~ 70)$;

\& End of build dN data matrix

Apply transmission efficiency (te) MF

8 count the rows so we can take other data segments and make a multiplier matrix

rowcount $1=$ size (relay1rows, 1$)$;

rowcount $2=$ size (relay2rows, 1 );

rowcount $3=$ size (relay3rows, 1 );

\& $\mathrm{MF}=10^{\wedge}(-1.3481 * \log \mathrm{Dp}-1.6796)$

\& Derived from ACE RF01 only

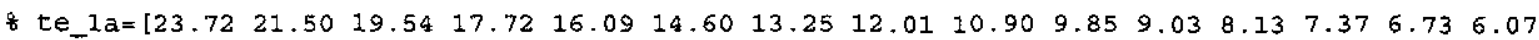
$5.515 .00 \quad 4.57 \quad 4.14 \quad 3.75 \quad 3.40 \quad 3.092 .81 \quad 2.54 \quad 2.31 \quad 2.09 \ldots$

$8 \quad 1.901 .721 .571 .421 .291 .171 .061 .001 .001 .001 .001 .001 .001 .001 .001 .001 .00$

$1.001 .001 .001 .001 .001 .001 .001 .001 .001 ;$

\& $\mathrm{MF}=10^{\wedge}(-1.8603 * \log (\mathrm{col}(\mathrm{Dp}))-2.4041)$

Derived from ACE RFO1 and RFO2 all scans

te_12 $=\left[\begin{array}{lllllllllllll}64.765 & 56.549 & 49.537 & 43.296 & 37.892 & 33.140 & 28.986 & 25.317 & 22.145 & 19.267 & 17.068 & 14.764\end{array}\right.$

$12.905 \quad 11.384 \quad 9.870 \quad 8.645 \quad 7.557 \quad 6.666 \quad 5.816 \quad 5.073 \quad 4.437 \ldots$ $\begin{array}{lllllllllllllllllllllll}3.884 & 3.406 & 2.973 & 2.603 & 2.274 & 1.994 & 1.738 & 1.522 & 1.334 & 1.165 & 1.019 & 1 & 1 & 1 & 1 & 1 & 1 & 1 & 1 & 1 & 1\end{array}$

11111111111113 ;

to $M F=10^{\wedge}(-1.4835 * \log (\operatorname{Col}(\mathrm{Dp}))-1.8488)$

\& Derived from ACE RFO1 and RFO2 $3000 \mathrm{C}$ scans

\& te_3 $=\left[\begin{array}{lllllllllllllll}32.570 & 29.230 & 26.302 & 23.623 & 21.241 & 19.088 & 17.155 & 15.400 & 13.841 & 12.386 & 11.245 & 10.017\end{array}\right.$

$\begin{array}{lllllllllllll}8.998 & 8.141 & 7.266 & 6.537 & 5.872 & 5.313 & 4.765 & 4.276 & 3.840 & 3.453 & \ldots\end{array}$

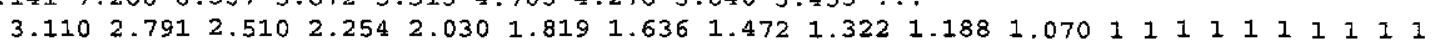

$\left.\begin{array}{lllllllllll:}1 & 1 & 1 & 1 & 1 & 1 & 1 & 1 & 1\end{array}\right]$

\& Apply the te to relays 1,2 and 3

MF $1=$ repmat (te_12, rowcount 1,1 );

MF2 = repmat (te_12, rowcount 2, 1);

\& $M F 3=$ repmat (te_3, rowcount 3,1 );

: Make the new dN values

dma_dNdlogdl=MFl .*dma_dNdlogdl;

dma dNdlogd2=MF2 . *dma dNdlogd2;

dma_dNdlogd $3=M F 3$ * *dma_dNdlogd 3 ;

$\%$ End MF

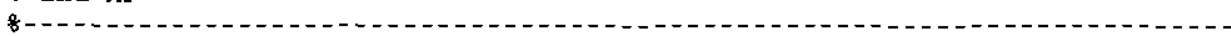

\& Apply charging correction (this correction applies only to the $1500 \mathrm{C}$ and $3000 \mathrm{C}$

o scans). The corrections stems from the inability of the DMA inversion program

s to know the original size of the charged particle and the associated shift in

o particle size after heating. The result is a false boltzman charge distribution

of being assigned to particle sizes. The correction factor was determined by CMc

8 during laboratory trials in Oct. of 2002 . - CMC - 10/28/02

charge $2=\left[\begin{array}{llllllllll}0.47885 & 0.47885 & 0.47885 & 0.47885 & 0.47885 & 0.48194 & 0.48541 & 0.48936 & 0.49376 & 0.4987\end{array}\right.$

$\begin{array}{lllllllllllll}0.50422 & 0.51043 & 0.51736 & 0.52513 & 0.53388 & 0.54346 & 0.55418 & 0.56605 & 0.57921 & 0.59367 & 0.50951\end{array}$

$0.62672 \ldots$

$\begin{array}{llllllllllll}0.64556 & 0.66584 & 0.68766 & 0.71086 & 0.73552 & 0.76136 & 0.78813 & 0.81558 & 0.84346 & 0.87109\end{array}$

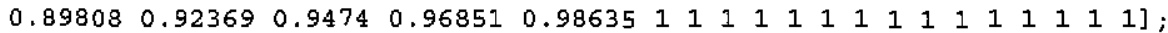




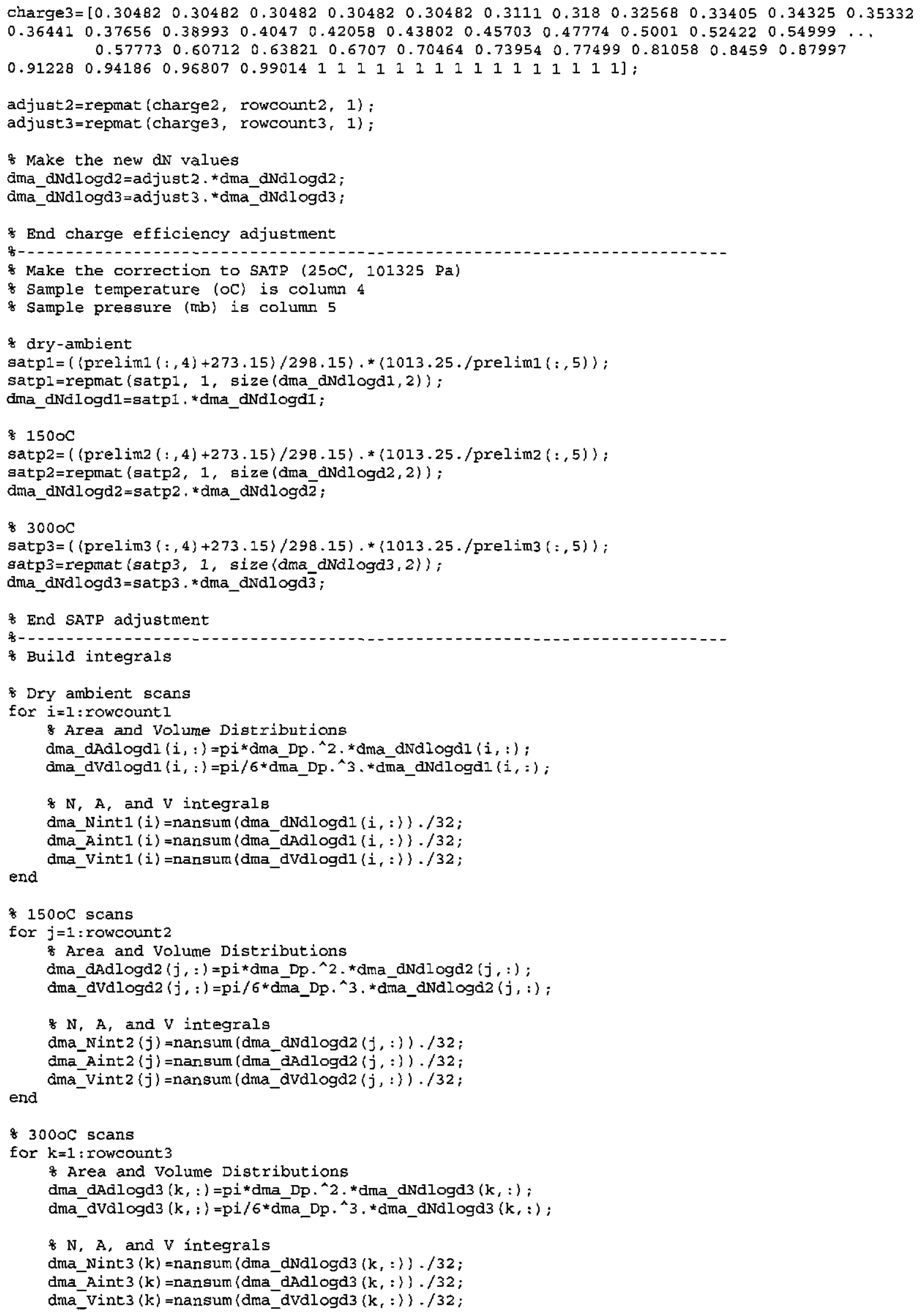




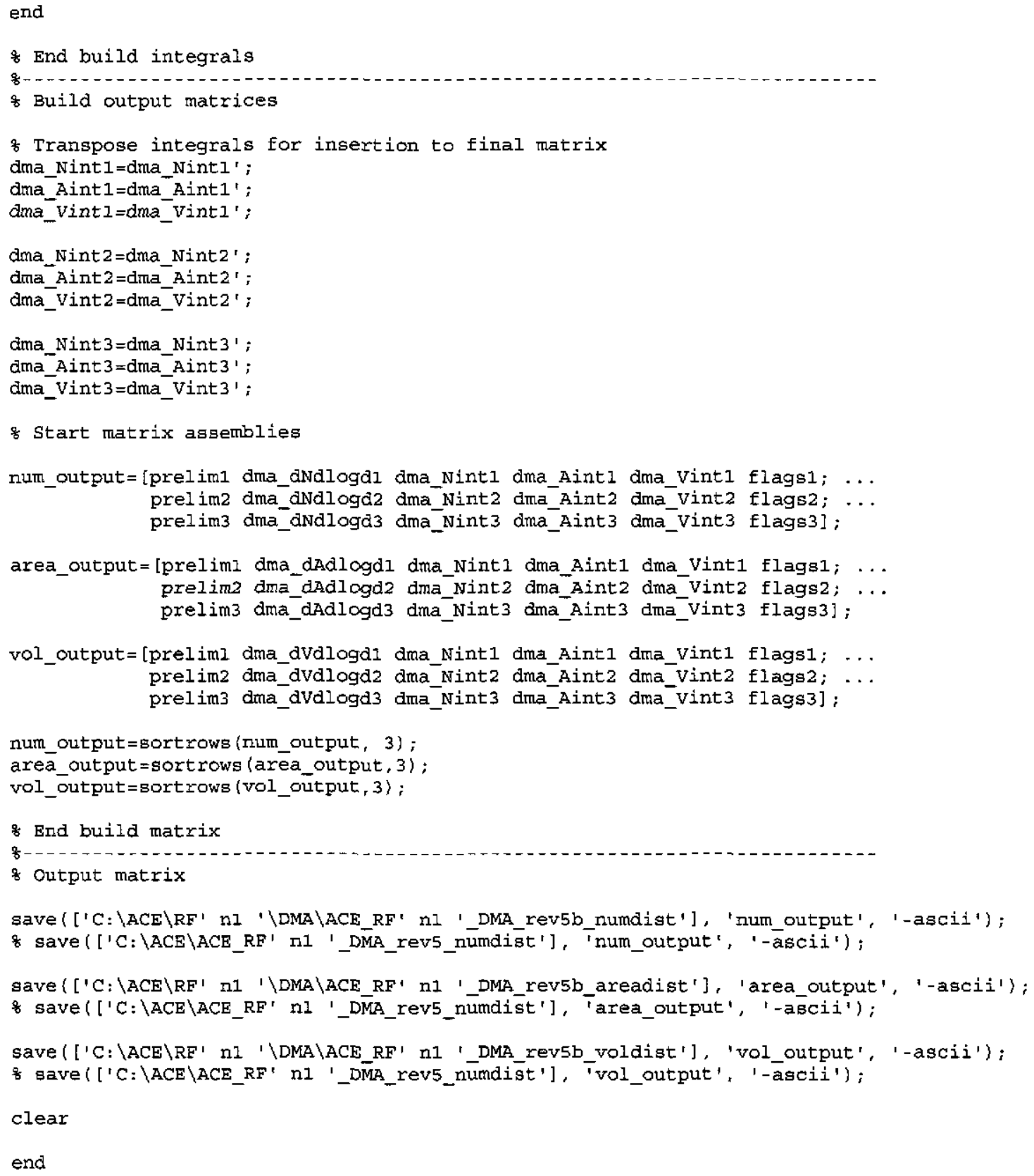




\subsection{Appendix B - MATLAB Size Distribution Function}

Radial DMA and OPC number size distributions can be combined and then integrated to produce the second and third moments (area and volume distributions). In order to facilitate this process two codes, $A C E$ sizedist_2dplot_ver $5 . m$ and TRACE_sizedist_2dplot_ver5.m were created. Both of the MATLAB functions need flight number, start time, stop time, maximum plotting values for the y-axis of the number, area and volume distribution, as well as a smoothing switch in order to run. The start and stop times correspond to the period of time that the user is interested in combining distributions over. This can be a short period of time or over a level leg. The total number of scans for the rDMA and the OPC are contained in a small matrix located in the volume panel (panel 3) of the $2 \mathrm{~d}$ plot. In order to facilitate identical plotting ranges, the option to include maxima for the number, area and volume distributions are available. If smoothing is desired the boxfilt.m function is invoked in order to apply a 5 bin smoothing to the rDMA distribution and a 19 bin smoothing for the OPC distributions. The selection of 5 bins and 19 bins is based on the logarithmically spaced bins for each instrument such that,

$\frac{19}{5}(32 D M A c h a n n e l s p e r d e c a d e) \approx 112$ OPCchannelsperdecade .

The rDMA and OPC size distributions overlap between 0.100 and $0.213 \mathrm{~mm}$. Over this region the joindists. $m$ function is invoked. This function can be tailored to weight the averaging. In our application the weighting is such that $50 \%$ weighting is applied at the bin occupying the centroid of the logarithmic spacing between 0.100 and $0.213 \mathrm{~mm}$. The

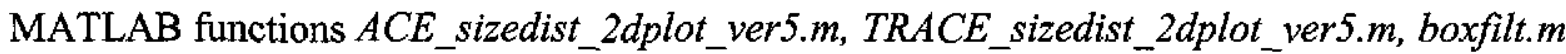
and joindists.m follow. 


\subsection{ACE_sizedist_2dplot_ver5.m}

function ACE_sizedist_2dplot_ver5( $f_{n}$, starthour, stophour, ymaxN, ymaxA, ymaxV, smooth)

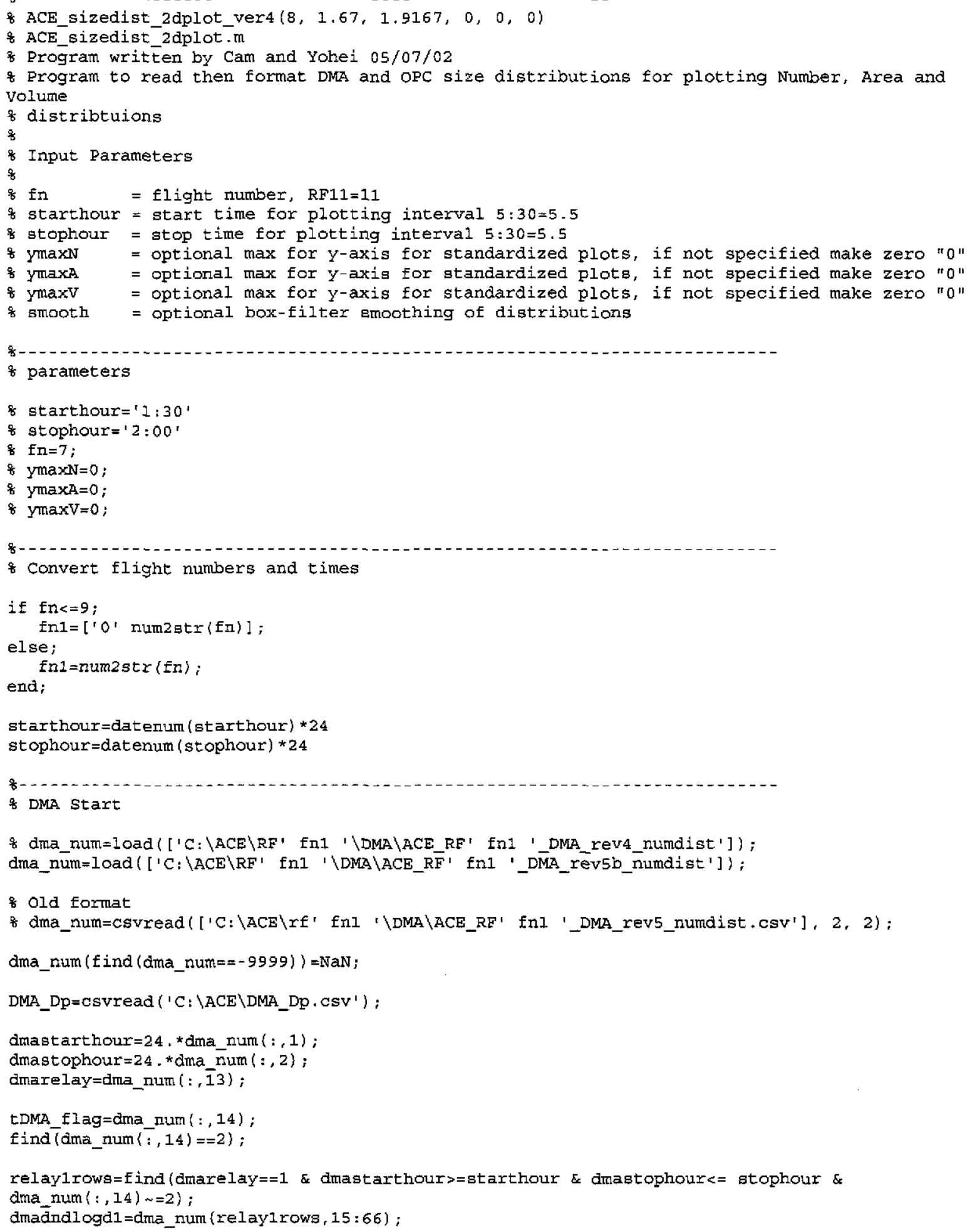


relay 2 rows $=$ find (dmarelay $==2$ \& dmastarthour $>=$ starthour \& dmastophour $<$ stophour \& dma num $(:, 14) \sim=2)$;

dmadndlogd2 =dma_num (relay2 rows , $15 ; 66$ );

relay3rows=find (amarelay==3\& dmastarthour>=starthour \& dmastophour<= stophour \& dima_num $(:, 14) \sim=2\rangle$;

dmadndlogd3=dma_num (relay3rows, 15:66) ;

\% Number distribution

if size (dmadndlogd1,1) $==1$;

dN_meandmar $1=$ dmadndlogd1;

elseif size (dmadndlogdl, 1 ) $==0$;

dN_meandmaRl $=\operatorname{repmat}(\mathrm{NaN}, 1,52)$;

else;

dN_meandmaRl $=$ narmean $($ madndlogdl $)$; end;

if size (dmadndlogd 2,1$)= \pm 1$;

dN meandmaR2 $=$ dmadndlogd2 ;

elseif size (dmadndlogdz, 1 ) $==0$;

dN meandmaR $2=$ repmat $($ NaN $, 1,52)$;

else;

dN_meandmaR2=nanmean (dmadndlogd2) ;

* Check for vector which doesn't plot properly end

if $s i z e($ dmadndlogd 3,1$)==1$

dN_meandmaR3 $=$ dmadndlogd 3 ;

elseif size (dmadndlogd3,1) ==0 ;

dN_meandmaR3 $=$ repmat $(\mathrm{NaN}, 1,52)$;

else;

dN_meandmaR3 =nanmean ( dmadndlogd3) ;

of Also check for empty, make it 'Nan'

음 Otherwise, fine end

\& Check for vector which doesn't plot properly

\% Also check for empty, make it 'Nan'

o otherwise, fine

\& Check for vector which doesn't plot properly

if Also check for empty, make it 'Nan'

of Otherwise, fine

\& End DMA

start OPC

opc_ap = opcdiams (112);

\& load distributions

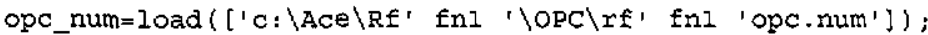

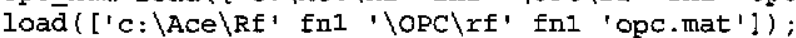

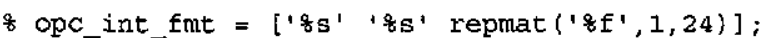

\& [opc date1, ope date2, opc temp, opc RH, Dcut, Ntot, Ndma, Nacc, Nsubhalf, Nsubum, Nsubaē̃o, Nsublo, Atot, Adma, Aacc, Asūbhalf, Asubum ...

\% Asubaero, Asub10, Vtot, Vdma, Vacc, Vsubhalf, Vsubum, Vsubaero, Vsub10] =

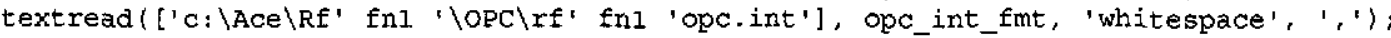

start: [388x1 double]

stop: [388x1 double]

relay: [388x1 double]

refvolt: [388x1 double]

$\mathrm{RH}$ : $[388 \times 1$ double]

$T$ : [388x1 double]

p: $[388 \times 1$ double

minidx: [388x1 double]

minak: [388xl double]

Ntot: [388x1 double]

Ndma : [388x1 double]

Nacc: [388x1 double]

Nsubhalf: [388x] double]

Nsubum: [388x1 double]

Nsubaero: [388x] double]

Nsub10: [388 1 double]

Atot: [388x1 double]

Adma: [388x1 double]

Aacc: [388x1 double]

Asubhalf: [388x1 double]

Asubum: [388x1 double]

date and time (will need to convert to dec hour)

date and time (will need to convert to dec hour)

dry-ambient, 1500C, 3000C

at the OPC

at the OPC

at the OPC

Total number distribution

Number $>0.2$ um

Number < Dcut

Number $<0.52$ um (median Dcut)

Number < 1 um

Number < $0.75 \mathrm{um}$ (about 1 um aerodynamic)

Number $<10 \mathrm{um}$

Area (same series as number) 
\& End smoothing

\& Call the "joindists.m" function to merge DMA and OPC size distributions

$\%$ if nargin $<8$

읭 8 max $D M A=\max (D M A D p) ;$

$\frac{8}{8}$ min_oPC $=\min \left(\mathrm{opc} \_\mathrm{dp}\right)$;

if के \& end

웅 웅 8

\% क क 'mindiam', [min(DMA_Dp) min_OPC], 'maxdiam', [max_DMA max (opc_dp)],

\& \& keyboard

[diam, dNdlogDpI] = joindists(DMA_Dp, dN_meandmaRl, opc_dp, dN_meanopcRl, 'overlap', 'smooth') :

[diam, dNdlogDp2] = joindists(DMA_Dp, dN_meandmaR2, opc_dp, dN_meanopcR2, 'overlap', 'smooth' ) ;

[diam, dNdlogDp3] = joindists(DMA_Dp, dN_meandmaR3, opc_dp, dN_meanopcR3, 'overlap', 'smooth') ;

\% Use "getdlogDp.m" function in order to compute new number integrals

dlogDp=getdlogd (diam);

\& Number integrals

Nint $1=$ nansum (alogDp. * dNdlogDpl);

Nint $2=$ nansum (dlogDp. *dNdlogDp2) ;

Nint $3=$ nansum ( $d \log D p . * d N d \log D p 3)$;

\& Use "dN2dA.m" function to create area distribution

dAdlogDpl =dN $2 \mathrm{dA}$ (diam, dNdlogDpl);

dAdlogDp2 $=\mathrm{dN} 2 \mathrm{dA}$ (diam, dNdlogDp2)

dAdlogDp $3=d N 2 d A(d i a m, d N d l o g D p 3) ;$

\% Area Integrals

Aint 1 =nansum (dlogDp . *dAdlogDpl) ;

Aint 2 =nansum ( $d \log D \mathrm{p} . * d A d \log D \mathrm{p} 2$ ) ;

Aint $3=$ nansum ( $d \log D p$. * dAdlogDp3) ;

o Use "dN2dV.m" function to create volume distribution

dVdlogDp1=dN2dV (diam, dNdlogDp1) ;

dVdlogDp2 $=d N 2 d V(d i a m, d N d l \circ g D p 2)$.

dVdlogDp3 =dN2dV (diam, dNdlogDp3) ;

\% Volume Integrals

Vint $1=$ nansum ( $d \log D p . * d V d \log D p 1)$;

vint 2 =nansum (dlogDp. *dvdlogDp2) ;

vint $3=$ nansum ( $\operatorname{llog} \mathrm{Dp} . * \mathrm{dVd} \log \mathrm{Dp} 3)$;

Fnd call the "joindista.m"

Get CN data to check accuracy of integrals

load ([' $\mathrm{C}: \backslash \mathrm{ACE} \backslash \mathrm{ACE}$ C130_MergeV4.mat '])

\% Convert time coordinates

cnhour $=\bmod ($ data . UTC_Time, 1);

o select only time interval from flight of interst

CNrows=find (data.Flight_Number $==$ fn \& cnhour $>=($ starthour $/ 24)$ \& cnhour $<=($ stophour $/ 24)$;

* Construct means and standard deviations of the $\mathrm{CN}$ data for the time interval

meanUCN=nanmean (data UHC UCN (CNrows) ) ;

stdevUCN=nanstd (data. UHC_UCN (CNrows) ) ;

meanRAF cn=nanmean (data.NC_CONCN (CNrows)) ;

stdevRAFCn=nanstd (data.NC_CONCN (CNrowa));

meanCNcold=nanmean (data. UHC CNcold (CNrows));

stdevCNCold=nanstd (data. UHC_CNCold (CNrows));

meancNhot $=$ nanmean $($ data. UHC_CNhot $($ CNrows $))$; 


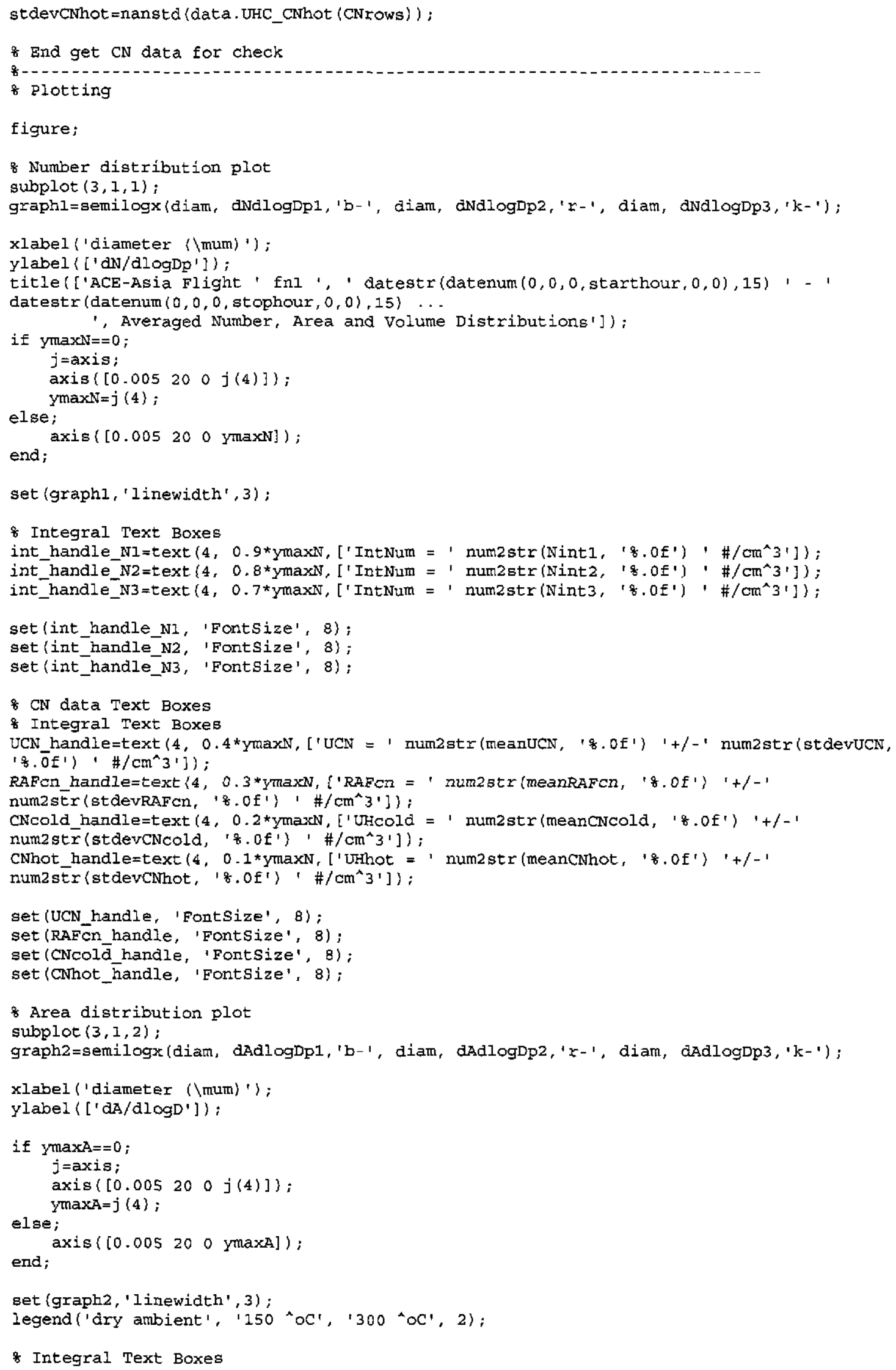

* Integral Text Boxes 


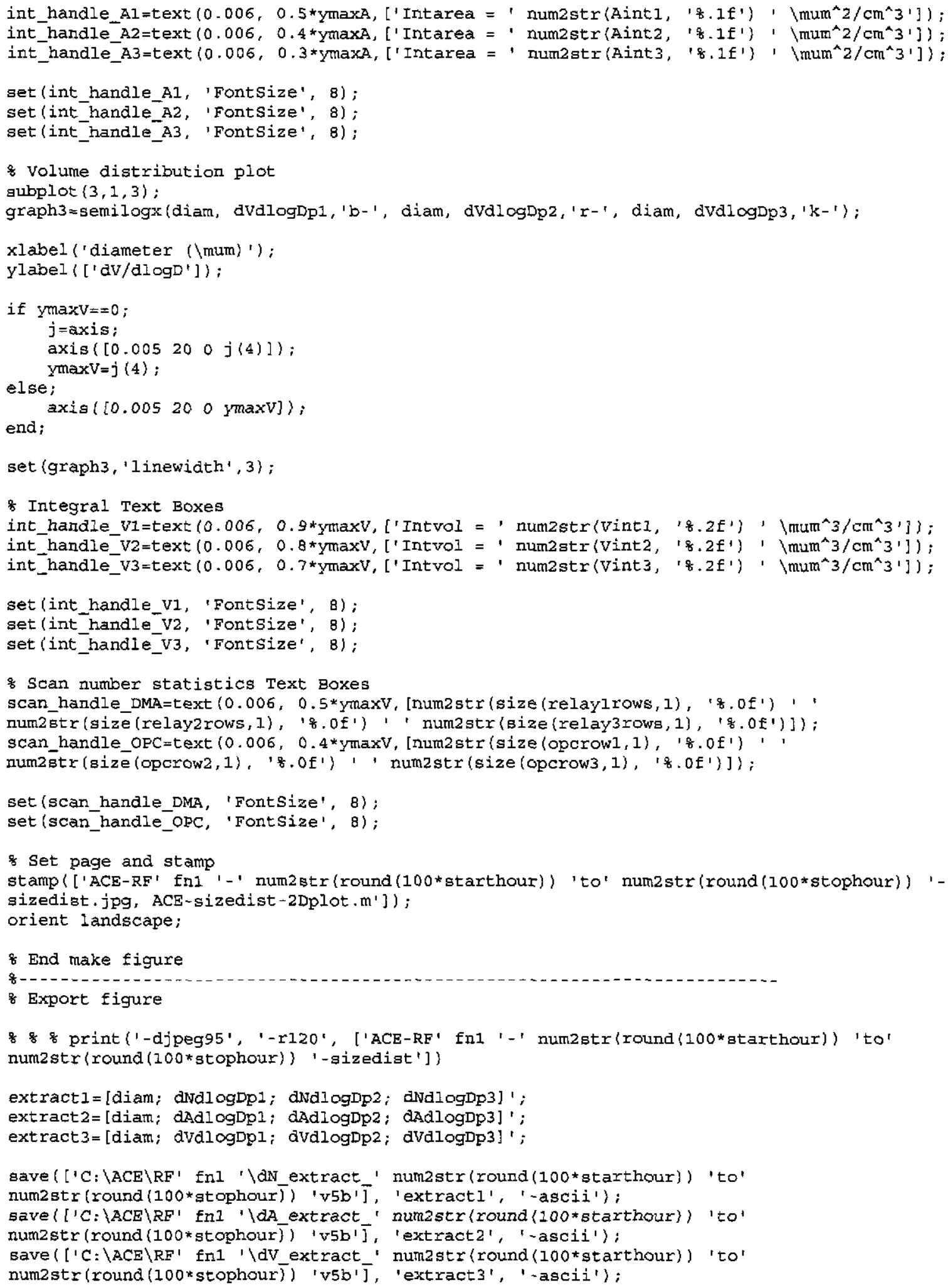




\subsection{TRACE_sizedist_2dplot_ver5.m}

function TRACE_sizedist_2dplot_ver5(fn, starthour, stophour, ymaxN, ymaxA, ymaxv, smooth)

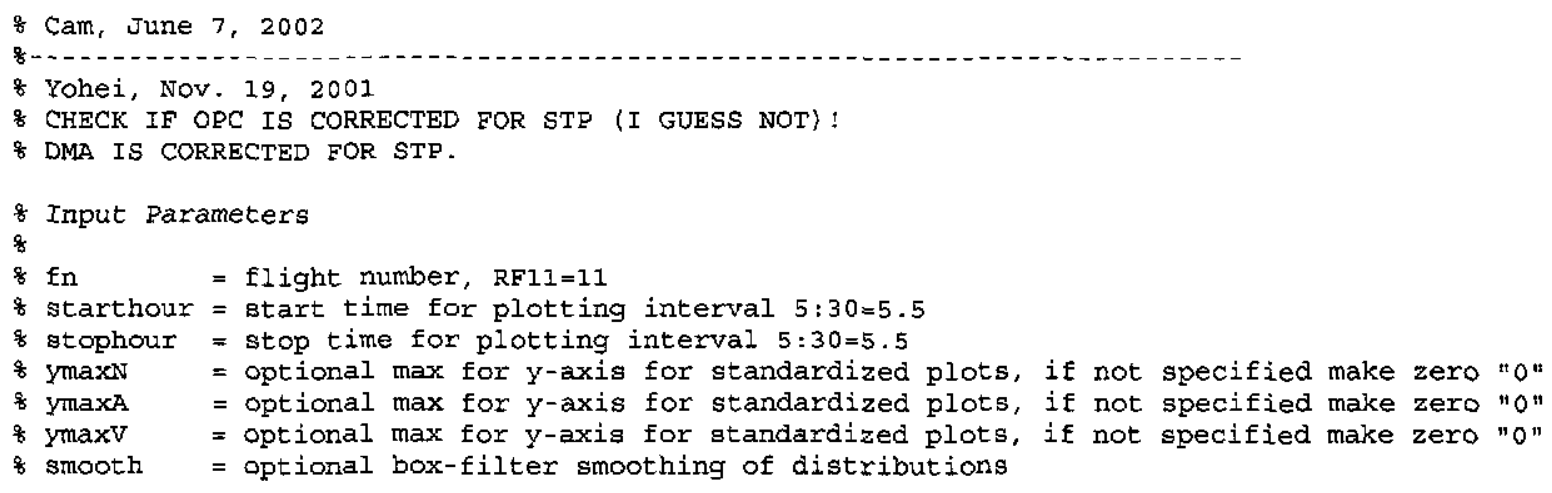


F End load DMA data

\& DMA averaging \& integrals

\& Change elements with -999 to Nan's

nines $=$ find $($ dma $(:, 8: 55)==-999)$

new_dN=dma $(:, 8: 55)$;

new dN (nines) $=\mathrm{NaN}$;

dma $(:, 8: 55)=$ new_dN;

\% Get the rows for the time interval

dmarow0=find (dma $(:, 2) / 3600>=$ starthoux \& dma $(:, 3) / 3600<=$ stophour \& dmarelay==0);

dmarowl=find $(\mathrm{dma}(:, 2) / 3600>=$ starthour \& dma $(:, 3) / 3600<=$ stophour \& dmarelay==1);

dmarow2 $=f i n d(\operatorname{dma}(:, 2) / 3600>=$ starthour \& dma $(:, 3) / 3600<=$ stophour \& dmarelay==2);

\% Find and count rows with -999 for integrals (used later to tell you the number of good/bad scans)

dmabado=size (find (dma (dmarowo, 56) $==-999), 1)$;

dmabad1 =size (find (dma (dmarow1, 56)==-999), 1);

dmabad2 =size (find (dma (Cmarow2, 56) ==-999), 1) ;

* Number distribution

if size (dma (dmarowo, $8: 55$ ), 1) $=: 1$;

dma dndlogd0=dma (dmarowo, $8: 55$ );

elseif size (dma (dmarow0, $8: 55), 1)==0$;

dma dndlogdo=repmat $(\mathrm{NaN}, 1,48)$;

else;

dma_dndlogdo=nanmean (ama (dmarowo, 8:55)) ; end;

if size (dma (dmarow1, 8:55), 1) =:1;

dma_dndlogdi=dma (dmarow1, $8: 55$ );

elseif size (dma (dmarow1, 8:55), 1) ==0;

dma_dndlogdl $1=\operatorname{repmat}(\mathrm{NaN}, 1,48)$;

else;

dma_dndlogdl=nanmean (dma (dmarow $1,8: 55)$ ); end;

if $\operatorname{size}($ dma $($ dmarow2, $8: 55), 1)==1$; dina dndlogd2 =dma (dmarow2, $8: 55$ )

elseit size (dma (dmarow2, $8: 55), 1)==0$; dma dndlogd $2=$ repmat $(\mathrm{NaN}, 1,48)$;

else;

dma_dndlogd2=nanmean (dma (dmarow2 , $8: 55)$ );

of Check for vector which doesn't plot properly

\& Also check for empty, make it 'Nan'

Otherwise, fine end

\& End DMA averaging \& integrals

o load OPC data

opc=load (['C: TTRACE \OPC \TPf' num2str(fn) '.num']); of number distribution

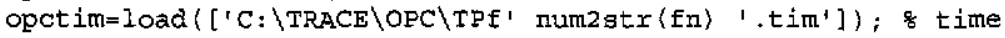

opcanc=load (['C: $\backslash$ TRACE \OPC \TPf' num2str(fn) ', anc']); \& ancillary data to get relay

opcrelay=opcanc $(:, 1)$.

clear opcanc

o End load opC data

s.

\% OPC Number distribution

opcd $=$ opediams $\{132\}$;

opcrowO=find (opctim $(:, 2) / 3600>=$ starthour \& opctim $(;, 3) / 3600<=$ stophour \& opcrelay==0); opcrowl=find (opctim $(:, 2) / 3600 s=$ starthour \& opctim $(:, 3) / 3600<=8 t o p h o u r$ \& operelay==1); opcrow $2=$ Eind (opctim $(:, 2) / 3600>=$ starthour \& opctim $(:, 3) / 3600<=$ stophour \& opcrelay=s);

\& construct the number integrals

if size (opc (opcrow0, : ), 1)=-1;

opc_dndlogdo=opc (opcrowo, : ) ;

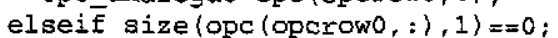

opc_dndlogd0 $=\operatorname{repmat}(\mathrm{NaN}, 1,256)$;

* Check for vector which doesn't plot properly

of Also check for empty, make it 'Nan' 


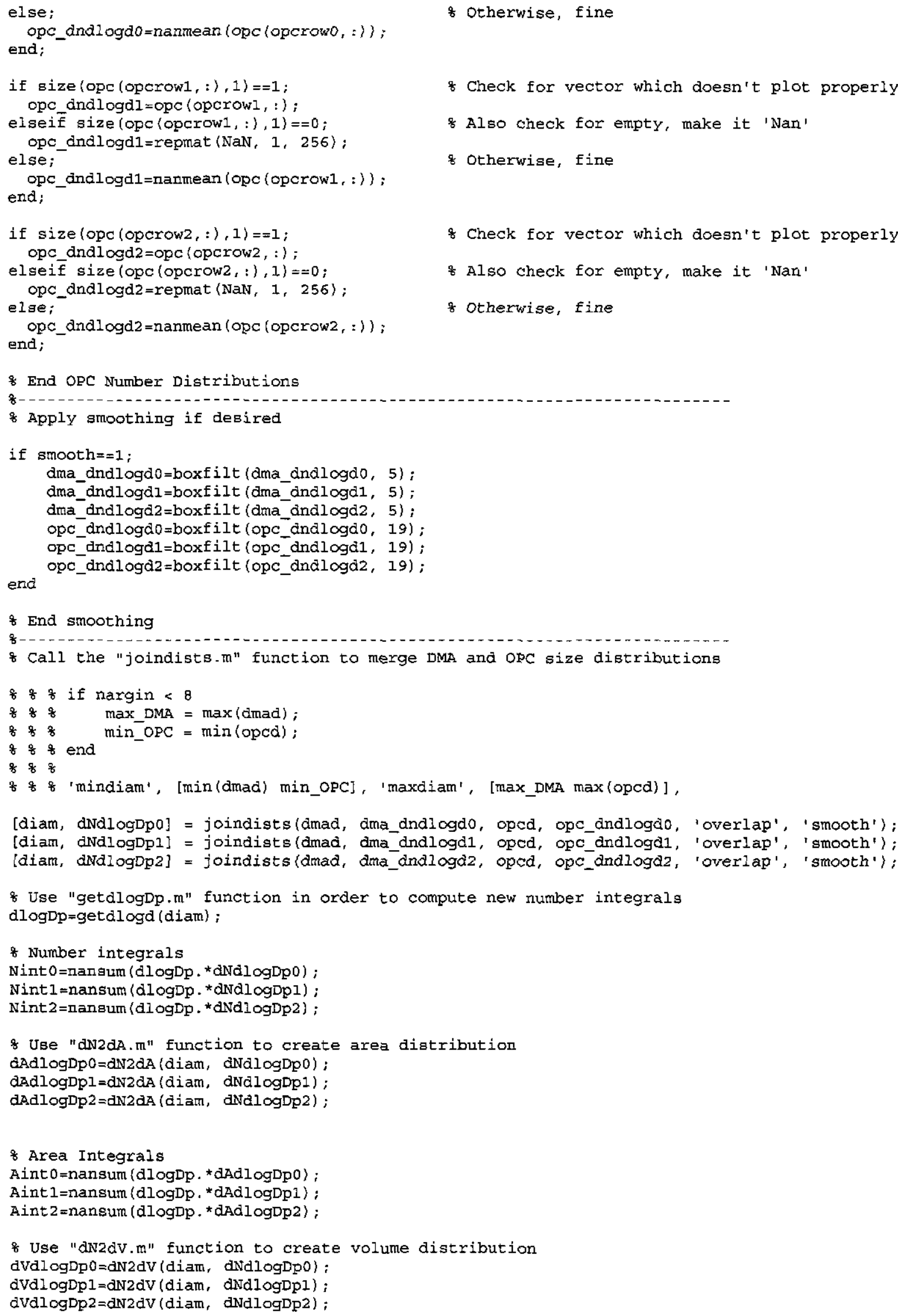


\% Volume Integrals

Vint $0=$ nansum (dlogDp. * $d v d \log D p 0)$;

Vint $1=$ nansum $(d \log D p . * d V d \log D p 1)$;

Vint $2=$ nansum ( $d \log D p . * d v d \log D p 2)$;

of End call the "joindists.m"

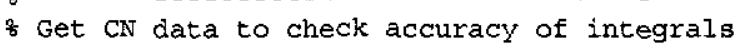

load (['c: (Trace \TRACE_Merge.mat']);

\& Convert time coordinates

cnhour=data. UTC. $/ 86400$;

\& select only time interval from flight of interst

CNrows $=$ find (data. FLIGHT $==f n \&$ cnhour $>=($ starthour $/ 24)$ \& cnhour $<=($ stophour $/ 24)$ );

: Construct means and standard deviations of the CN data for the time interval

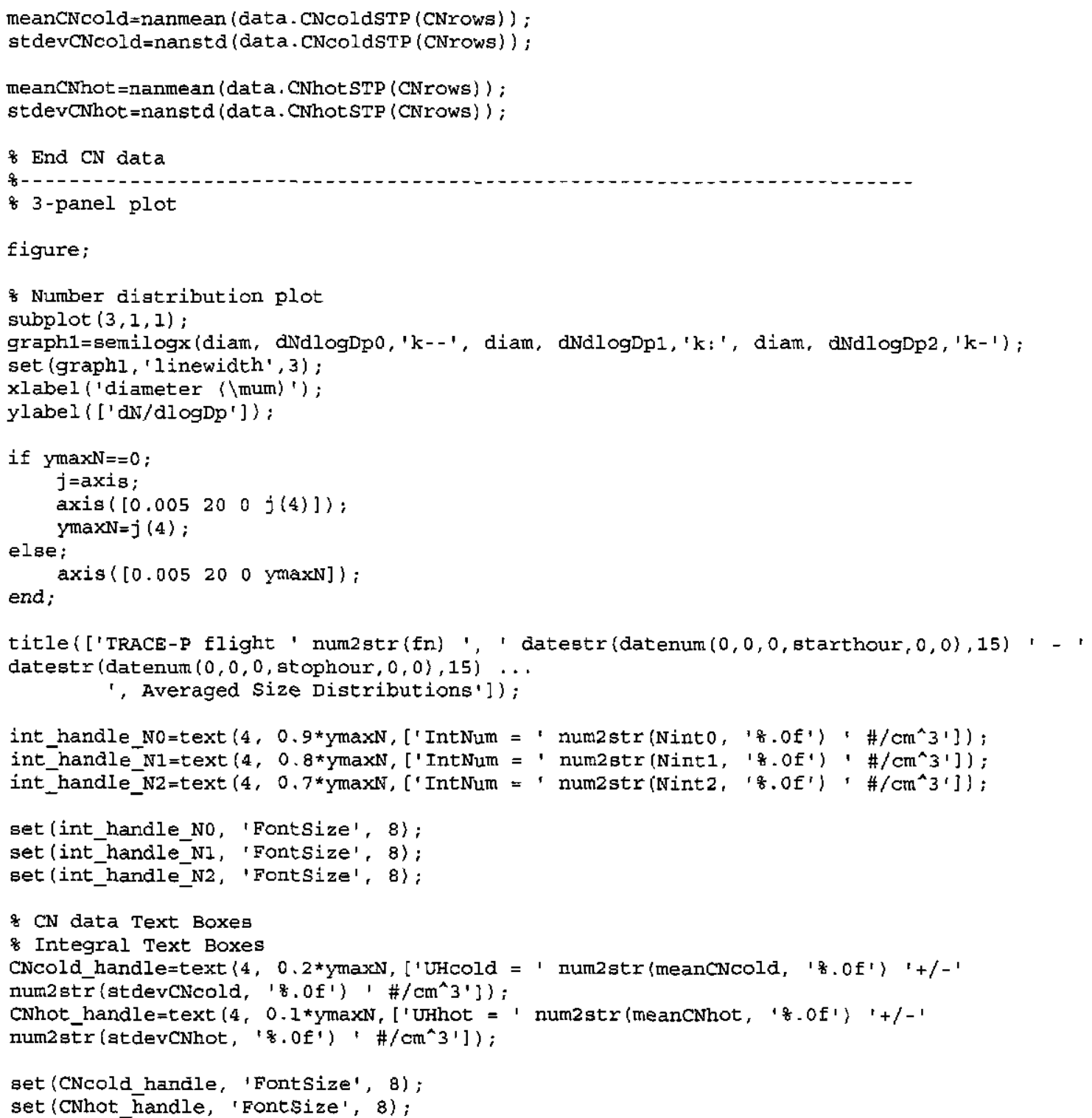




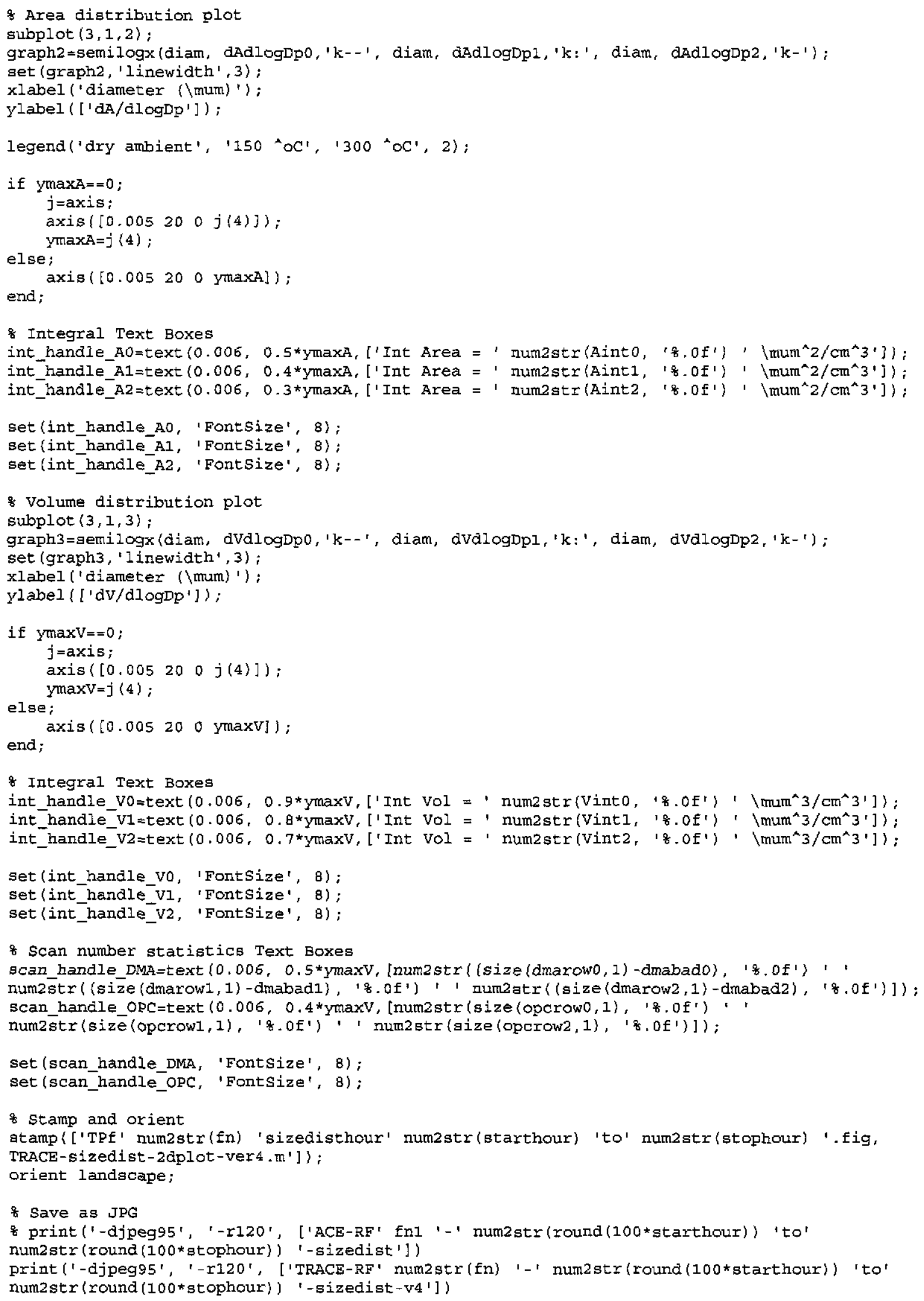


extract $1=[d i a m ; d N d \log D p 0 ; d N d \log D p 1 ; d N d \log D p 2] ' ;$ extract 2 =[diam; dAdlogDpo; dAdlogDpl; dAdlogDp2 ]'; extract $3=[d i a m ;$ dVAlogDp0; dValogDp1; dVdlogDp2]';

save (['C: TRACE \RF14 \dN extract ' num2str (round(100*atarthour)) ' to' num2str (round (100*stophour)) 'v4'], 'extract1', '-ascii'); save (['C: \TRACE\RF14 \dA_extract_' num2str (round(100*starthour)) 'to' num2str (round (100*stophour)) 'v4'], 'extract2', '-ascii'); save ([ 'C: \TRACE \RF]4 \dv_extract_' numzstr (round(100*starthour)) 'to' num2str (round (100*atophour)) 'v4'], 'extract3', '-ascii');

\section{3 boxfilt.m}

function $y^{f}=$ boxfilt $(y, b I)$

\& function $y f=\operatorname{boxfilt}(y, b l)$

\& Apply a boxcar filter, first padding the ends of the series

\% with constant values to reduce end effects.

* The filter length, bl, must be an odd integer.

\& y must be a vector, either row or column.

if $\operatorname{rem}(b I, 2)=1$, end

error ('Boxcar length must be an odd integer');

[nrows, ncols] = size $(\mathrm{y})$;

$\mathrm{nr}=\max$ (nrows, ncols);

npad $=(\mathrm{bl}-1) / 2$

box $=$ ones $(\mathrm{bl}, 1) / \mathrm{bl}$

yf $=\operatorname{conv}\{[$ ones $($ npad, 1$) * y(1) ; y(:) ;$ ones $($ npad, 1)*y (nr)], box);

$y f=y f(b l:(n r+b l-1))$

8 If the input is a row vector, convert output to row also.

if nrows $==1, \mathrm{yf}^{\mathrm{f}}=\mathrm{yf}^{\prime}$;

elseif ncols $r=1$, error ('input to boxfilt is a matrix');

end

\section{4 joindists.m}

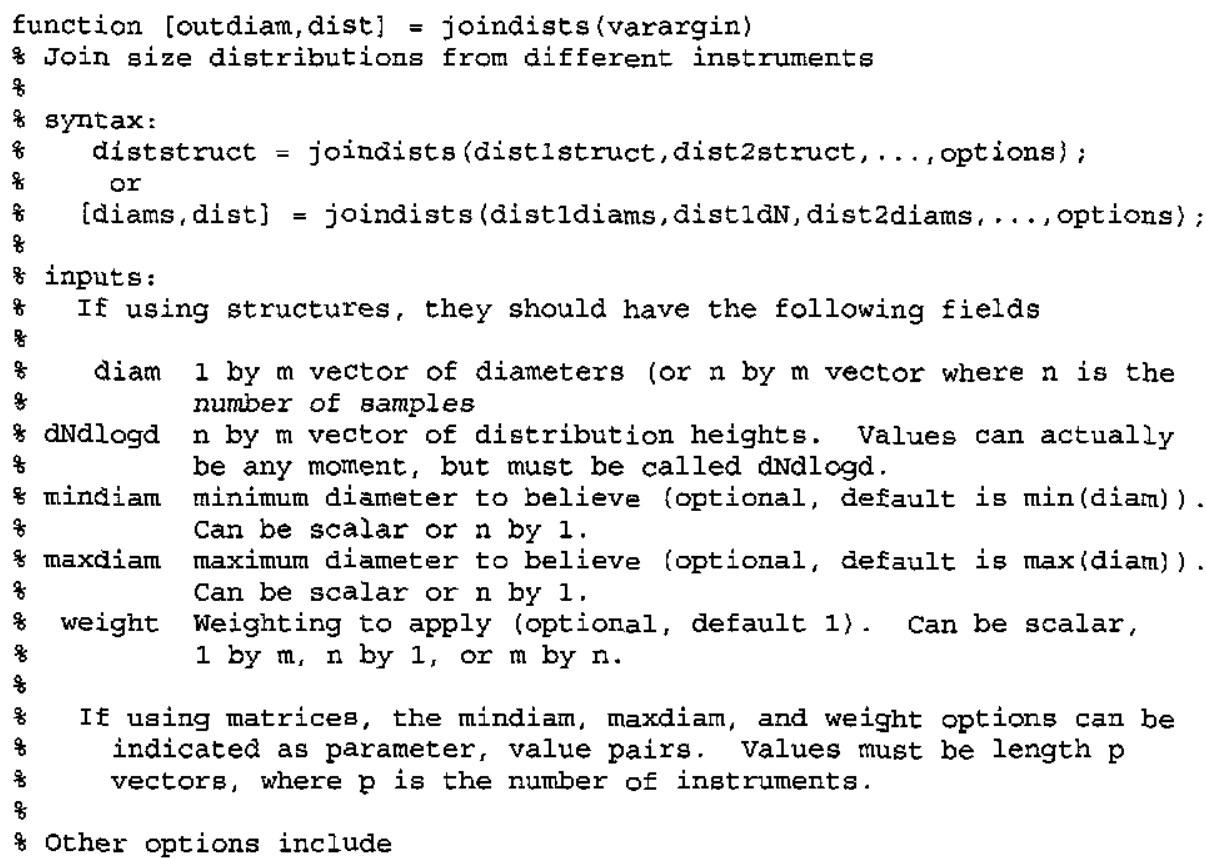




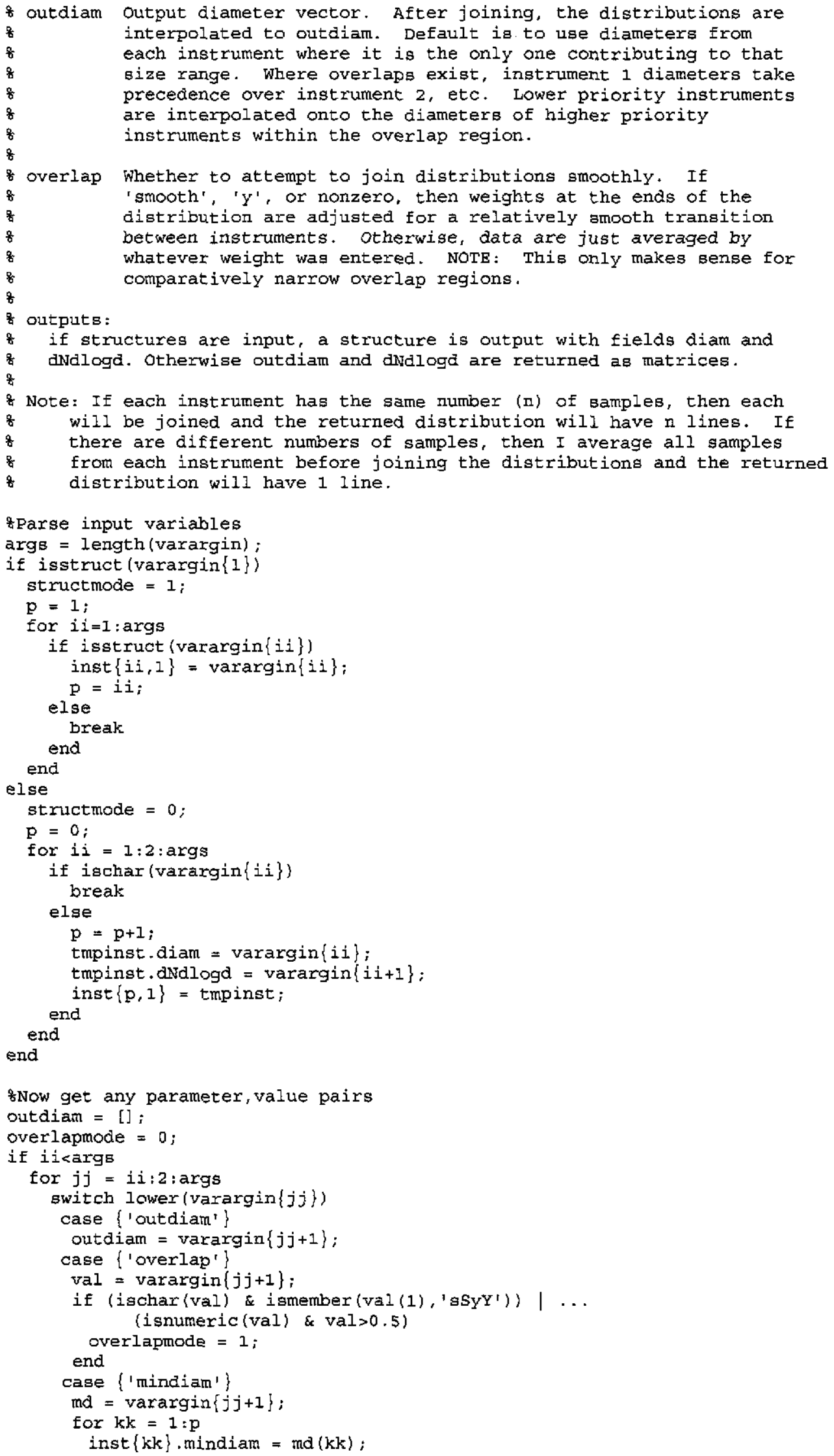




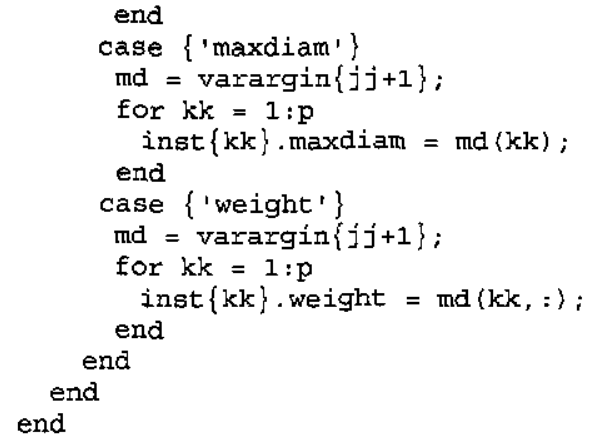




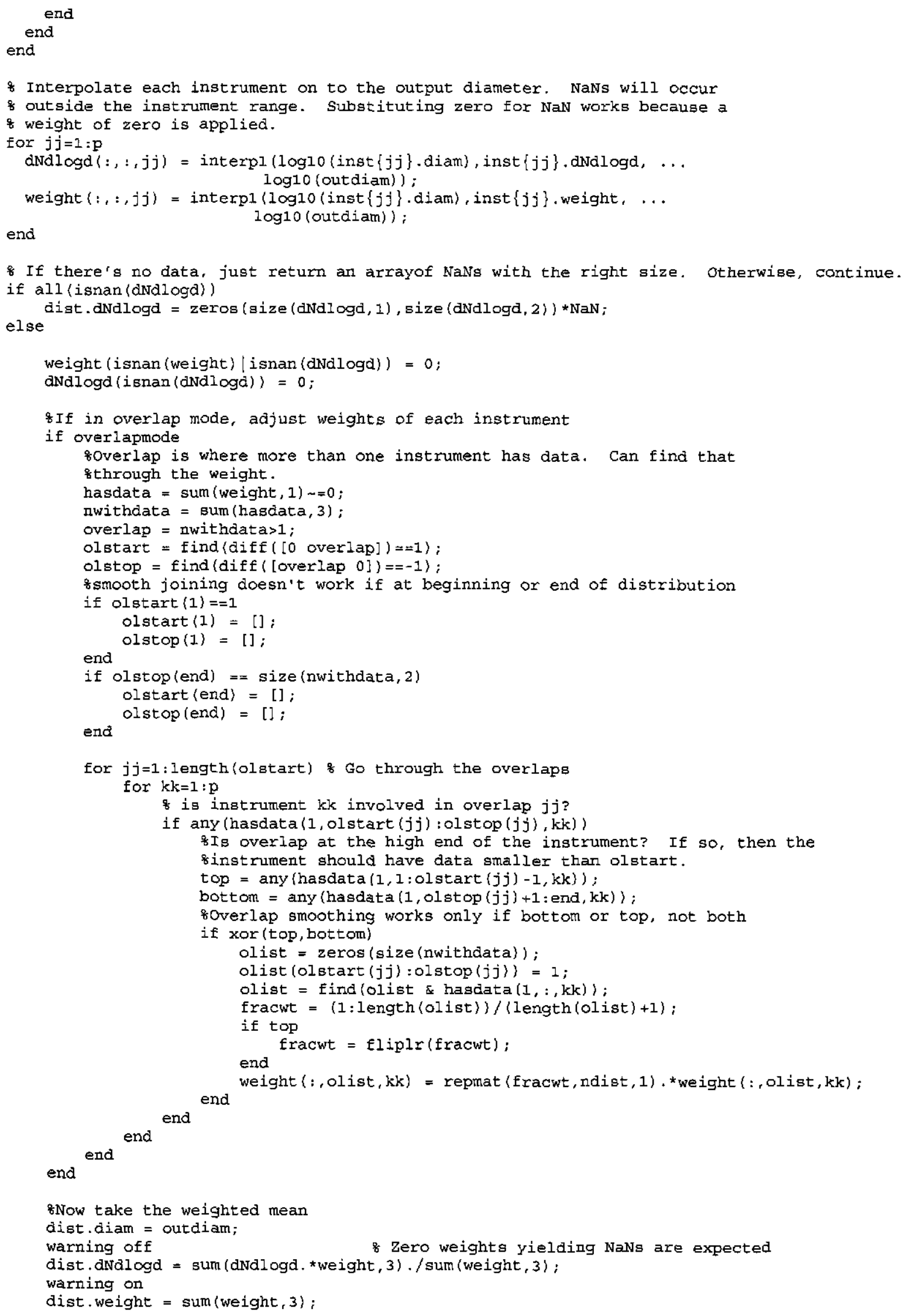


end of if all(isnan(dNdlogd))

gif not in structure mode, output the diameters and dNdlogd

if structmode

if nargout $==1$

outdiam = dist;

end

else

dist $=$ dist $\cdot d N d \log d$ 


\subsection{Appendix C - MATLAB Condensation and Coagulation Modeling}

Kulmala et al. [2001] use a simple formulation based on the size distribution and $\mathrm{dDp} / \mathrm{dt}$ to estimate the condensation of sulfuric acid to the size distribution. Seinfeld and Pandis [1998] have summarized the work of Fuchs for calculating the coagulation rate for a particle of given size when the remainder of the size distribution is known. The theory associated with these calculations is contained in Section 2.0. Section 12.1 contains the MATLAB function $A C E \_C o n d e n s a b l e \_V a p o u r s . m$. This code was used to calculate the sulfuric acid flux rates summarized in table 7.2. Section 12.2 contains the MATLAB function $A C E$ Fuchs_Coagulation.m. This code was used to calculate the coagulation rates for the nucleation mode particles as summarized in table 7.4

\subsection{ACE_Condensable_Vapours.m}

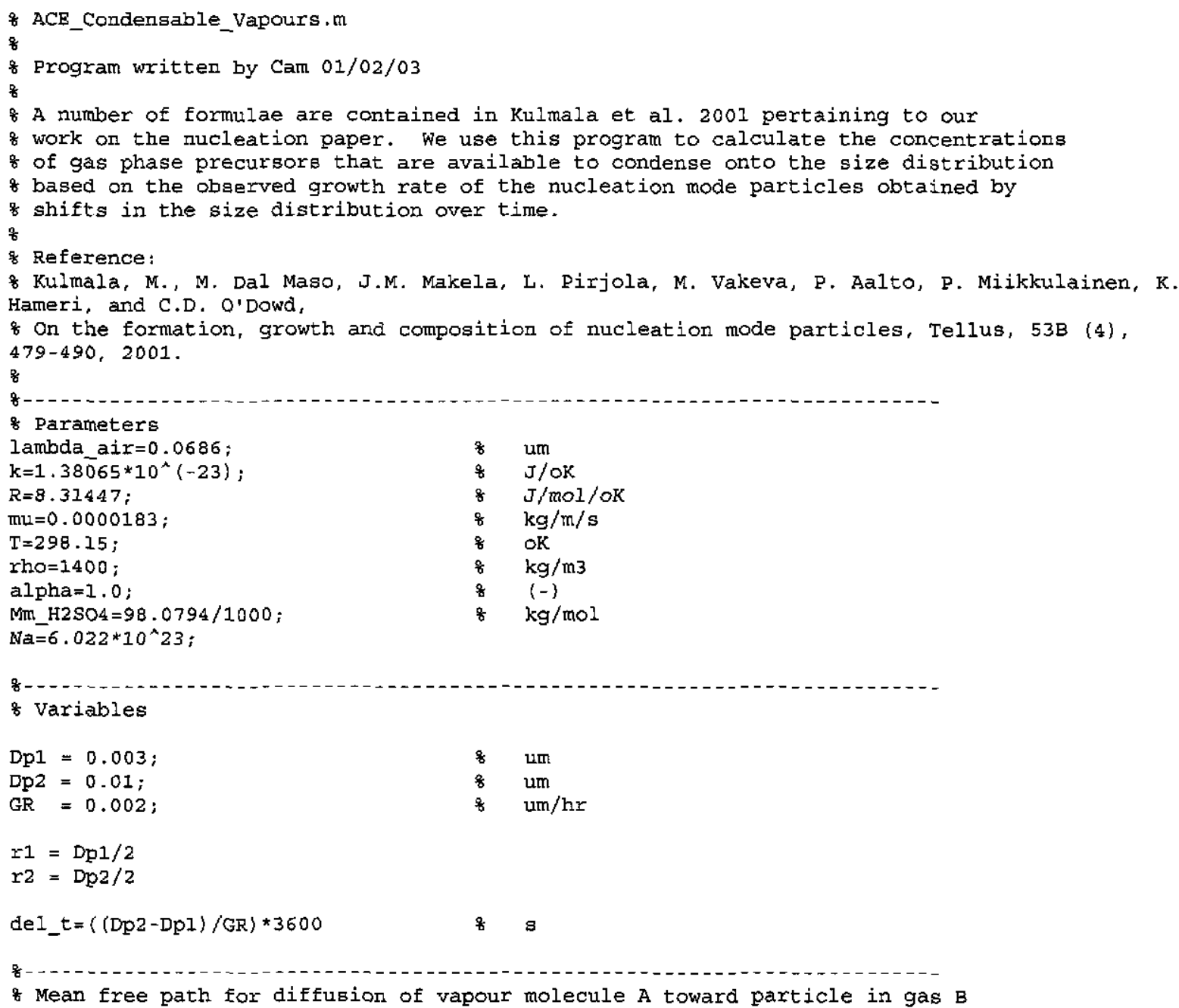




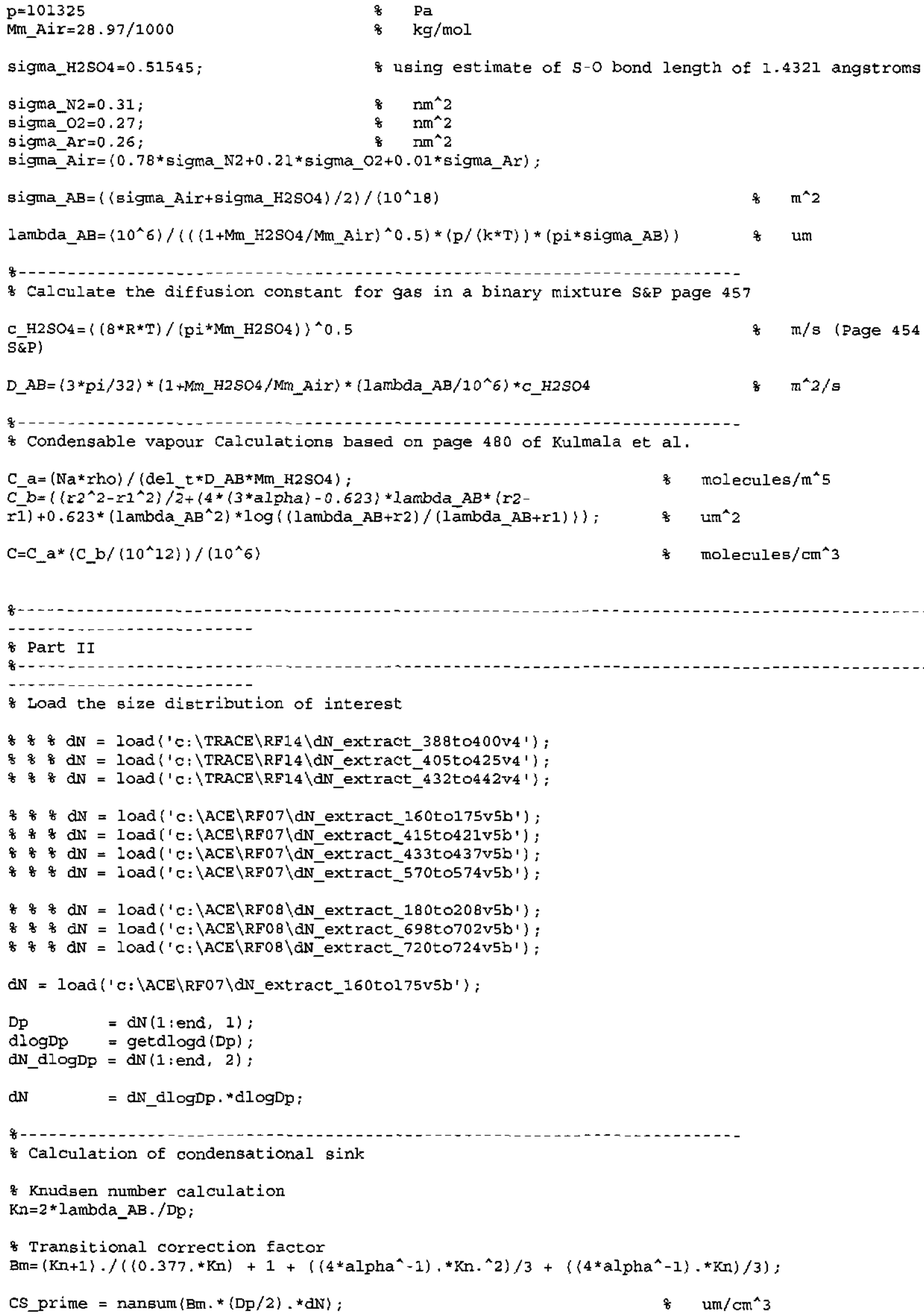




\subsection{ACE_Fuchs_Coagulation.m}

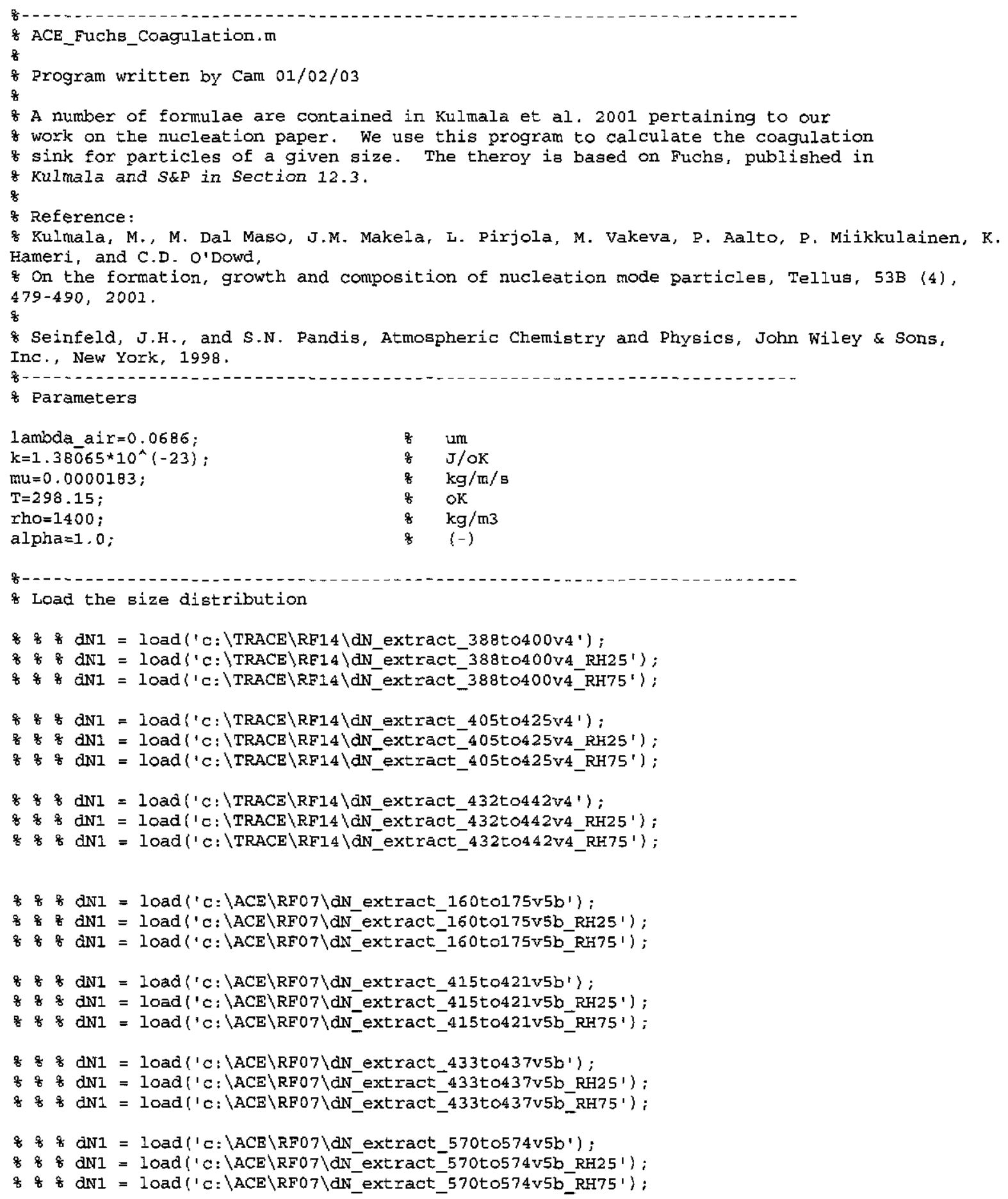




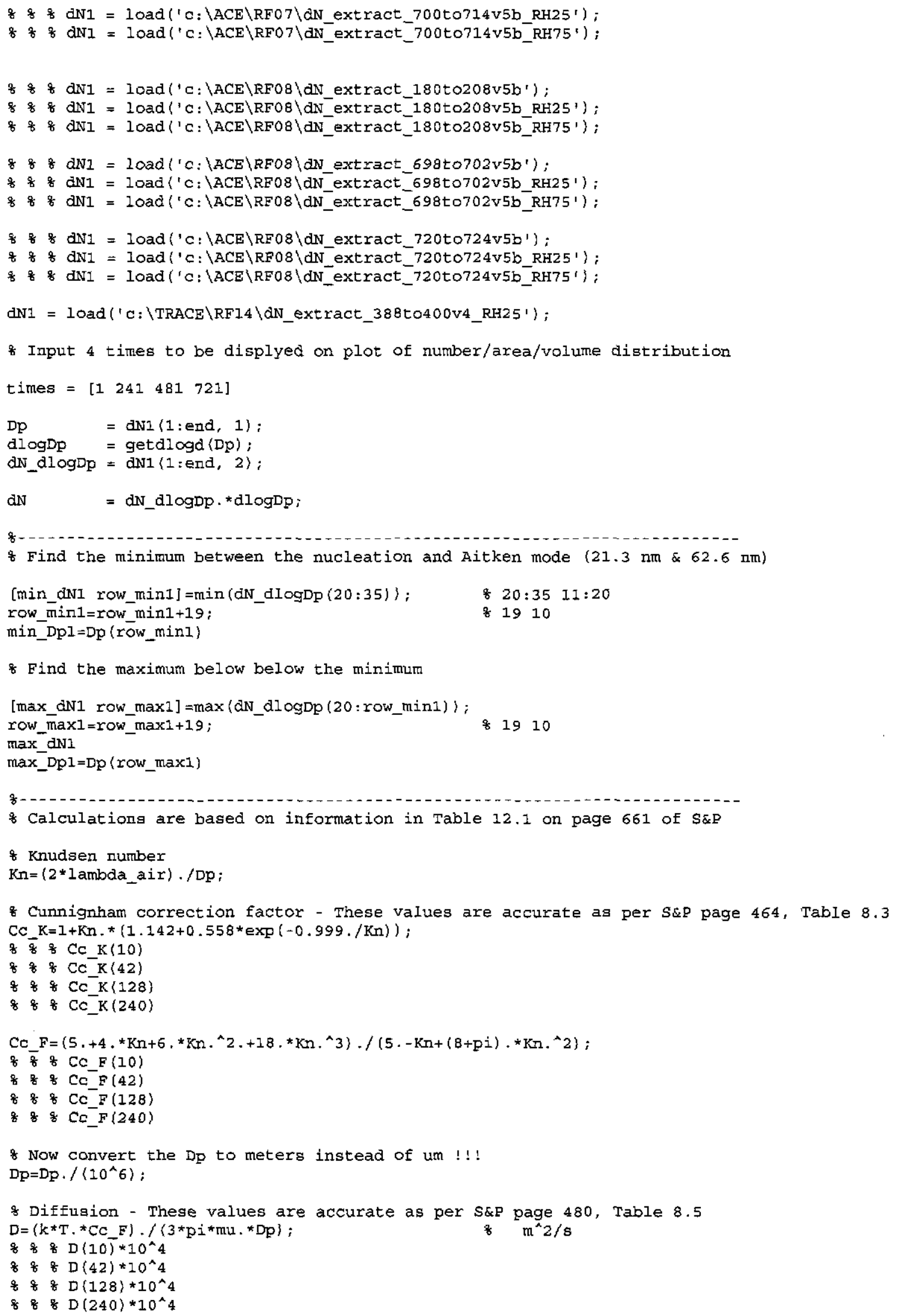




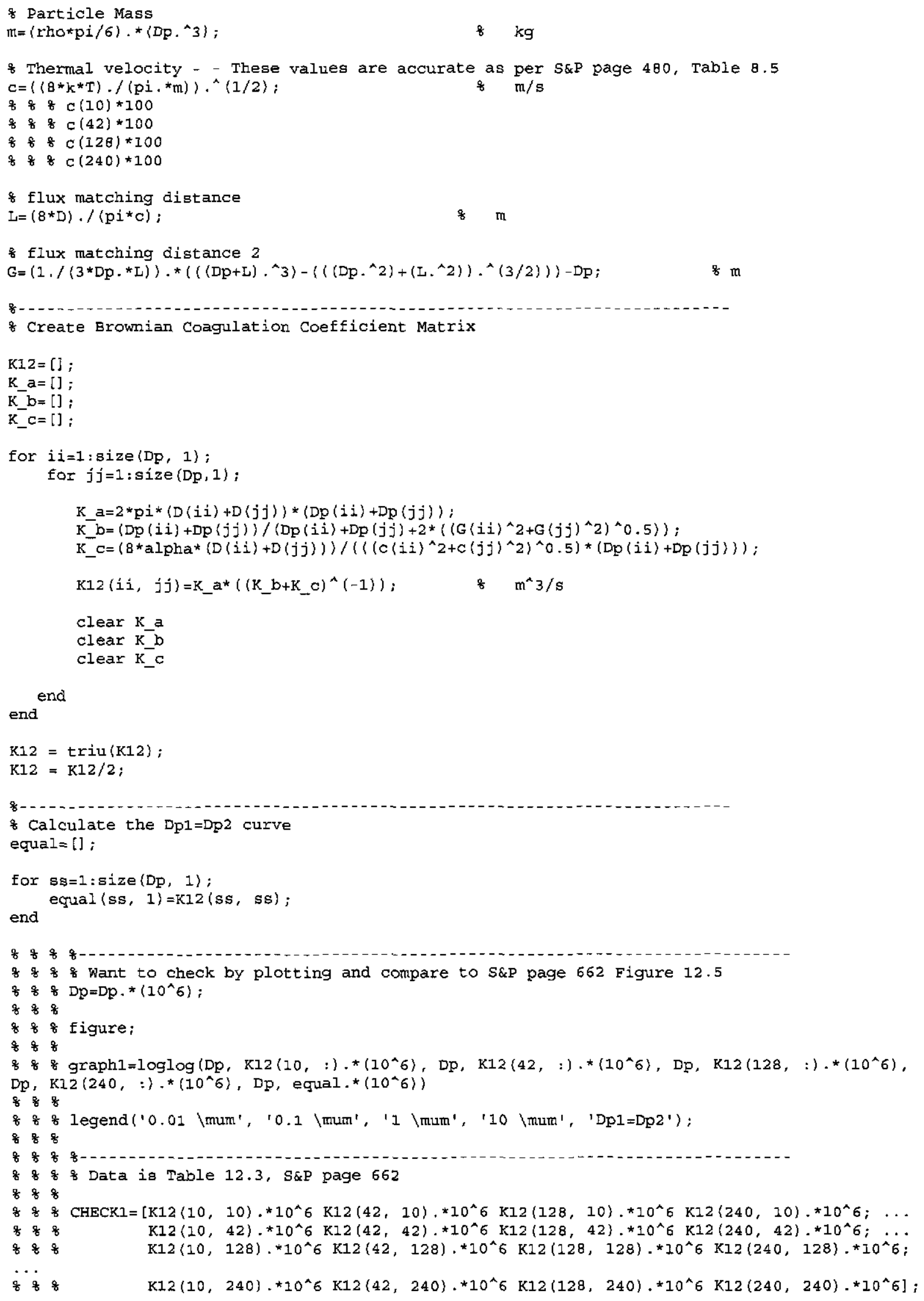




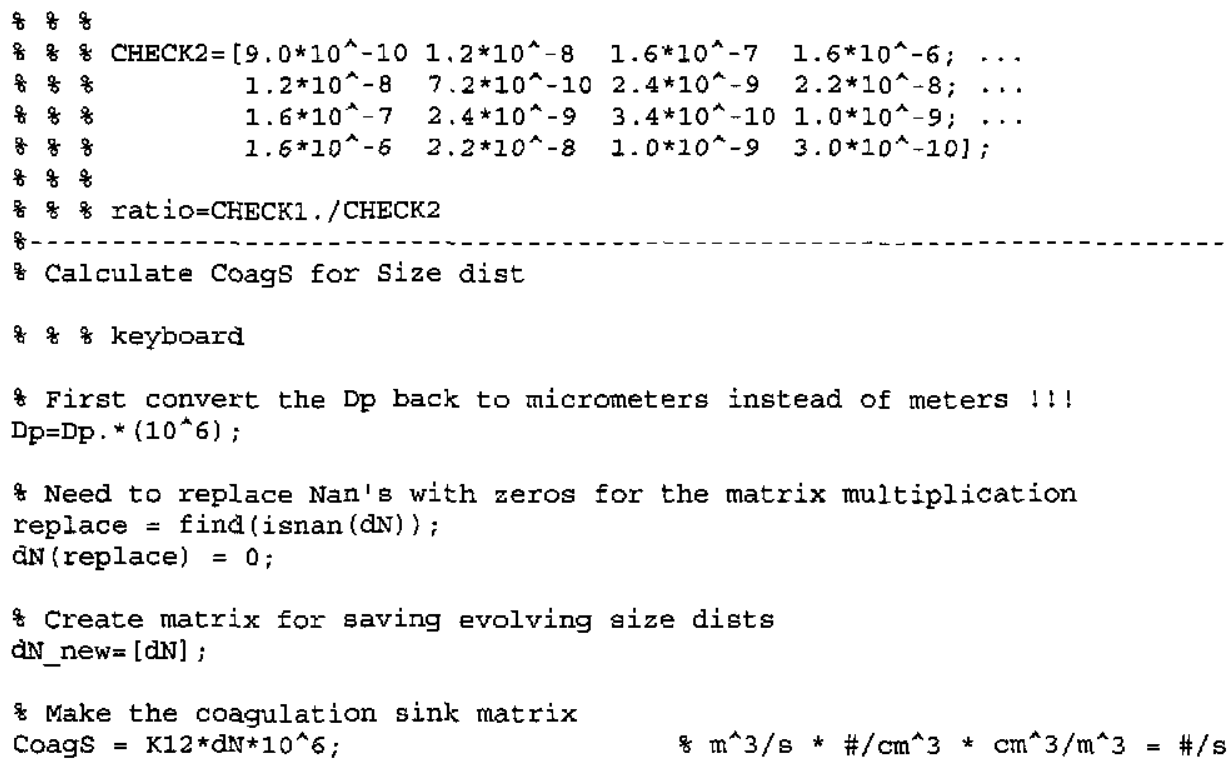

8

Check the number and area integrala

for $\mathrm{kk}=\mathrm{l}:$ size ( $\mathrm{N}$ new)

dA_check $(k \mathrm{kk})=\operatorname{nansum}\left(\left(\mathrm{pi} * \mathrm{Dp} \cdot{ }^{\wedge} 2\right) .{ }^{*} \mathrm{dN}\right.$ new $\left.(:, \mathrm{kk})\right)$;

end

$d v_{-}$check $(k k)=\operatorname{nansum}\left(\left((\mathrm{pi} / 6){ }^{*} \mathrm{Dp} \cdot{ }^{\wedge} 3\right) .{ }^{*} \mathrm{dN} \_\right.$new $\left.(:, \mathrm{kk})\right) ;$

display $=\left[N_{-}\right.$new dA_check' dV_check'] ;

of Calculate the number conc. for nucl., Aitken, accum. and coarse modes

for $\mathrm{pp}=1: 4$

B Break it up by Raes et al. [2000] structure

N_nuc $(p p)=$ nansum $\left(d N \_\right.$new $\left.(1: 10, \operatorname{times}(1, p p))\right) ;$

$\mathrm{N}^{-}$ait $(\mathrm{pp})=$ nansum (dN new $(11: 42$, times $\left.(1, \mathrm{pp}))\right)$;

N_acc $(\mathrm{pp})=$ nansum (dN_new $(43: 128, \operatorname{times}(1, \mathrm{pp})))$;

N_coa $(\mathrm{pp})=$ nansum $\langle\mathrm{dN}$ _new $(128:$ end, $\operatorname{times}(1, \mathrm{pp})\})$;

\& Look only at what "was" the nucleation mode, and what's "left"

end

$N_{-} \operatorname{mode}(p p)=\operatorname{nansum}\left(d N \_n e w\left(1: \operatorname{row}_{-} \min 1, \operatorname{times}(1, p p)\right)\right)$;

percents $=[100 * \mathrm{~N}$ nuc $(1) /(\mathrm{N}$ new $($ times $(1))) 100 * \mathrm{~N}$ nuc $(2) /(\mathrm{N}$ new $($ times $(2)))$

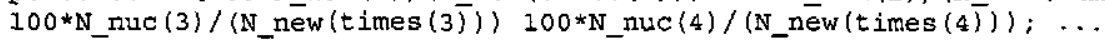


$100 * N$ ait (1)/(N_new(times (1))) 100*N_ait (2)/(N_new(times (2)))

$100 * N$ ait (3)/(N_new $(\operatorname{times}(3))) 100 * \mathrm{~N}$ _ait $(4) /\left(N_{-}\right.$new $(\operatorname{times}(4 \overline{)})) ; \ldots$

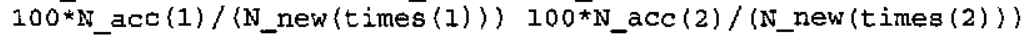

$100 * N$ acc $(3) /\left(N_{-}\right.$new $(\operatorname{times}(3 \overline{)})) 100 * N_{-}$acc $(4) /(\mathrm{N}$ new $($ timeg $(4))) ; \ldots$ $100{ }^{\circ} \mathrm{N}$ coa (1)/(N new (times (1))) $100 * \mathrm{~N}$ coa (2)/(N new (times (2)))

$100 * N$ Ncoa $(3) /\left(N_{-}\right.$new $($times $(3 \bar{j})) 100 * N_{-}$coa $(4) /(\mathrm{N}$ new $($ times $(4))) ; \ldots$ $100 \bar{\star}_{\mathrm{N}}$ mode (1)/(N new (times (1))) $10 \overline{0}^{*} \mathrm{~N}$ mode (2)/(N_new (times (2))) $100 * N$ mode $(3) /\left(N_{-}\right.$new $(\operatorname{times}(3 \bar{J})) 100 * N_{-}$mode $(4) /\left(N_{-}\right.$new $\left.\left.(t i \operatorname{mes}(4))\right)\right] ;$

percents (5, : )'

o \& $8=[$ find $(-i \operatorname{snan}(D p)) \quad D p$ dN_new $(:, 1)]$

\% Generic Plotting

\& 8 \& keyboard

figure;

subplot $(3,1,1)$

graph1 = semilogx $\left(D p, a N \_d \log D p, 1 k-1, D p,\left(d N \_n e w(:, \quad(t i m e s\langle 2))\rangle, / d l o g D p\right\rangle, 1 b-1, D p\right.$, (dN_new $(:,(t \operatorname{imes}(3\rangle)) . / \bar{d} \log D p), ' g-1, D p,(d N$ new $(:,(t i m e s\langle 4))\rangle . / d l o g D p), 1 r-1\rangle$; $\operatorname{axis}([0.005200010000])$;

ylabel (['dN/dlogDp']);

set (graphl, ' linewidth', 1.5);

i Integral Text Boxes

$a=$ get $(g c a$, 'ylim');

int handle $\mathrm{N} 1=\operatorname{text}\left(2,0.9 * \mathrm{a}(2),\left[{ }^{\prime} \operatorname{IntNum}(' \operatorname{num} 2 \mathrm{str}(\mathrm{times}(1)) ')=\right.\right.$ ' num2str(N new (times(1)), (s. $\overline{0}$, ) $\left.\left.\overline{\#} / \mathrm{cm}^{\star} 31\right]\right)$;

int handle N2=text $(2,0.8 * a(2),[1 \operatorname{IntNum}(1 \operatorname{num} 2 \mathrm{str}((\operatorname{times}(2)-1) / 10)$, hours $)=1$

num $\bar{s} \operatorname{str}(\mathrm{N}$ new (times $\left.\left.(2)),\left(8.0 \mathrm{f}^{\prime}\right), \mathrm{\prime} / \mathrm{cm}^{\wedge} 3^{\prime}\right]\right)$;

int_handle $\bar{e}_{\text {N3 }}=\operatorname{text}(2,0.7 * a(2),[$ 'IntNum $('$ num2atr $($ times(3)-1)/10) ' hours) = '

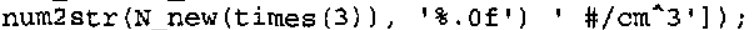

int_handle_N4 =text $\left(2,0.6 * a(2),\left[{ }^{\prime} \operatorname{IntNum}(' \operatorname{num} 2 \mathrm{str}((\mathrm{times}(4)-1) / 10)\right.\right.$, hours $)=1$

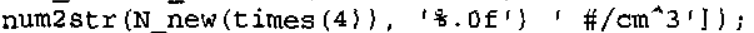

set (int handle $\mathrm{NI}$, 'Fontsize', 8 , 'Color', 'k');

set (int_handle_N2, 'Eontsize', 8, 'Color', 'k');

set (int handle N3, 'FontSize', 8, 'Color', 'k') ;

set (int_handle_N4, 'Fontsize', 8, 'Color', 'k') ;

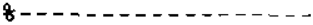

subplot $(3,1,2)$

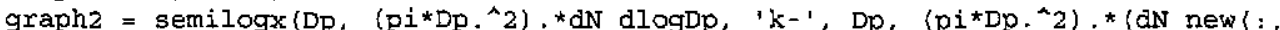

(timea (2)))./dlogDp), 'b-', $D p,\left(p i * \overline{D p} .{ }^{\wedge} 2\right) . \star(d \mathbb{N}$ new $(:,($ times (3)))./dlogDp), 'g-', $D p$,

(pi*Dp.^2).*(dw_new (:, (times (4)) )./dlogDp), 'r-');

axis $([0.00520 \overline{0} 700])$ :

legend ('Initial', 'Time 2', 'Time 3', 'Time 4', 2);

ylabel ( ['dA/dlogDp']);

set (graph2, 'Iinewidth', 1.5);

Integral Text Boxes

$\mathrm{b}=$ get (gca, 'ylim');

int_handle_Al=text $\left(0.006,0.4 * \mathrm{~b}(2),\left[\right.\right.$ 'IntArea Initial $=1$ num2str $\left(\mathrm{dA} \_\right.$check $(1), 18.0 \mathrm{f}$ ' $)$ ' (mum $\left.\left.\bar{m}^{\wedge} 2 / \mathrm{cm}^{\wedge} \overline{3} \cdot\right]\right\rangle$;

int_handle_A2=text $(0.006,0.3 * b(2),[$ 'IntArea Final $=$ ' num2str(dA_check (end), 'q.0f') ' (muma $\left.\left.2 / \operatorname{cm}^{\wedge} \overline{3} 1\right]\right) ;$

set (int_handle_A1, 'FontSize', 8, 'Color', 'k') ;

set (int handle A2, 'Fontsize', 8, 'Color', 'k');

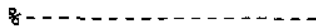

subplot $(3,1,3)$ 


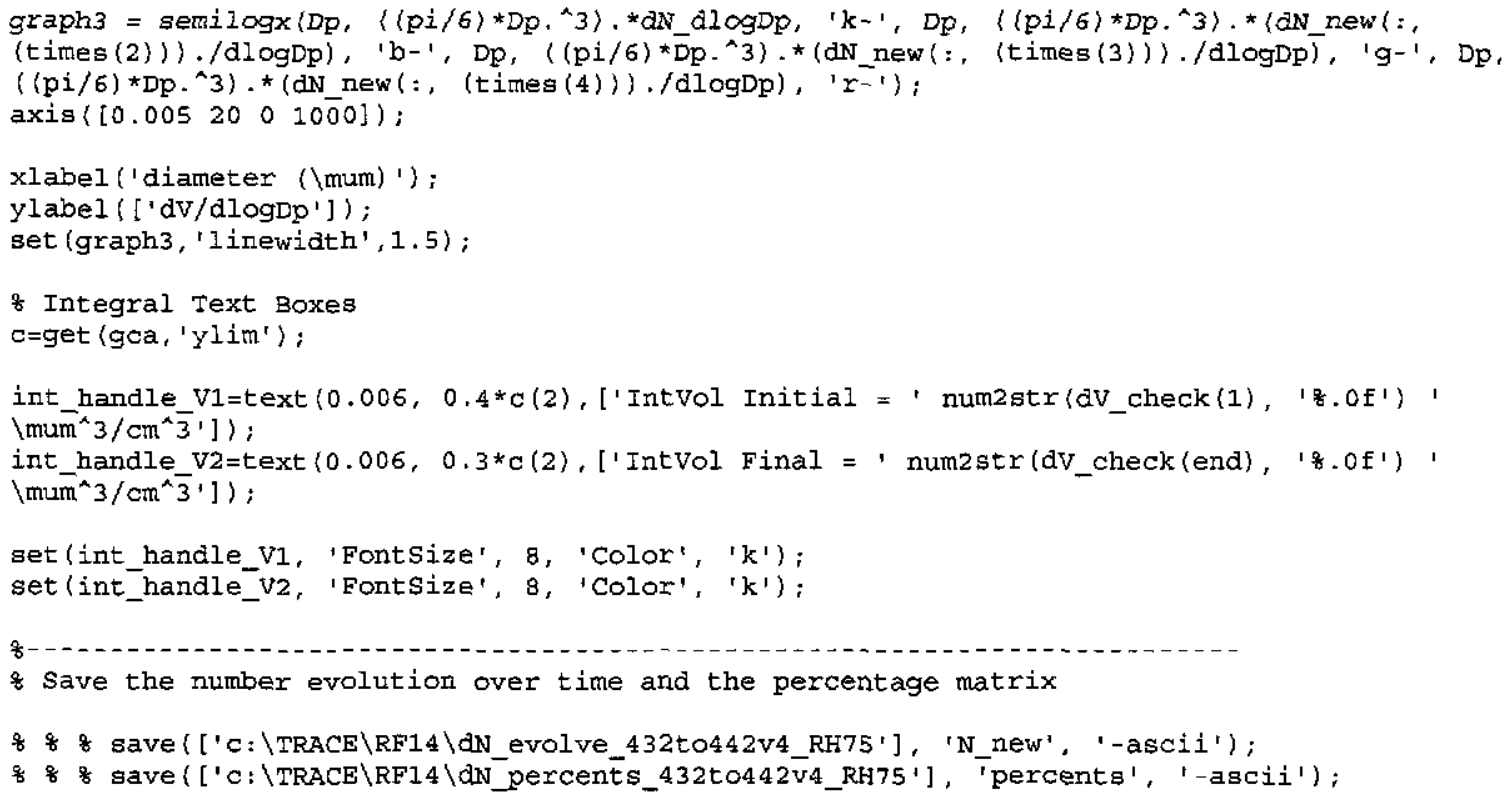

